*ak RMIS View/Frint Document Cover Sheet tow

This document was retrieved from the Documentation and Records Manaqement (DRM) ISEARCH System. It is intended for Information only and may not be the most recent or updated version. Contact a Document Service Center (see Hanford Info for locations) if you need additional retrieval information.

Accession \#: D196015737

Document \#: SD-WM-SEMP-002

Title/Desc:

TWRS SYSTEMS ENGINEERING MGMT PLAN

Pages: 117 


\begin{tabular}{|l|l|}
\hline $\begin{array}{l}\text { 2. To: (Receiving organization) } \\
\text { Distribution }\end{array}$ & $\begin{array}{l}\text { 3. From: coriginating Organization) } \\
\text { TWRS Technical Integration }\end{array}$ \\
\hline 5. Proj./Prog./Dept./Div.: & $\begin{array}{l}\text { 6. Cog. Engr.: } \\
\text { TWRS }\end{array}$ \\
\hline
\end{tabular}

8. Originator Remarks:

Approval/Release

4. Related EDT No.

N/A

7. Purchase Order No.:

N/A

9. Equip./Component No.:

$N / A$

10. Systen/Bldg./Facility:

$\mathrm{N} / \mathrm{A}$

11. Receiver Remarks:

12. Major Assm. Dwg. No.: $N / A$

13. Permit/Permit Application No.: $N / A$

14. Required Response Date:

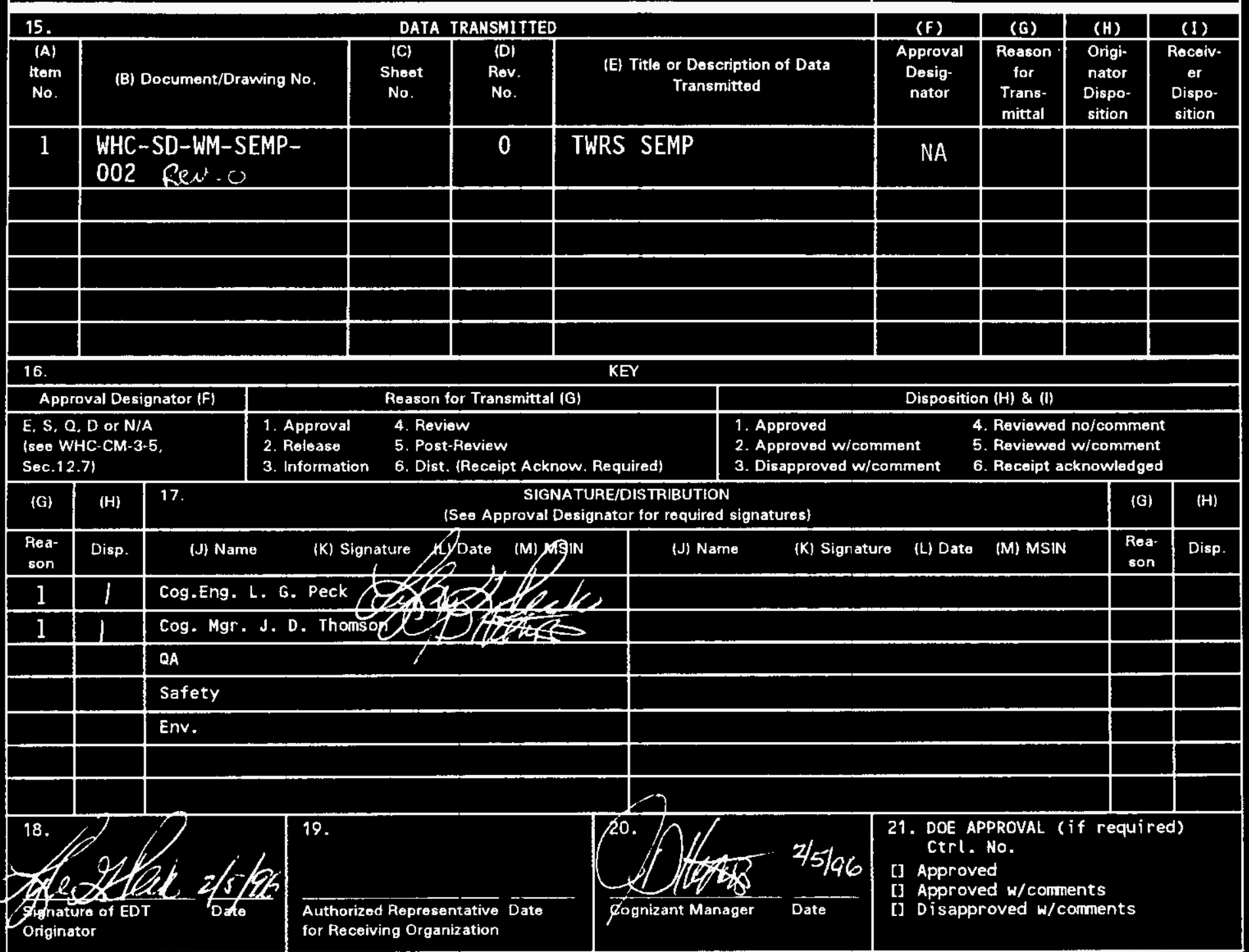

BD-7400-172-2(04/94) GEF097 


\section{Tank Waste Remediation System Systems Engineering Management Plan}

L. G. Peck

Westinghouse Hanford Company, Richland, WA 99352

U.S. Department of Energy Contract DE-AC06-87RL10930

$\begin{array}{lllc}\text { EDT/ECN: } & 612837 & \text { UC: } & 2000 \\ \text { Org Code: } & 74440 & \text { Charge Code: } & \text { D1M20 } \\ \text { B\&R Code: } & \text { EW3120075 } & \text { Tota1 Pages: } & 113\end{array}$

Key Words: TWRS, SEMP, Functions, Requirements, Architecture, Systems Engineering

Abstract: This Systems Engineering Management Plan (SEMP) describes the Tank Waste Remediation Systems (TWRS) implementation of U.S. Department of Energy (DOE) Systems Engineering (SE) policy provided in Tank Waste Remediation System Systems Engineering Management Policy, DOE/RL letter, 95-RTI-107, 0ct. 31, 1995. This SEMP defines the products, process, organization, and procedures used by the TWRS Program to accomplish SE objectives. This TWRS SEMP is applicable to all aspects of the TWRS Program and will be used as the basis for tailoring SE to apply necessary concepts and principles to develop and mature the processes and physical systems necessary to achieve the desired end states of the program.

TRADEMARK DISCLAIMER. Reference herein to any specific commercial product, process, or service by trade name, tradenark, manufacturer, or otherwise, does not necessarily constitute or imply its endorsement, recommendation, or favoring by the United States Government or any agency thereof or its contractors or subcontractors.

Printed in the United States of America. To obtain copies of this document, contact: WHC/BCS Document Control Services, P.O. Box 1970, Mailstop H6-08, Richland WA 99352, Phone (509) 372-2420; Fax (509) 376-4989.
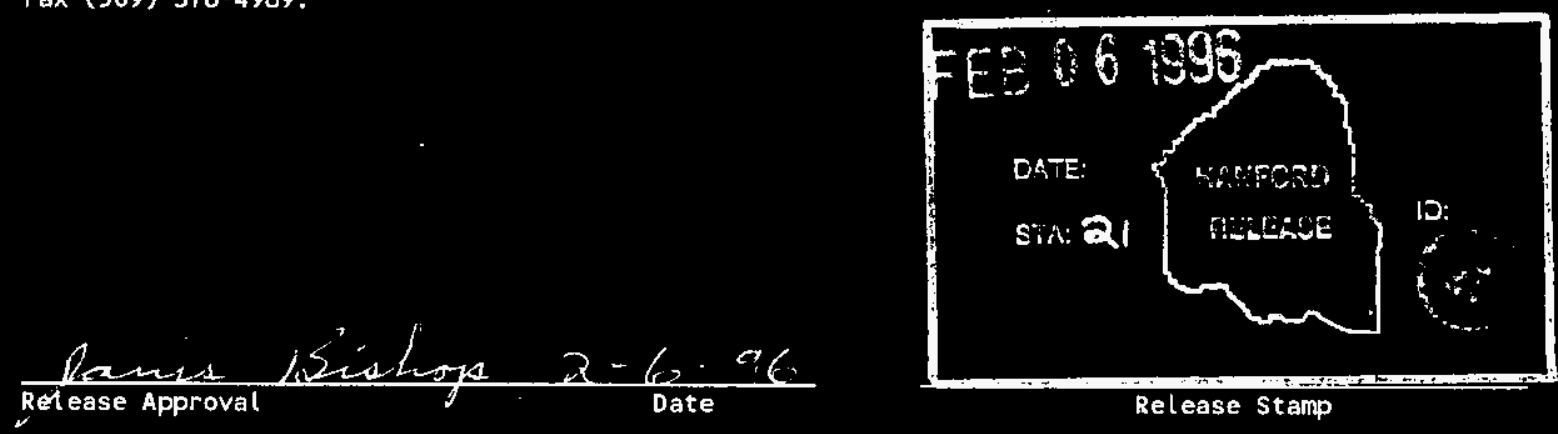

Approved for Public Release 
WHC-SD-WM-SEMP-002 Rev. 0

TANK WASTE REMEDIATION SYSTEM SYSTEMS ENGINEERING MANAGEMENT PLAN

February 5, 1996 
WHC-SD-WM-SEMP-002 Rev. 0

[This page intentionally left blank.] 
WHC-SD-WM-SEMP-002 Rev. 0

\author{
CONTENTS
}

1.0 INTRODUCTION . . . . . . . . . . . . . . . . . . . . . . . . 1-1

1.1 SYSTEMS ENGINEERING MANAGEMENT PLAN SUMMARY $\ldots \ldots$. . $1-1$

1.1.1 Systems Engineering Purpose and Benefits ............1

1.1.2 Systems Engineering Management Plan Structure . . . . . . . . . 1-2

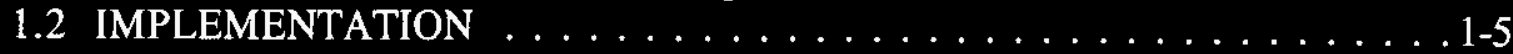

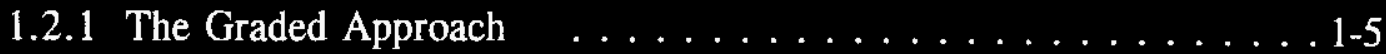

1.2.2 External Implementation $\ldots \ldots \ldots \ldots \ldots \ldots \ldots \ldots \ldots$

1.3 KEY PARTICIPANTS . . . . . . . . . . . . . . . . . 1-8

1.3.1 U.S. Department of Energy - Headquarters . . . . . . . . . . . 1-8

1.3.2 U.S. Department of Energy - Richland Operations Office . . . . . . 1-9

1.3.3 Management and Operations Contractor . . . . . . . . . 1-9

1.3.4 Project Hanford Management Contractor . . . . . . . . . . . . . . 1-9

1.3.5 Technology Development Contractor . . . . . . . . . . 1-10

1.3.6 Integration Support Team $\ldots \ldots \ldots \ldots \ldots \ldots \ldots$

1.3.7 Privatization Contractors . . . . . . . . . . . . 1-10

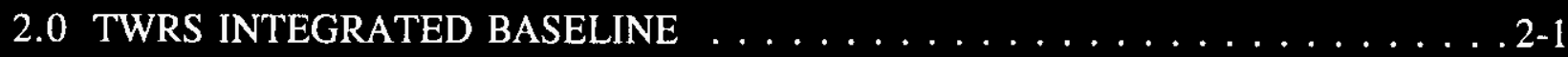

2.1 TWRS INTEGRATED BASELINE DEFINITION . . . . . . . . . 2-1

2.1.1 Cost, Scope and Schedule Baseline . . . . . . . . . . . 2-1

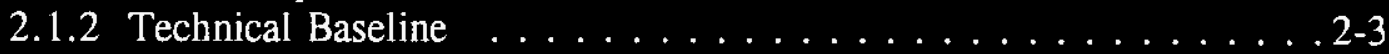

2.2 PROGRAM PHASES $\ldots \ldots \ldots \ldots \ldots \ldots \ldots \ldots \ldots \ldots \ldots . \ldots \ldots \ldots$

2.2.1 Major Technical Products . . . . . . . . . . . . . 2-5

2.2.2 Independent Technical Reviews . . . . . . . . . . 2-6

3.0 SYSTEMS ENGINEERING PROCESS $\ldots \ldots \ldots \ldots \ldots \ldots \ldots \ldots \ldots$. . . . . . . .

3.1 MISSION ANALYSIS . . . . . . . . . . . . . . . . . . 3-1

3.2 FUNCTIONS AND REQUIREMENTS ANALYSIS AND

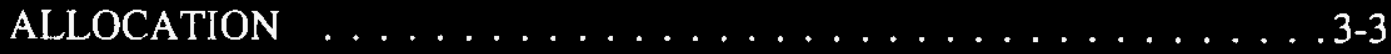

3.2 .1 Functional Analysis $\ldots \ldots \ldots \ldots \ldots \ldots \ldots \ldots \ldots \ldots$. . . . . . . . . .

3.2.2 Requirements Analysis . . . . . . . . . . . . . . 3-4

3.3 ALTERNATIVE GENERATION AND ANALYSIS $\ldots \ldots \ldots \ldots \ldots$. . . . . .

3.4 EVALUATION AND OPTIMIZATION $\ldots \ldots \ldots \ldots \ldots \ldots \ldots \ldots$

3.4.1 Trade Studies . . . . . . . . . . . . . . . . . 3-5

3.4.2 System and Cost Effectiveness . . . . . . . . . . . . 3-6

3.4.3 Life-Cycle Costs . . . . . . . . . . . . . . . . . . 3-8

3.5 TEST AND EVALUATION $\ldots \ldots \ldots \ldots \ldots \ldots \ldots \ldots \ldots . . \ldots \ldots$ 
CONTENTS (continued)

4.0 SYSTEMS MANAGEMENT AND CONTROL . . . . . . . . . . . . . . 4-1

4.1 SYSTEMS MANAGEMENT . . . . . . . . . . . . . . . 4-1

4.1.1 Program Management Structure . . . . . . . . . . . . . 4-1

4.1 .2 Organizational Interfaces . . . . . . . . . . . . . . . . . . 4-1

4.1.3 Roles and Responsibilities . . . . . . . . . . . . . . . . . 4-1

4.1.4 Technical Discipline Integration . . . . . . . . . . . . 4-3

4.1 .5 Systems Integration $\ldots \ldots \ldots \ldots \ldots \ldots \ldots \ldots . \ldots \ldots 4$

4.1 .6 Training . . . . . . . . . . . . . . . .

4.2 SYSTEMS CONTROLS $\ldots \ldots \ldots \ldots \ldots \ldots \ldots \ldots \ldots \ldots$. . . . . . . . .

4.2 .1 Risk Management . . . . . . . . . . . . . . . . . . . 4-6

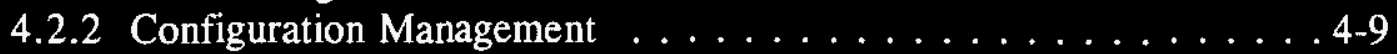

4.2 .3 Interface Management $\ldots \ldots \ldots \ldots \ldots \ldots \ldots \ldots . . \ldots \ldots$

4.2.4 Requirements Traceability . . . . . . . . . . . 4-10

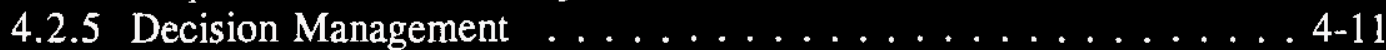

4.2 .6 Test and Evaluation . . . . . . . . . . . . . . 4-13

4.2.7 Technical Performance Measurement . . . . . . . . . . 4-14

5.0 ADDITIONAL SYSTEMS ENGINEERING RESPONSIBILITIES $\ldots \ldots \ldots \ldots$. $5-1$

5.1 STANDARDS AND PROCEDURES $\ldots \ldots \ldots \ldots \ldots \ldots \ldots \ldots \ldots$. . . . . . $\ldots \ldots \ldots$

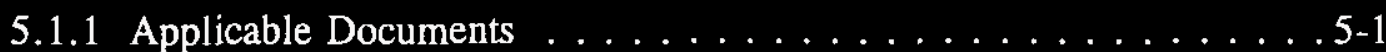

5.1 .2 Guidance Documents . . . . . . . . . . . . . . 5-2

5.2 OTHER PLANS AND CONTROLS $\ldots \ldots \ldots \ldots \ldots \ldots \ldots$. . . . . . . . .

5.3 LONG-LEAD ITEMS $\ldots \ldots \ldots \ldots \ldots \ldots \ldots \ldots \ldots \ldots . . . \ldots \ldots$. . . . . . . . . . .

5.4 DEVELOPING AND APPLYING CRITICAL TECHNOLOGIES $\ldots \ldots \ldots$. . .

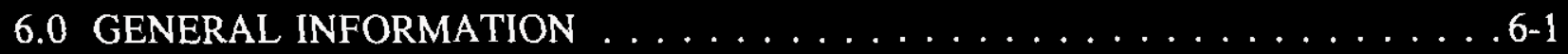

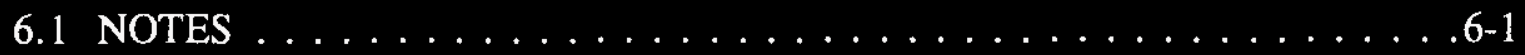

6.2 GLOSSARY . . . . . . . . . . . . . . . . . .6-1

6.3 REFERENCES $\ldots \ldots \ldots \ldots \ldots \ldots \ldots \ldots \ldots \ldots \ldots \ldots \ldots \ldots$

APPENDIX A SYSTEMS ENGINEERING GRADING GUIDELINES . . . . . . . A A-1 APPENDIX B TECHNICAL REVIEWS . . . . . . . . . . . . B APPENDIX C ROLES AND RESPONSIBILITIES MATRIX . . . . . . . . . C C-1 APPENDIX D SPECIALTY ENGINEERING DESCRIPTIONS . . . . . . . . D-1 


\section{LIST OF FIGURES}

1-1 TWRS Systems Engineering Management Plan $\ldots \ldots \ldots \ldots \ldots \ldots \ldots$

1-2 Formal Organizational Interfaces $\ldots \ldots \ldots \ldots \ldots \ldots \ldots \ldots \ldots \ldots$

2-1 TWRS Integrated Baseline Document Hierarchy $\ldots \ldots \ldots \ldots \ldots \ldots . . \ldots$. . . . .

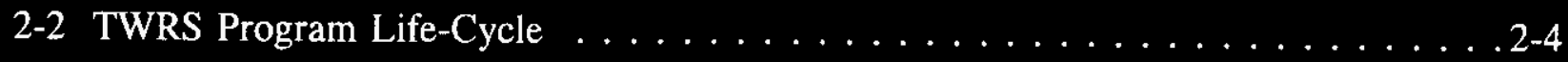

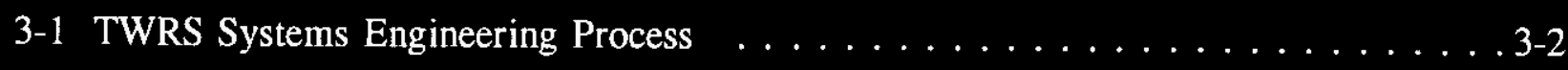

3-2 Cost Effectiveness $\ldots \ldots \ldots \ldots \ldots \ldots \ldots \ldots \ldots \ldots \ldots \ldots . \ldots \ldots \ldots \ldots$

4-1 TWRS Program Organization $\ldots \ldots \ldots \ldots \ldots \ldots \ldots \ldots \ldots . . \ldots . . \ldots .4$

4-2 Risk Management List Organizational Structure . . . . . . . . . . . . . 4-6

4-3 Risk Management Functions . . . . . . . . . . . . . . . . 4-7

4-4 Risk Management Process $\ldots \ldots \ldots \ldots \ldots \ldots \ldots \ldots \ldots . . \ldots \ldots$

4-5 Information Infrastructure $\ldots \ldots \ldots \ldots \ldots \ldots \ldots \ldots \ldots \ldots$ 4-10

4-6 Decision Process $\ldots \ldots \ldots \ldots \ldots \ldots \ldots \ldots \ldots \ldots \ldots . \ldots \ldots$ 4-11

4-7 Technical Performance Measurement Relationships . . . . . . . . . . . . 4-17

\section{LIST OF TABLES}

1-1 The Graded Approach - Summary $\ldots \ldots \ldots \ldots \ldots \ldots \ldots$. . . . . . . . .

2-1 Program Systems Engineering Technical Documents $\ldots \ldots \ldots$. . . . . . 2-5

2-2 Project Systems Engineering Technical Documents $\ldots \ldots \ldots$. . . . . . . 2-6 


\section{LIST OF TERMS}

ABL

BSD

CM

CMPP

CRML

D\&D

D\&DR

DCBL

DDR

DOE

DRBL

DRD

DRR

DT\&E

ERC

FRAT

FRBL

FRD

FY

HQ

ICD

ICWG

IPT

IST

ITP

LCC

$\mathrm{M} \& \mathrm{O}$

MAR

MCR

MYPP

OBL

OCRWM

ORR

OT\&E

PDR

PDT

PHMC

PNNL

RL

RMACS

RML

SDR

As-Built Baseline

Baseline System Description

Configuration Management

Configuration Management Program Plan

Critical Risk Management List

Decontamination and Decommissioning

Decontamination and Decommissioning Review

Design Configuration Baseline

Definitive Design Review

U.S. Department of Energy

Design Requirements Baseline

Design Requirements Document

Design Requirements Review

Development Test and Evaluation

Environmental Restoration Contractor

Functions, Requirements, Architecture, and Test

Functional Requirements Baseline

Functions and Requirements Document

Fiscal Year

U.S. Department of Energy, Headquarters

Interface Control Document

Interface Control Working Group

Integrated Product Team

Integration Support Team

Integrated Technology Plan

Life-Cycle Cost

Maintenance and Operations

Mission Analysis Report

Mission Complete Review

Multi-Year Program Plan

Operations Baseline

Office of Civilian Radioactive Waste Management

Operations Readiness Review

Operational Test and Evaluation

Preliminary Design Review

Product Development Team

Project Hanford Management Contract

Pacific Northwest National Laboratory

U.S. Department of Energy, Richland Operations Office

Requirements Management and Assured Compliance System

Risk Management List

System Design Review 


\section{LIST OF TERMS (continued)}

SE

SEMP

SRR

SSC

$\mathrm{T} \& \mathrm{E}$

TEP

TFA

TPM

TRBL

TRR

TRS

TWRS

WBS

WIPP
Systems Engineering

Systems Engineering Management Plan

System Requirements Review

Systems, Structures, and Components

Test and Evaluation

Test and Evaluation Plan

Tank Focus Area

Technical Performance Measurement

Technical Requirements Baseline

Technical Requirements Review

Technical Requirements Specification

Tank Waste Remediation System

Work Breakdown Structure

Waste Isolation Pilot Plant 
WHC-SD-WM-SEMP-002 Rev. 0

This page intentionally left blank. 


\section{TANK WASTE REMEDIATION SYSTEM SYSTEMS ENGINEERING MANAGEMENT PLAN}

\subsection{INTRODUCTION}

This Systems Engineering Management Plan (SEMP) describes the Tank Waste Remediation Systems (TWRS) implementation of U.S. Department of Energy (DOE) Systems Engineering (SE) policy provided in Tank Waste Remediation System Systems Engineering Management Policy, DOE/RL letter, 95-RTI-107, Oct. 31, 1995. This SEMP defines the products, process, organization, and procedures used by the TWRS Program to accomplish SE objectives. This TWRS SEMP is applicable to all aspects of the TWRS Program and will be used as the basis for tailoring SE to apply necessary concepts and principles to develop and mature the processes and physical systems necessary to achieve the desired end states of the program.

This SEMP is intended to be a living document that will be revised as necessary to reflect changes in SE guidance as the program evolves. DOE Headquarters has issued program management guidance, DOE Order 430.1, Life Cycle Asset Management, and associated guideline documents that include substantial SE guidance. DOE Order 430.1 guidance will be applicable to the TWRS Program starting with the upcoming contract implementation for the Project Hanford Management Contractor (PHMC). The TWRS SEMP will be revised to reflect DOE Order 430.1 following contract award. Until then, the SEMP will reflect DOE Order 4700.1 and DOE-RL Systems Engineering policy direction. When applicable and not in conflict with 4700.1 , the SEMP is consistent with 430.1 guidelines.

\subsection{SYSTEMS ENGINEERING MANAGEMENT PLAN SUMMARY}

SE is the approach selected by the DOE to establish and maintain the TWRS Program baseline over the life of the program. To carry out the SE process in an orderly manner and fulfill DOE SE policy requirements, a SEMP is developed to define and describe the processes and controls to be used by the participants.

\subsubsection{Systems Engineering Purpose and Benefits}

SE is the application of scientific and engineering principles to; 1) transform an operational need into a system of defined performance and configuration characteristics through iterative, disciplined, and documented processes; 2) ensure all necessary related parameters are integrated to optimize a system design that meets program cost, schedule, and technical performance goals; and 3) maintain controlled definition of the system over its' lifecycle. The disciplined application of SE principles offers several benefits. 
- An ordered and structured approach to systems development.

- A common understanding of program goals and expectations by all participants.

- An integrated schedule of activities and how they relate.

- Documented evidence of the current condition or status.

- Traceability of significant program characteristics and system configuration at any point in the program life-cycle.

- Control of program cost, schedule, and technical performance.

- Assurance that the system being built will accomplish the mission.

\subsubsection{Systems Engineering Management Plan Structure}

The SEMP contains seven sections (see Figure 1-1, TWRS Systems Engineering Management Plan):

1) Introduction

- $\quad$ Provides a road map to the SEMP.

- $\quad$ Describes the scope and applicability of the SEMP.

- $\quad$ Discusses the graded approach used for implementing the SEMP across the TWRS Program and projects.

- $\quad$ Summarizes the roles of the key participants.

2) Integrated Baseline -- What we are trying to achieve

- Describes the relationship of the program cost, scope, schedule, and technical performance baseline.

- Describes the phases of the TWRS Program life cycle including SE products in each phase.

- $\quad$ Describes an integrated approach to identifying and establishing physical interfaces for systems and subsystems.

- $\quad$ Describes the purpose for independent technical reviews.

3) SE Process -- How we intend to achieve the integrated baseline

- Contains the general description of elements that constitute the SE Process.

-- Mission Analysis

-- Function and Requirement Analysis and Allocation

-- Alternative Generation and Analysis

-- Evaluation and Optimization

-- Test and Evaluation (T\&E) 
WHC-SD-WM-SEMP-002 Rev. 0

Figure 1-1. TWRS Systems Engineering Management Plan.

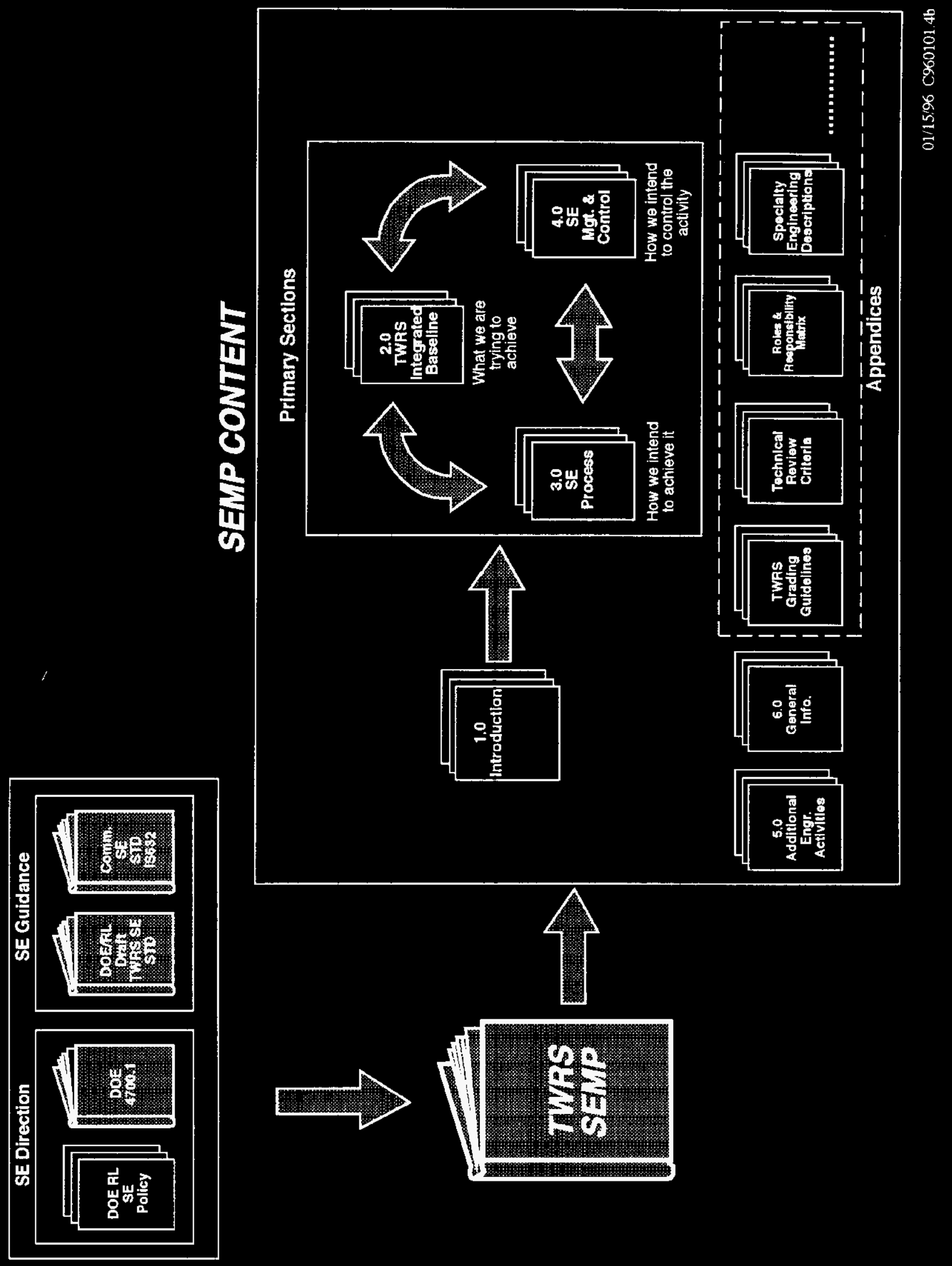


4) Systems Management and Control -- How we intend to control activities and products

- $\quad$ Describes the activities required to manage the SE process and related activities to ensure quality products.

- $\quad$ Defines roles and responsibilities for developing SE products and activities.

- Describes controls used to manage the activity.

5) Additional SE Responsibilities

- Identifies applicable standards and procedures to be used.

- Describes other plans and controls that are necessary to accomplish the tasks.

- Describes any identified elements of the system that because of the long lead times required for their acquisition, require special early recognition and actions.

- Describes the need for recognition and development of critical technologies that may be necessary to mitigate risks throughout the program life cycle.

6) General Information

- Contains information related to the TWRS Program that may be helpful in performing SE tasks.

- $\quad$ Provides a glossary of SE and program management terms that may be helpful in understanding concepts and principles.

- $\quad$ References used to develop the SEMP.

7) Appendices

- Contains details required to perform SE activities.

A) The Graded Approach - Tailored application of SE is achieved through a screening process that categorizes activities by risk associated with cost, scope, and complexity. Guidelines for screening and tailored SE application is contained in this appendix.

B) Technical Reviews - Approval to proceed through phases of the program are achieved through the review process. Descriptions of the purpose and content of each independent technical review and sample criteria for entering and exiting a technical review is included in this appendix.

C) Roles and Responsibility Matrix - Defines responsibility for SE activities and products throughout the program life cycle.

D) Specialty Engineering Discipline Descriptions - Defines the purpose and intent of technical disciplines that need to be integrally involved in the establishment and development of system requirements and designs. 


\subsection{IMPLEMIENTATION}

This SEMP applies to each TWRS activity (i.e., projects, subprojects) being performed under the TWRS portion of the Maintenance and Operations (M\&O) contract. SE will be implemented using a graded approach to perform the necessary and sufficient SE tasks to achieve program goals. Each project will prepare an activity specific SEMP to reflect any differences from this SEMP that arise due to the application of the graded approach described below. The activity specific SEMP can be prepared in a "by exception" format using this TWRS SEMP as a model and should define how the project activities will differ from that outlined in this SEMP.

It is recognized that many of the activities of the TWRS Program are in different phases of the program life-cycle. SE tasks appropriate to the stage of the activity will be accomplished in accordance with the graded approach through mutual agreement of the M\&O task leader and DOE/RL counterpart.

\subsubsection{The Graded Approach}

The many activities within TWRS differ greatly in type, cost, scope, and complexity. It is appropriate that the level of detail related to SE be tailored to the particular effort. This "graded approach" will allow for a screening of the proposed activity by program/project personnel and, based on consideration of key elements and present state of the activity, establish the appropriate level of SE and documentation to be generated. Agreement on the chosen SE approach must then take place between project management and the DOE customer. The graded approach will be applied to ensure that:

The appropriate level of planning is performed,

Necessary and sufficient documentation is created,

- Needed levels of reviews are conducted, and

The project is integrated with the overall program.

The primary elements of the graded approach have to do with the risk/complexity of a project and the present stage of the project. The latter element recognizes the fact that within TWRS many projects have already begun. Detailed implications of the results of the grading are discussed in Appendix A. It should be noted that examples given both here and in Appendix A are meant for illustration only. Actual determination of the level of SE required should be based on careful evaluation of the project against the criteria in the following sections.

The steps to determine the level of implementation of systems engineering to a project are as follow:

1. Determine the project risk/complexity factors (high/moderate/low). 
2. Select the overall SE level for the project

- SE-1: Rigorous application of SE (high risk/complexity)

- SE-2: Full set of SE, but tailored to project (moderate risk/complexity)

- SE-3: Selective application of SE (low risk/complexity)

- SE-4: Does not require SE products (management decision, virtually no risk)

3. Determine required project SE activities and products

This process description is expanded in Appendix A. Tables are provided to assist in accomplishing the above steps.

1.2.1.1 SE Levels. The result of the process described in Appendix A is the determination of the level of SE to be accomplished by a particular product, based on a determination of the risk/complexity of the project being conducted. Four grades of projects are defined, in decreasing level of risk/complexity and applicability of SE.

The first level, SE-1, requires full SE documentation. Projects within this category include, technically complex Major System Acquisitions and Major Projects involving systems, structures, and/or components (SSCs). This type of project is typical of those that follow the guidance in DOE-4700.1.

The second level, SE-2, requires the full set of SE activities and documentation, but the effort is tailored to the level of risk/complexity of the project. Projects within this category include, (a) an existing systems modification with significant complexity, and (b) modification to facilities or systems undergoing a change in status if they have been in one condition or had one purpose or function for an extended period of time, and a substantial change in condition or purpose is planned (includes facilities that have been in standdown or shutdown for several months, and are being returned to service). This type of projects would have documentation that is significantly less detailed than the SE-1 projects.

The third level, SE-3, requires selective SE documentation. Projects within this category include, an equipment/system changeout not-in-kind. In addition, many analysis and software projects may fall into this category, even though they do not involve SSCs. Software projects are required to follow software SE as defined in WHC-CM-3-10, "Software Practices."

The fourth level, SE-4, does not require SE. Projects within this category include, "changeout-in-kind," where the change is a form, fit and/or function replacement of essentially identical specification to the replaced part.

The SE levels are summarized in Table 1-1. They are described in more detail, including selection criteria and examples, in Appendix A. 
WHC-SD-WM-SEMP-002 Rev. 0

Table 1-1. The Graded Approach - Summary.

\begin{tabular}{|c|c|}
\hline SE LEVEL* & EXAMPLES \\
\hline Rigorous application of SE & $\begin{array}{l}\text { - Major Systems Acquisition. } \\
\text { - Major Projects }\end{array}$ \\
\hline Full, but tailored application of SE & $\begin{array}{l}\text { - Existing systems modification with significant } \\
\text { complexity. } \\
\text { - Modification to facilities or systems undergoing a } \\
\text { change in status; substantial change in condition } \\
\text { or purpose planned. }\end{array}$ \\
\hline$\frac{\text { SE-3 }}{\text { Selected application of SE }}$ & $\begin{array}{l}\text { - Equipment/system changeout-not-in-kind. } \\
\text { - Analysis projects. } \\
\text { - Software projects. }\end{array}$ \\
\hline$\frac{\mathrm{SE}-4}{\text { Does not require SE }}$ & - Equipment/system changeout-in-kind \\
\hline
\end{tabular}

* See Appendix A for descriptions and criteria

1.2.1.2 Present Stage of Project. The diagonal diagram shown in Figure 2-2 indicates that the start of a "project" is defined by a specification, called a Design Requirements Document (DRD), generated by the program. However, some TWRS projects have started prior to program generation of a DRD. In these cases, where it has been decided to continue the project, a modification to the normal SE process must be carried out. Typically this involves project generation of a project mission analysis, and an "equivalent" DRD, along with an upfront determination of the program risks assumed by this process.

Appendix A gives criteria and specific examples of how to deal with projects of different SE levels that are already within the project life-cycle prior to applying SE.

\subsubsection{External Implementation}

For those activities that are the responsibility of TWRS under the M\&O contract but that are expected to be awarded to subcontractors for execution, the implementation of the SE process is still a requirement. Actions performed that are critical elements of SE integration (e.g., interface control and management, risk and decision management, configuration control, etc.) will be addressed to ensure that integral parts of the program produce sufficient products and documentation such that the program goals are met in an integrated and cost-effective manner. The mechanism for implementing the SE process can be significantly different than for activities performed by TWRS personnel. It is important to note that the basic principles of the graded approach as described in Appendix A remain the same, but the external agent is allowed to implement the requirements in a manner consistent with industry practices. This ensures consistency for TWRS activities and compliance with the TWRS SEMP, while allowing flexibility to outside agents to take full advantage of their existing procedures, documentation, and organization. 


\subsection{KEY PARTICIPANTS}

The primary participants and their general responsibilities are identified in this section. Roles and responsibilities for carrying out SE tasks and activities are identified in Section 4.1.3 and Appendix C, Roles and Responsibility Matrix. Figure 1-2, Formal Organization Interfaces, shows the existing formal relationships between the major participants. Informal communication links exist between all of the participants.

\subsubsection{U.S. Department of Energy - Headquarters}

The DOE/Headquarters (HQ) provides support to the DOE/Richland Operations Office (RL) TWRS Program Office for technical integration among the following:

1) The TWRS Program

2) The Waste Isolation Pilot Plant Program (WIPP)

3) The Office of Civilian Radioactive Waste Management Program (OCRWM)

The WIPP and OCRWM Programs provide the current technical interfaces for offsite disposal of transuranic and high-level radioactive wastes, respectively.

Figure 1-2. Formal Organizational Interfaces.

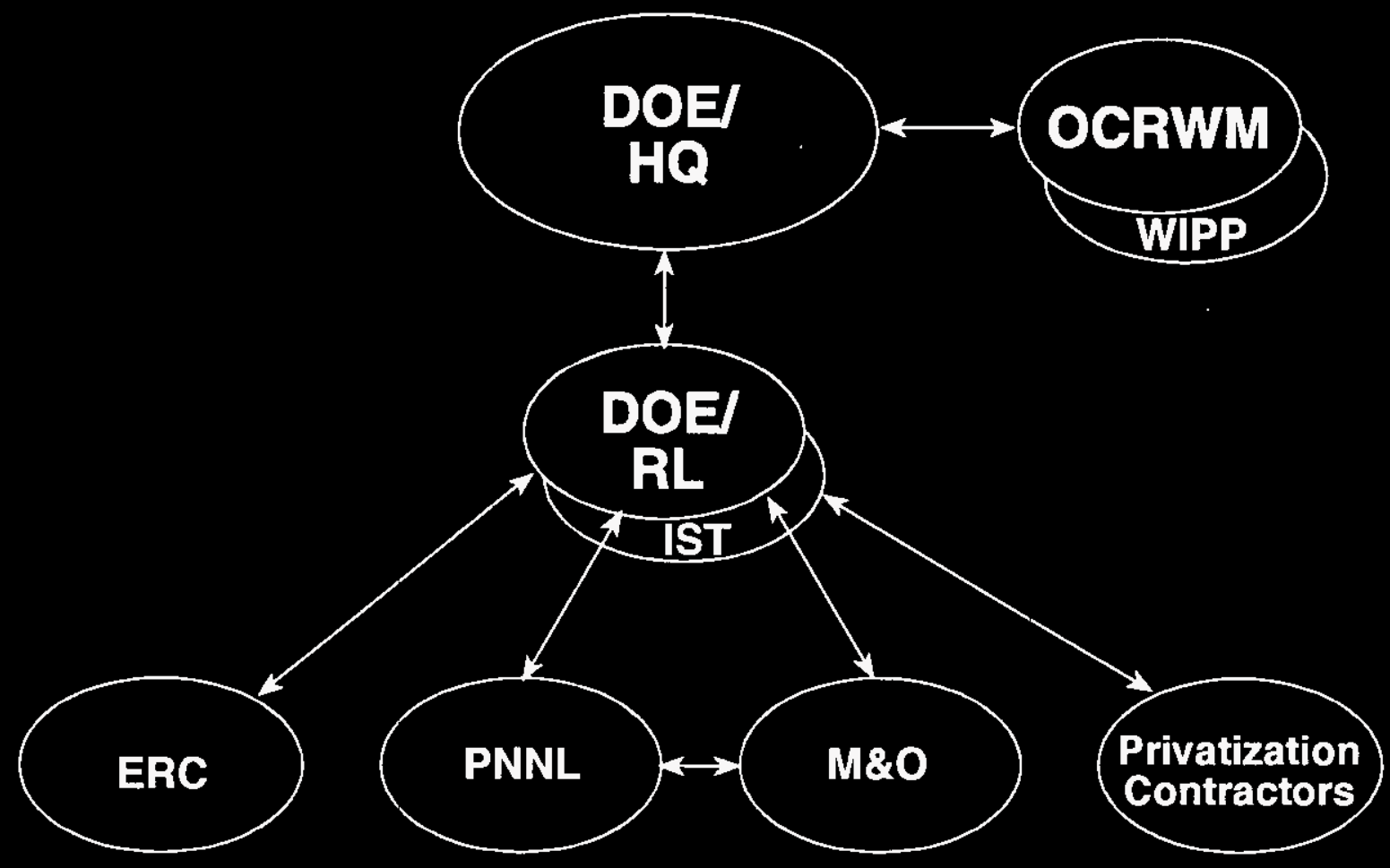


WHC-SD-WM-SEMP-002 Rev. 0

\subsubsection{U.S. Department of Energy - Richland Operations Office}

The responsibility and authority for formulating the TWRS SE program has been delegated to RL by HQ. The RL TWRS Program Office has assigned the Tank Waste, Retrieval, Treatment, and Immobilization Division as the oversight authority to monitor, assess, and ensure the adequacy of the TWRS Program SE activities. It has established TWRS SE policy for implementation by the M\&O contractor. It will review and accept toplevel program requirements and system descriptions as part of the SE process through established technical planning and control activities. It will identify, review, and accept project-level design requirements baselines for selected critical projects. It will also review and accept change requests to selected critical health, safety, and environmental requirements, regulatory requirements, selected performance requirements, and TWRS Program system-level interface requirements. It will ensure that TWRS Program SE goals, objectives, and priorities are clear and reflected in the products produced by the M\&O contractor. RL has primary responsibility for ensuring participants, involved internally and externally with the TWRS Program, establish and maintain appropriate lines of communication. External technical communications will include: (1) technical committees, (2) government agencies, (3) national laboratories, and (4) other participants in the TWRS Program. As required, the TWRS participants will provide technical support and interact with these participants.

\subsubsection{Management and Operations Contractor}

As the Design Authority, the M\&O contractor has primary responsibility and authority for executing the TWRS Program for DOE-RL. The execution of the TWRS Program will include implementing the SE activities outlined in this document. The M\&O contractor will also identify the TWRS Program technology needs. The Westinghouse Hanford Company (WHC) vice president for TWRS has assigned the TWRS Safety and Technical Integration organization the responsibility to direct and review TWRS Program technical integration activities using SE processes and technical management techniques.

M\&O contractor SE tasks will be performed in accordance with DOE Order 4700.1 and DOE/RL SE policy until initiation of the Project Hanford Management Contract currently scheduled for October 1996.

\subsubsection{Project Hanford Management Contractor}

The M\&O contractor role will be replaced by a Project Hanford Management Contractor whose primary focus will be integrating the activities of private contractors tasked with accomplishing portions of the tank waste remediation activities. SE activities will be conducted in accordance with DOE Order 430.1 upon initiation of the PHMC contract in October 1996. 


\subsubsection{Technology Development Contractor}

The tank waste problem spans more than the Hanford Site. Accordingly, the DOE is approaching the challenges of technology development in a multi-site methodology. The Tank Focus Area (TFA) is a multiple laboratory, multiple site technical team lead by Pacific Northwest National Laboratory and comprised of Idaho National Engineering Laboratory, Los Alamos National Laboratory, Oak ridge National Laboratory, Sandia National Laboratories, Westinghouse Savannah River, and WHC. The DOE/RL serves as the lead field office and administrator for the team.

The TFA manages, coordinates, and leverages technology development to provide integrated solutions to remediation problems that will accelerate safe and cost-effective cleanup and closure of the tanks across the DOE Complex. The technical scope covers the major functions that comprise a complete remediation system.

Initial focus of the TFA Integration Team is on technologies that can be rapidly deployed or meet near-term needs at multiple sites under multiple baselines. A major responsibility of the TFA is to ensure that DOE's tank technology budget is leveraged to the greatest benefit across the sites.

\subsubsection{Integration Support Team}

The Integration Support Team (IST) will assist the DOE/RL Manager of the TWRS Disposal Program in defining requirements, establishing tasks and working relationships, and managing the private contractors contracted to perform portions of the TWRS Program. The IST will provide liaison between the M\&O contractor and the private contractors for information products, services, and physical interfaces that are necessary for the integrated conduct of the TWRS Program.

\subsubsection{Privatization Contractors}

DOE has undertaken an initiative to reduce waste remediation costs through the privatization of certain portions of the program to clean up Hanford. For the TWRS Program, privatization is being conducted in two phases. In phase I, portions of the TWRS activity related to processing tank waste are being demonstrated through proof of concept contracts with selected private contractors. These private contractors will receive sample tank waste, process the waste, and return immobilized waste product for continued storage at Hanford. Phase II expands the effort initiated in Phase I to include retrieval and immobilization of the remaining tank waste. 


\subsection{TWRS INTEGRATED BASELINE}

The TWRS mission is to store, treat, and immobilize highly radioactive Hanford waste (current and future tank waste and the encapsulated cesium and strontium) in a safe, environmentally sound, and cost-effective manner. The mission includes retrieval, pretreatment, immobilization, interim storage and disposal, and tank closure. The TWRS Program Strategy integrates waste operations, safety issue resolution, retrieval, pretreatment, immobilization and waste disposal (Knutson 1995). In order to accomplish this strategy TWRS is using a combined program and technical management approach to develop an integrated baseline that combines the cost, schedule, and technical basis for remediating the tank waste.

\subsection{TWRS INTEGRATED BASELINE DEFINITION}

The TWRS Integrated Baseline is the complete set of cost, scope, schedule, and technical information used to define and manage the total program. The Integrated Baseline will evolve with increasing detail throughout the life-cycle of the system. At various points throughout the program life, a "snapshot" of the total cost, scope, schedule, and technical effort will be reviewed. After approval, this set of data is the baseline used to manage future work. The baseline will be controlled using existing Configuration Management (CM) procedures as referenced in Section 4.2.2.

\subsubsection{Cost, Scope, and Schedule Baseline}

The cost, scope, and schedule baseline is contained in the Multi-Year Program Plan (MYPP). The MYPP is a cost and schedule management product, and is built around the work breakdown structure (WBS). As the TWRS system architecture develops, the WBS will be re-examined for modification as part of the normal program planning. The WBS will evolve to become product based. Figure 2-1, TWRS Document Hierarchy, shows this relationship. During the transition to a product-based WBS, crosswalks between the WBS and the functions will be developed to ensure that all functions are covered and responsibility is understood.

The MYPP contains a Program Summary Schedule, that includes program and project schedules. The Program Summary schedule is an integrated schedule that defines the engineering and technical activities performed at the program and project level. When fully implemented, it will be a milestone-driven, product-based schedule that complements the modified WBS. The integrated schedule will provide management with a tool to evaluate progress against planned events and milestones. Lower-level program and project schedules are integrated into higher-level program or project schedules. Program schedules integrate the overall effort by including program requirements and architecture development, as well as technical activities for ongoing and new projects. 
WHC-SD-WM-SEMP-002 Rev. 0

Figure 2-1. TWRS Integrated Baseline Document Hierarchy.
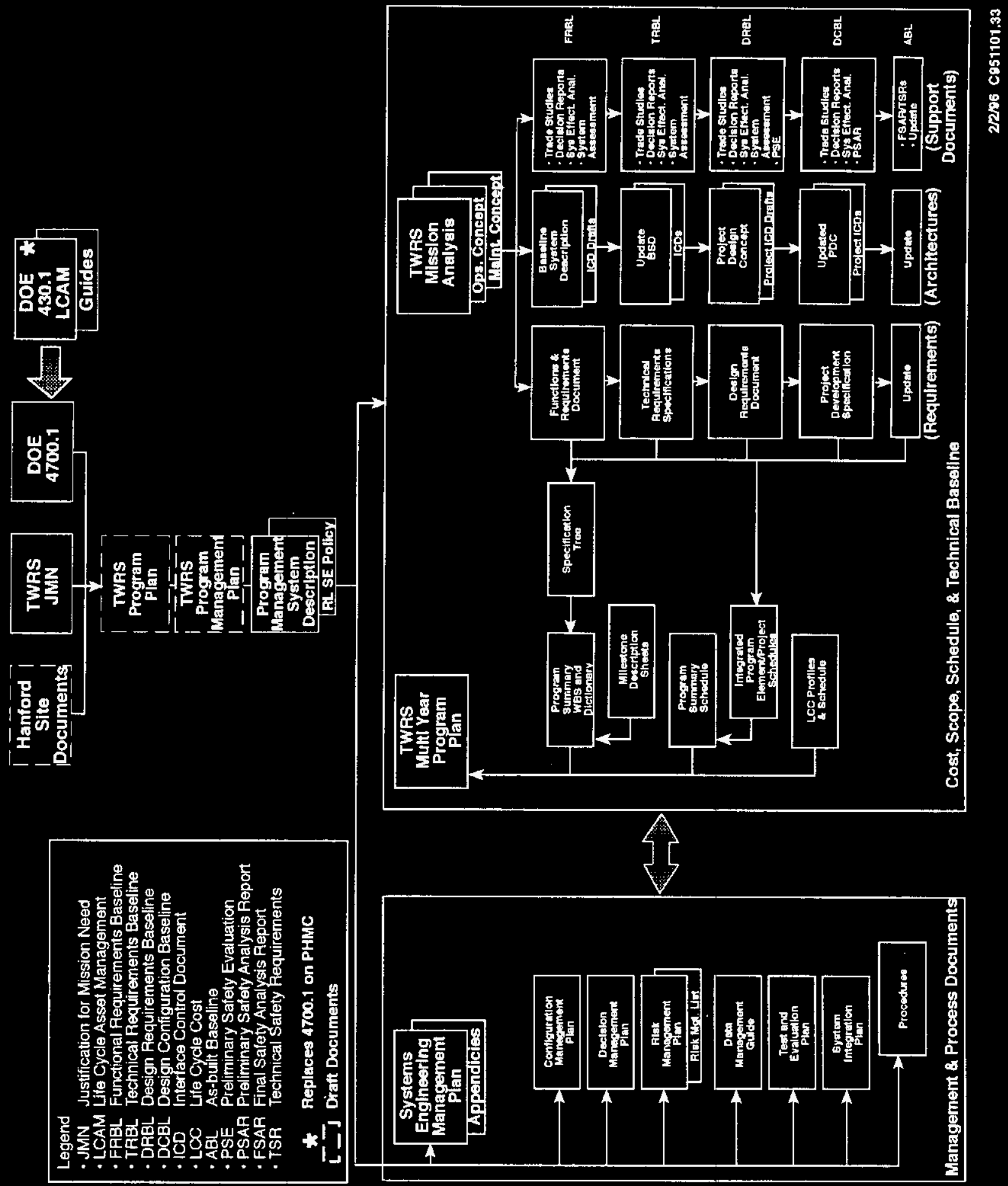


\subsubsection{Technical Baseline}

The technical baseline is the reference set of technical data. It contains all technical requirements, architectures, and interfaces generated using the SE process (see Section 3.0) to satisfy the TWRS Mission need. Technical data includes but is not limited to:

- Requirements (constraints, performance, interface, and verification requirements).

- Requirements analysis references and supporting data.

- Trade study results and supporting data.

- Authorization basis and supporting data.

- Architecture selections (hardware, software, and facilities).

- Interfaces (physical and functional).

- System Assessment Data.

- Decision Analysis and supporting data.

- Configuration control reference data requirements.

To reflect the evolution of the system description, the Technical Baseline is given different names as it matures. The baselines are: (1) Functional Requirements, (2) Technical Requirements, (3) Design Requirements, (4) Design Configuration phases 1-3, (5) As-built Configuration, (6) Operational, and (7) Decontamination and Decommissioning. Figure 2-2, TWRS Program Life Cycle, shows the evolution of the TWRS Technical Baseline, the documents defining the baseline at each phase, and the related technical baseline reviews.

\subsection{PROGRAM PHASES}

Program definition will be performed using a life-cycle phased approach. The phases include; preconcept, conceptual design, preliminary design, definitive design, construction, operations, and decontamination and decommissioning. The SE deliverables required to support these phases are described in Tables 2-1 and 2-2.

The TWRS Program includes existing projects, operations of the existing tank farm, support facilities and infrastructure. The existing projects are at varying stages of completion, from conceptual design to construction. These projects will establish traceability of each project mission and requirements to TWRS Program mission and requirements to ensure all program functions and requirements are fulfilled. 
WHC-SD-WM-SEMP-002 Rev. 0

Figure 2-2. TWRS Program Life-Cycle.

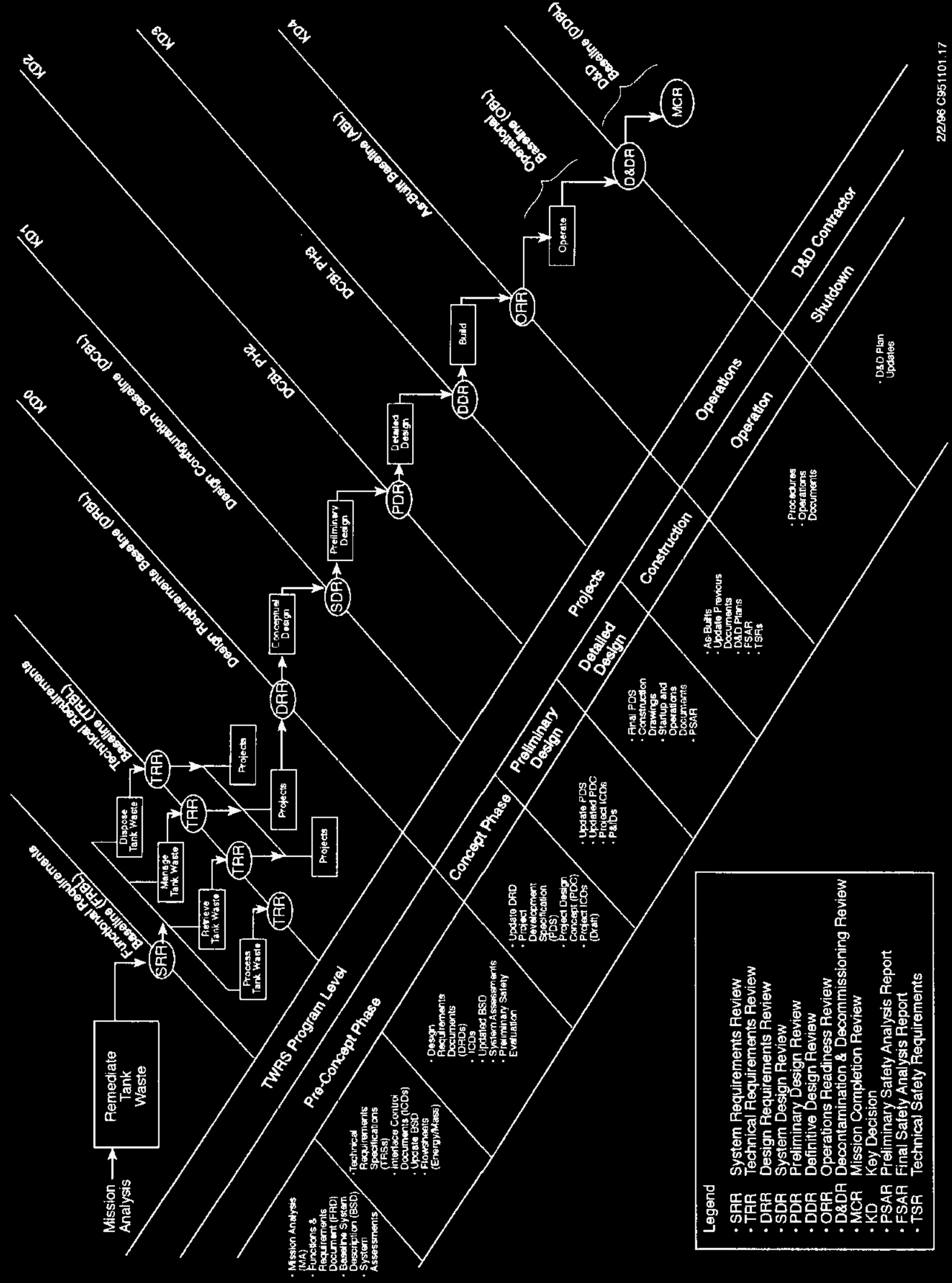


WHC-SD-WM-SEMP-002 Rev. 0

\subsubsection{Major Technical Products}

The TWRS will generate products to communicate the Program's technical baseline evolution. Initial mission analysis will be described in a Mission Analysis Report. TWRS system-level requirements will be published in a Functions and Requirements document. Further definition of program-level requirements will be published in a Technical Requirements Specification (TRS), Design Requirements Documents (DRD), and Project Development Specifications using tailored Military Standard 490A formats. Architecture concepts will be published in Baseline System Descriptions (BSD) and Project Design Concepts. Formats for the TRS, DRD and BSD are contained in the Document Format Guide (Orsag et al. 1996). Previous Hanford implementation of Mil-Std-490 is described in WHC-CM-6-1 EP 1.2, Single Use Non-Construction Specification. Design agreements between participants will be documented using Interface Control Documents (ICD). Tables 2-1 and 2-2 provide a more detailed listing and brief explanation of each product. The document hierarchy is shown in Figure 2-1.

The TWRS is using a database tool to control and manage the information developed to define the TWRS. The database contents were published as the Functions and Requirements Document (FRD), WHC-SD-WM-FRD-020 Rev. 0 (Carpenter 1996). The FRD included applicable portions of constraining documents, functional interfaces, boundary diagrams, and issues as generated from the database. Future F\&Rs will include architectures and test methodologies.

Table 2-1. Program Systems Engineering Technical Documents.

\begin{tabular}{|c|c|}
\hline $\begin{array}{l}\text { Program } \\
\text { Document }\end{array}$ & Document Description \\
\hline $\begin{array}{l}\text { Mission Analysis } \\
\text { Report }\end{array}$ & $\begin{array}{l}\text { Documents the mission analysis results that translate mission needs and objectives from the mission or } \\
\text { problem statement and other top-level documents into mission requirements. Includes top-level system } \\
\text { architecture concepts, operations, and maintenance strategies. }\end{array}$ \\
\hline $\begin{array}{l}\text { TWRS Functions } \\
\text { and Requirements } \\
\text { Document (FRD) }\end{array}$ & $\begin{array}{l}\text { Documents the results of the functions and requirements analysis and allocation process that transforms } \\
\text { the mission analysis results into a set of executable functions defined by requirements including } \\
\text { constraints, functional, interface, and performance requirements. Includes top-level functions analysis, } \\
\text { requirements identification and assignment, architecture selections, and test methodologies. }\end{array}$ \\
\hline $\begin{array}{l}\text { Baseline Systerns } \\
\text { Description (BSD) }\end{array}$ & $\begin{array}{l}\text { Contains summary text and illustrations for visualizing the selected architectures. References to trade } \\
\text { study reports are included as pointers to the detailed supporting information as it develops. The BSD is } \\
\text { used as a communication tool, for cost estimates and studies, and the next level of requirements } \\
\text { generation. The document is updated for independent reviews and for each baseline revision to maintain } \\
\text { baseline definition. }\end{array}$ \\
\hline $\begin{array}{l}\text { Interface Control } \\
\text { Document (ICD) }\end{array}$ & $\begin{array}{l}\text { Documents design agreements between projects and program or the program and the external } \\
\text { environment. }\end{array}$ \\
\hline $\begin{array}{l}\text { Technical } \\
\text { Requirements } \\
\text { Specification } \\
\text { (TRS) }\end{array}$ & $\begin{array}{l}\text { Documents the functions and requirements analysis and allocation results in a specification format } \\
\text { starting from the TWRS FRD document and continuing until the major program element missions are } \\
\text { defined to a level that functions and requirements are sufficiently detailed to assign to projects. Includes } \\
\text { functions and requirements analysis results: interface, performance, and verification requirements. }\end{array}$ \\
\hline $\begin{array}{l}\text { Design } \\
\text { Requirements } \\
\text { Documents } \\
\text { (DRD) }\end{array}$ & $\begin{array}{l}\text { Reference ICDs, functions and requirements allocated to a specific project. Describes the essential } \\
\text { technical requirements for designing, constructing, operating, and maintaining the system. Includes the } \\
\text { verification recuirements for determining if the requirements have been met. Will be used by the } \\
\text { project as a starting point for the design process. }\end{array}$ \\
\hline
\end{tabular}


Table 2-2. Project Systems Engineering Technical Documents.

\begin{tabular}{|c|c|}
\hline Project Document & Document Description \\
\hline $\begin{array}{l}\text { Project Mission } \\
\text { Analysis }\end{array}$ & $\begin{array}{l}\text { Produced only when the DRD is not available to the project. Documents the mission analysis } \\
\text { results for the project. Gives the project mission objectives and establishes a link to the Program } \\
\text { Mission. }\end{array}$ \\
\hline Project ICDs & Documents design agreements within a project and between projects. \\
\hline $\begin{array}{l}\text { Project Design } \\
\text { Concept }\end{array}$ & A project-level BSD. See Table 2-1 for more information \\
\hline $\begin{array}{l}\text { Project Development } \\
\text { Specification }\end{array}$ & $\begin{array}{l}\text { Lower-level specification based on the Project functions and requirements analysis and traceable } \\
\text { to the program-level requirements in the DRD. Provided as basis to perform design. }\end{array}$ \\
\hline $\begin{array}{l}\text { Mass/energy flow } \\
\text { sheets }\end{array}$ & $\begin{array}{l}\text { Mass and energy flowsheets describing clearly to the Architect/Engineer or design group what } \\
\text { the process must do. }\end{array}$ \\
\hline $\begin{array}{l}\text { Piping and } \\
\text { Instrumentation } \\
\text { Diagram (P\&ID) }\end{array}$ & Diagram showing piping and instrumentation schematic layouts. \\
\hline $\begin{array}{l}\text { Technology } \\
\text { Development Report }\end{array}$ & $\begin{array}{l}\text { Summarizes emerging or innovative technologies used in design concept. Addresses technical } \\
\text { adequacy of the technology. Summarizes associated risk management and TEP. (Supporting } \\
\text { document, only written if using emerging or innovative technologies.) }\end{array}$ \\
\hline Project Logistics Plan & $\begin{array}{l}\text { Describes the desired logistics program for supporting the project architecture. The plan } \\
\text { addresses system availability, maintenance planning, supply support, technical data requirements, } \\
\text { computer resources support, manpower, training support requirements, and packaging, handling, } \\
\text { storage, and transportation requirements. }\end{array}$ \\
\hline Project Reports & $\begin{array}{l}\text { Reports needed by the project to fully define their project activities. Examples of project reports } \\
\text { are Alternative Solution Reports, Trade Study Reports, or Decision Analysis Reports. These } \\
\text { reports document project-level work related to choosing the project design solution. }\end{array}$ \\
\hline $\begin{array}{l}\text { System Assessment } \\
\text { Reports }\end{array}$ & $\begin{array}{l}\text { Documents the approach and results of assessing existing systems against allocated requirements } \\
\text { to determine what modifications (if any) are required so the system complies with requirements. }\end{array}$ \\
\hline
\end{tabular}

\subsubsection{Independent Technical Reviews}

Independent technical reviews are conducted to assess the development of the integrated baseline. These reviews are conducted according to DOE Order 4700.1, Project Management System, and are expanded to ensure proper development, establishment, and control of the TWRS Program baseline. Reviews are used to verify conformance with system requirements at the WHC TWRS Program level and with design requirements or specifications at the WHC TWRS Project level. Technical reviews provide data for HQ and DOE/RL (Key Decisions).

There are nine baseline reviews. These reviews are the System Requirements Review, the Technical Requirements Review (TRR), the Design Requirements Review (DRR), the System Design Review (SDR), the Preliminary Design Review (PDR), the Definitive Design Review (DDR), the Operations Readiness Review (ORR), the Decontamination and Decommissioning Review (D\&DR) and Mission Complete Review (MCR). Figure 2-2 shows the relationship between the reviews and the technical baseline. Additional internal reviews are conducted, as necessary for TWRS Program and Project management. 
Each independent review must be successfully completed before starting the next baseline phase. For example, successful completion of the TRR is required before the Technical Requirements Baseline can be used as the input data to the Design Requirements Baseline. Reviews will only be performed after entry and exit criteria are established. Appendix B contains descriptions of the reviews and sample entry and exit criteria for TRR.

The organizers and participants of the baseline reviews will vary from review to review. For example, the SRR will be organized by WHC TWRS Program-level organization while the DDR will be organized by a Project. Program stakeholders will participate in reviews, as required, to ensure the consistency and technical adequacy of the evolving TWRS technical baseline. DOE/RL participation will depend on the baseline being approved. 
WHC-SD-WM-SEMP-002 Rev. 0

This page intentionally left blank. 


\subsection{SYSTEMS ENGINEERING PROCESS}

The TWRS SE process is described in the following sections and is shown in Figure 3-1. The process starts with mission analysis and continues with the TWRS SE process, which is a modification of the Functions, Requirements, Architecture, and Test (FRAT) process developed by Brian Mar (1994). The FRAT process consists of function analysis, requirements analysis and allocation, architecture selection, and test definition.

The process will be used to translate stakeholder needs into a system design and develop an optimized cost-effective solution to the identified system need. The end product of the process is documentation describing the preferred system and required performance. The process will be used throughout the life-cycle of the system. It will be used in a systematic approach that integrates the development, construction, test, operations, support, and decommissioning of the system.

The TWRS Mission Analysis (Knutson 1995) has been completed and functions and requirements developed to support the Privatization Request for Proposals. Subsequent work will further develop the functions, requirements, architectures, and test methodology to define necessary projects.

\subsection{MISSION ANALYSIS}

Mission Analysis translates the mission needs and objectives, customer desires, and other inputs, such as the value system, into mission requirements. The mission or problem to be solved must be traceable to a documented customer need. The Mission Analysis is conducted in accordance with the Mission Analysis Procedure, WHC-IP-1231 (Orsag et al. 1996) and the results are documented in a Mission Analysis Report (MAR). The information contained in the MAR will be placed under configuration control as part of the TWRS technical baseline and is the initial input for the BSD.

The MAR will contain:

1) Statement and description of the TWRS Program mission, including the description of the initial unacceptable state and a definition of the acceptable end state.

2) The scope and boundary of the TWRS Program, including a description of its interfaces to other systems both onsite and offsite.

3) Listing of imposed external constraints (fixed policy, legislation, regulations, and DOE directives) that provide the source of external requirements for subsequent requirements analysis and allocation. 
WHC-SD-WM-SEMP-002 Rev. 0

Figure 3-1. TWRS Systems Engineering Process.

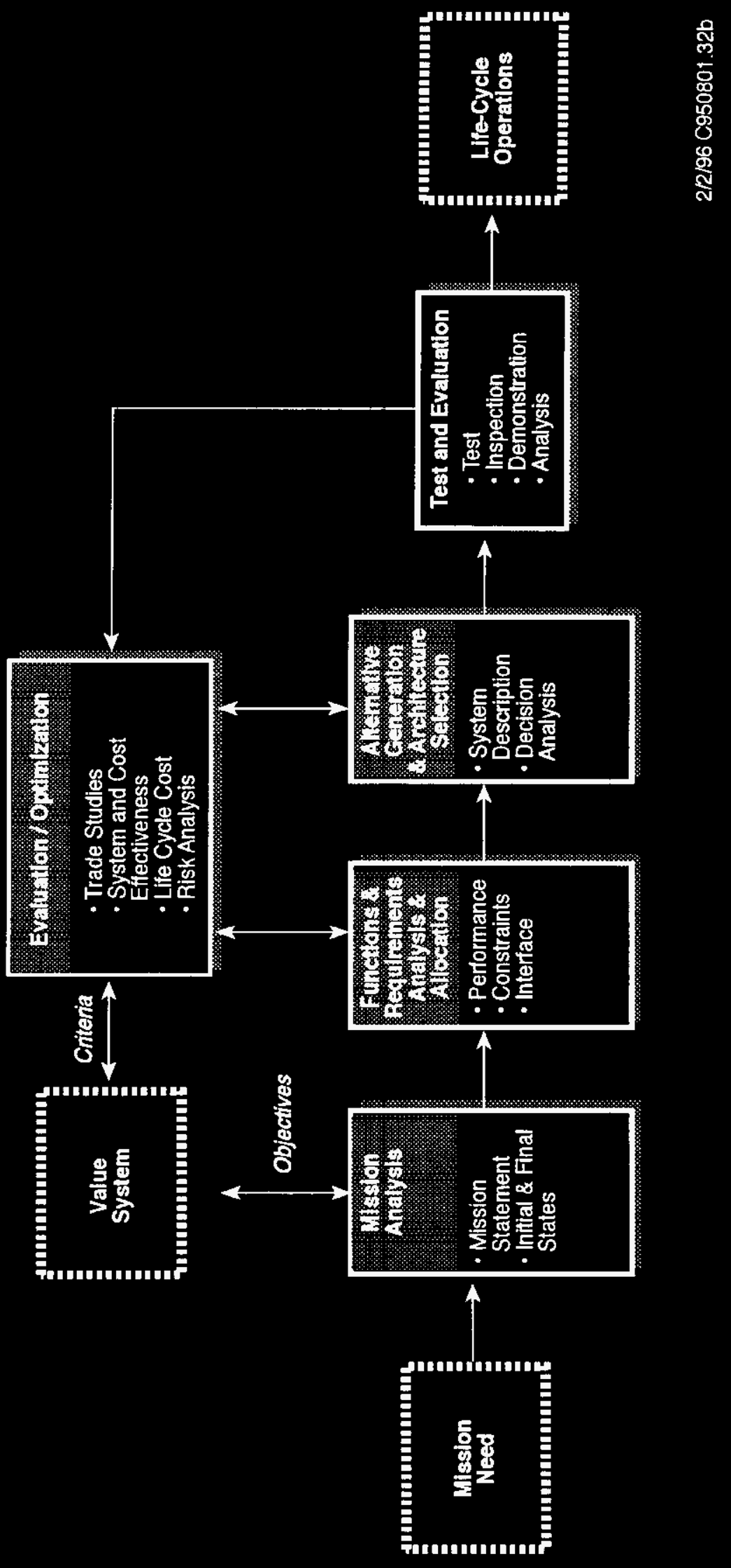


4) TWRS Program technical objectives and values that will be the basis for developing lower-level functions, requirements, and architectures.

5) The key system-level performance requirements, technical performance measures, and measures of system effectiveness to identify and measure how well the system end state must perform.

6) System-level enabling assumptions and associated risks. These assumptions will be carried into the functional analysis and identified and tracked from identification through resolution or validation of the assumption.

7) System-level T\&E methodology to verify that the integrated system performs as intended and the system level requirements are fulfilled.

Mission analysis forms the basis for the next step in the SE process, which is functions and requirements analysis and allocation.

\subsection{FUNCTIONS AND REQUIREMENTS ANALYSIS AND ALLOCATION}

The TWRS will iterate through the functions and requirements analyses and allocation in accordance with the Functions and Requirements Analysis and Allocation procedure (Orsag et al. 1996) to transform mission analysis results into functions and requirements for accomplishing the mission. Existing architecture and initial conditions will be used as inputs to this process. Functions and requirements analyses and allocation breaks down complex systems into simpler related parts. The result is a framework of functions, constrained by applicable requirements, to satisfy the mission.

\subsubsection{Functional Analysis}

The TWRS performs functional analysis to decompose the mission into a hierarchy of functions that are both necessary and sufficient to satisfy the mission. The functional analysis is documented in a functional hierarchy, function flow block diagrams, and descriptions of the functions and functional interfaces. The functional analysis results, when verified and approved, will be placed under CM as part of the TWRS Program integrated baseline.

The TWRS Program functions and their associated inputs and outputs will be integrated with the Site functions. Integration means that functions will be directly traceable between the Site, the TWRS Program, and the TWRS Projects in one continuous function tree. 
WHC-SD-WM-SEMP-002 Rev. 0

\subsubsection{Requirements Analysis}

TWRS will perform three basic requirements analysis activities: 1) requirements identification and development, 2) requirements validation, and 3) requirements allocation. The first activity identifies constraints, interface requirements, and performance requirements from the three categories are explained below. After identification and development, performance requirements are then validated by simulations, modelling, or analysis to ensure that they will satisfy the mission need. Requirements are then allocated to the applicable functions, interfaces, and architectures. Functions and the associated requirements are allocated to each architecture to prescribe how well each architecture must perform to meet the overall mission requirements, or to prescribe the characteristics of each interface.

1) Externally Imposed Constraints, include regulatory requirements that are derived from external sources such as the U.S. Congress, U.S. Environmental Protection Agency, Washington State Department of Ecology, and other regulatory agencies, DOE Orders, Secretarial Notices, and other external requirements of a mandatory nature. Where necessary, these constraints will be interpreted to derive a performance requirement that is quantifiable and verifiable.

2) Performance Requirements, are developed during the Mission Analysis and requirements analysis, or imposed on the system by the Site requirements allocation that are necessary to achieve the mission of the TWRS Program and each of the individual system elements.

3) Interface Requirements, apply to the system and may be imposed either by external sources or derived through the TWRS Mission Analysis.

The results of the requirements analysis and allocation, when approved, are incorporated into the TWRS Program technical baseline.

All information associated with functional analysis and requirements analysis will be entered into the Requirements Management and Assured Compliance System (RMACS). RMACS, the primary SE tool, will be used as the central repository for all functions, requirements, architectures, and supporting data. It will be used to generate specifications and test requirements and is used to provide top-to-bottom traceability of functions, requirements, architectures, and components. RMACS will also be used to track requirements and analyze the impact of functional and requirement changes (see Section 4.2.4).

The functions and requirements analysis and allocation process provides the starting point for alternative generation and architecture selection. 


\subsection{ALTERNATIVE GENERATION AND ANALYSIS}

Alternative Generation and Analysis (AGA) is used to identify and analyze alternative system configurations that satisfy mission analysis and technical baseline functions and requirements, to make alternative architecture selection decisions. All reasonable alternative architectural concepts will be screened against the functions and requirements. Those that satisfy all requirements are candidates for further analysis and decision making. When existing systems are an alternative, the system will be assessed against the requirements, all deficiencies will be identified, and the resources required to modify the system will be estimated for use in evaluation and optimization activities.

The AGA Procedure (Orsag et al. 1996) describes the steps necessary to develop and analyze alternative architectures and the Decision Management Procedure (Orsag et al. 1996) outlines the steps necessary to make the architecture selection decision.

The architecture, in the form of selected engineering data, requirements, and specifications, will form the basis for the technical baseline, and then be formalized through internal and external reviews and controlled using the CM process. The architecture will start as concepts and strategies at the upper level, and mature into greater detail at lower levels. This process continues until an architectural element can be obtained as a single unit, by subcontracting, purchasing, constructing, writing unit level software, etc.

To focus the design efforts, a BSD document is produced and maintained. The BSD document provides summary text and illustrations of the architectural concepts of the TWRS Program and becomes part of the technical baseline. The BSD will mature as the architecture matures. The architecture selection and decision management activities will be captured in the RMACS to provide a traceable basis for the TWRS Program.

\subsection{EVALUATION AND OPTIMIZATION}

Evaluation and optimization provides the main feedback mechanism for the SE process and facilitates the development of a balanced, optimized design solution. Thus, evaluation and optimization is performed throughout the SE process. Typically, there are numerous considerations in selecting an optimum system and the evaluation and optimization process ensures that no single characteristic dominates the design. Principal methods for evaluation and optimization are described in the following sections.

\subsubsection{Trade Studies}

Engineering trade studies will be performed during all phases of the program and project life cycles, whenever there is a need to select from two or more options. Trade-offs are conducted among architectures, as well as the following: (1) requirements, (2) engineering designs, (3) project schedule and budget, (4) cost effectiveness, (5) technical, programmatic, environmental, safety and health risk, and (6) other significant factors. Trade studies vary in extent and cost, depending on the complexity of the project. Planning of 
trade studies will be initiated early in the program to minimize impact on the development of requirements documents, specifications, etc., and continue through the life of the project. Trade study planning should use a graded approach to ensure a cost-effective implementation while still providing sufficient time and resources for analyzing substantial alternatives. However, all selection between alternatives will be substantiated by some level of trade studies.

\subsubsection{System and Cost Effectiveness}

The basic design objective is to optimize the development of a system that will do the best job at the lowest cost. To accomplish this, all elements of the system should be addressed on an integrated basis and system analysis and trade-offs are accomplished to develop a preferred approach. The proper balance of design attributes is an important factor in analyzing a system or selecting an architecture, but the ultimate decision criteria is some form of cost effectiveness.

System Effectiveness is defined (Blanchard and Fabrycky 1981) as "the probability that a system can successfully meet an overall operational demand within a given time when operated under specified conditions" or "the ability of the system to do the job for which it was intended." System effectiveness is a term used to reflect the operational aspects and technical characteristics of a system. These include system performance, maturity of technology, availability, supportability, and dependability.

Cost effectiveness is the measure of a system in terms of mission fulfillment (system effectiveness) and total Life-Cycle Cost (LCC). Cost effectiveness includes the elements shown in Figure 3-2 and can be expressed in several different Figures-of-Merit, which relate LCC to system effectiveness, and system capacity.

System and cost effectiveness criteria, Figures-of-Merit, and related Technical Performance Measures, will be determined at the mission analysis level, and be continually updated and used as criteria during the alternative evaluation and decision making process to ensure the development of a system that operates effectively at the lowest possible LCC. 
WHC-SD-WM-SEMP-002 Rev. 0

Figure 3-2. Cost Effectiveness.

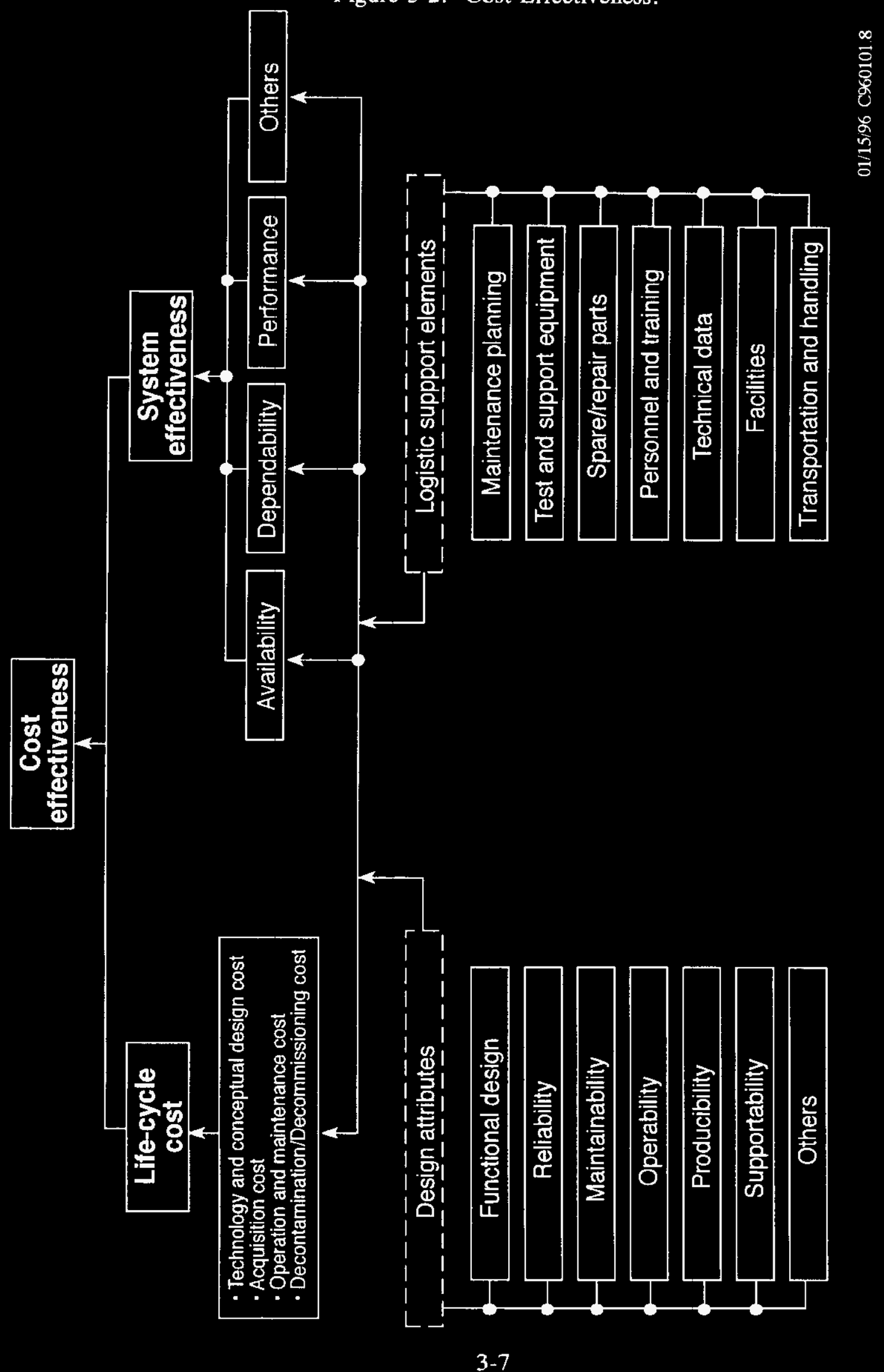


WHC-SD-WM-SEMP-002 Rev. 0

\subsubsection{Life-Cycle Costs}

System LCC analyses will be performed to develop the requisite cost information to support decisions on alternatives, personnel, product, process solutions, and risk assessments. LCC is the total of the direct, indirect, recurring, nonrecurring, and related costs incurred or estimated to be incurred during the anticipated life span of the system. Early design evaluations will include system trade studies that establish a desirable balance among performance, risk, reliability, supportability, schedule, cost, and other significant attributes while complying with safety, regulatory, and permitting requirements. The TWRS Program LCC analysis will be performed on a continuing basis as the program evolves and will be established specifically at each technical baseline review. The TWRS SE LCC Procedure (Orsag et al. 1996) describes the development of a LCC Program.

\subsection{TEST AND EVALUATION}

Test and Evaluation (T\&E) is the TWRS activity that will verify that the completed system meets the customer's requirements. Performance requirements will be different for components, subsystems, and systems, but are the inputs for each level of the T\&E activity. The determination of the methodology to verify that the system, and its subelements, satisfies its performance requirements is an integral step in the SE process. Section 4.2.6 explains the TWRS T\&E approach.

The specific T\&E method for verification will be determined as the functions, requirements, and architectures are developed to ensure that the performance requirements can be met. To be verifiable the performance requirements must be measurable, quantifiable, complete, accurate, and traceable. T\&E ensures that mission objectives are satisfied because the system requirements (which were developed from the mission objectives) are used as the criteria during T\&E.

The specific method to be used for requirements verification depends on various factors including cost of verification, importance of requirements, optimum system measurement point, and schedule constraints. Requirements verification methods will include one or more of the following:

1) Analysis

2) Demonstration

3) Testing

4) Inspection.

A grading system will be established to determine the extent to which the above methods should be applied to optimize usage of the verification resources and avoid expenditures where they are not warranted. For example, the most important safety and performance characteristics of the system should be extensively reviewed, analyzed, and tested to ensure satisfactory performance, while low risk, low cost elements may be verified through inspection and limited analysis. 
WHC-SD-WM-SEMP-002 Rev. 0

\subsection{SYSTEMS MANAGEMENT AND CONTROL}

\subsection{SYSTEMS MANAGEMENT}

Systems management includes the TWRS organizational structure, organizational interfaces, roles and responsibilities, technical discipline integration, and systems integration activities required to develop a cost-effective system that satisfies the user's needs.

\subsubsection{Program Management Structure}

The TWRS Program management structure has been revised since first published in the TWRS Program Management Plan [1993] to focus on the projects. The revised structure has a program level Technical Integration organization and project organizations. The organizational structure is shown in Figure 4-1, TWRS Program Organization. The individual project management structures are developed based on the needs of the project and reflected in the individual Project Management Plans.

TWRS Technical Integration has been chartered to integrate the TWRS Program technical baseline, and to implement the SE process in TWRS. Technical Integration provides leadership in creating and managing the technical baseline, defining technical strategies and objectives, and implementing performance metrics to monitor progress.

\subsubsection{Organizational Interfaces}

TWRS will manage internal and external organizational interfaces. The internal organizational interfaces are defined and communicated using organization charts based on workscope (see Figure 4-1, TWRS Organization). For repetitive activities that call upon personnel from different organizations, a Working Group Charter will be developed.

Interactions with external activities and organizations (e.g., Privatization Contractors, IST) will be developed through negotiation and documented in Memorandums of Agreement. TWRS will identify a liaison to the external agency.

\subsubsection{Roles and Responsibilities}

A roles and responsibilities matrix is included as Appendix C. The matrix correlates the activities and products with the organizations, which are lead, support, review approval, and customer for those activities and products. 
WHC-SD-WM-SEMP-002 Rev. 0

Figure 4-1. TWRS Program Organization.

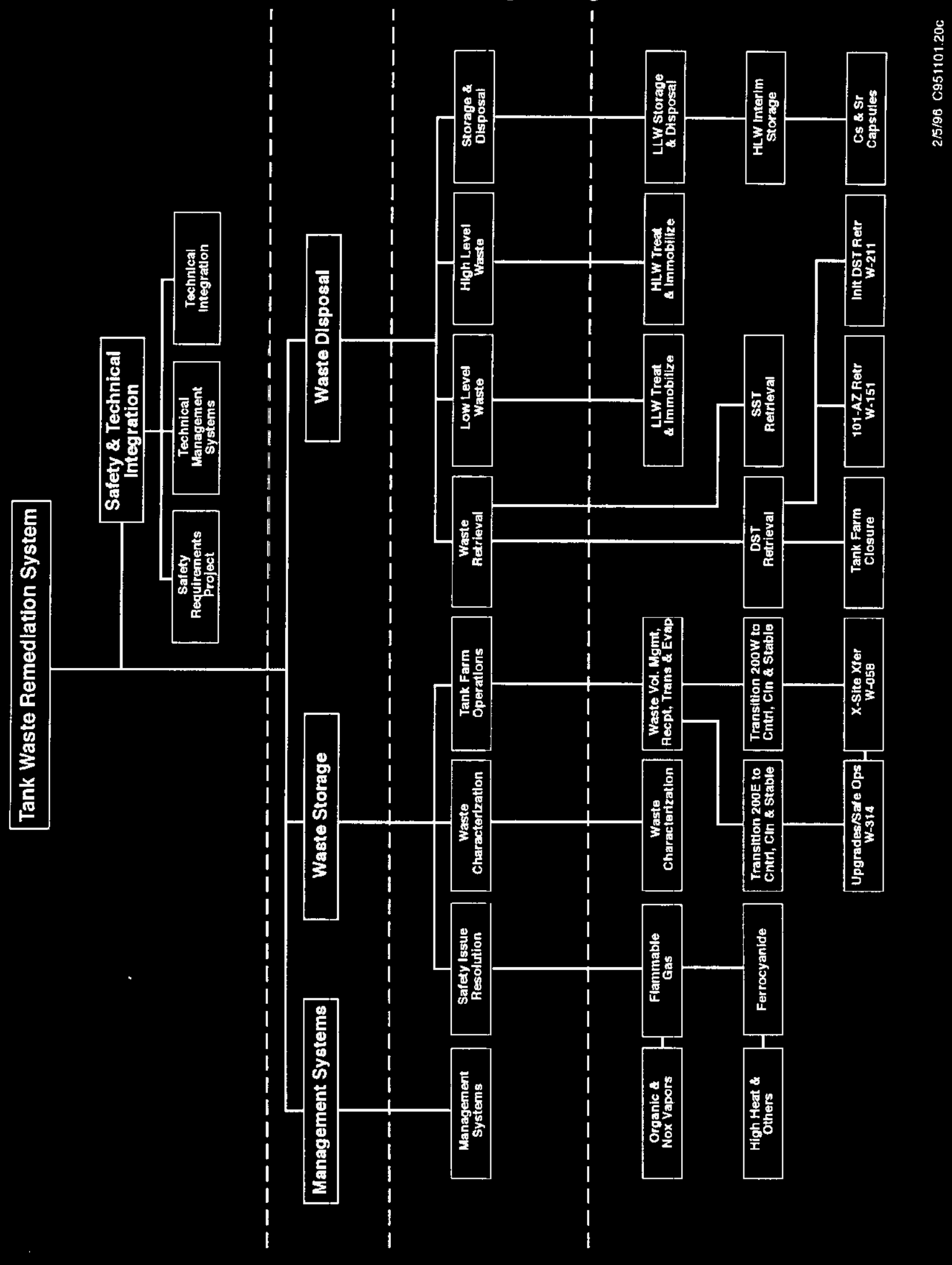




\subsubsection{Technical Discipline Integration}

Systems Engineers, and other personnel with responsibility for developing the technical baseline, will ensure that individuals in the regulatory, health and safety, and other specialty disciplines participate in the development of the technical baseline. These technical personnel are an integral part of the engineering development process, and will therefore participate throughout the SE process, starting with the Mission Analysis and continuing with the process of developing the lower-level functions, requirements, architectures, and T\&E activities. The methodology for ensuring participation of the specialty engineers is the formation of Product Development Teams (PDT) or Integrated Product/Process Teams (IPT) to accomplish the FRAT process. The PDTs would be responsible for one of the hierarchical functions (or subfunctions) and consist of process engineers and systems engineers who form the core group. The core group would be supplemented by "specialty engineers," who participate when the specific expertise is needed.

There are many types of engineering and non-engineering specialists who's participation in baseline development is vital to ensuring a fully integrated system. The following is a list of typical specialties that will participate in the TWRS development:

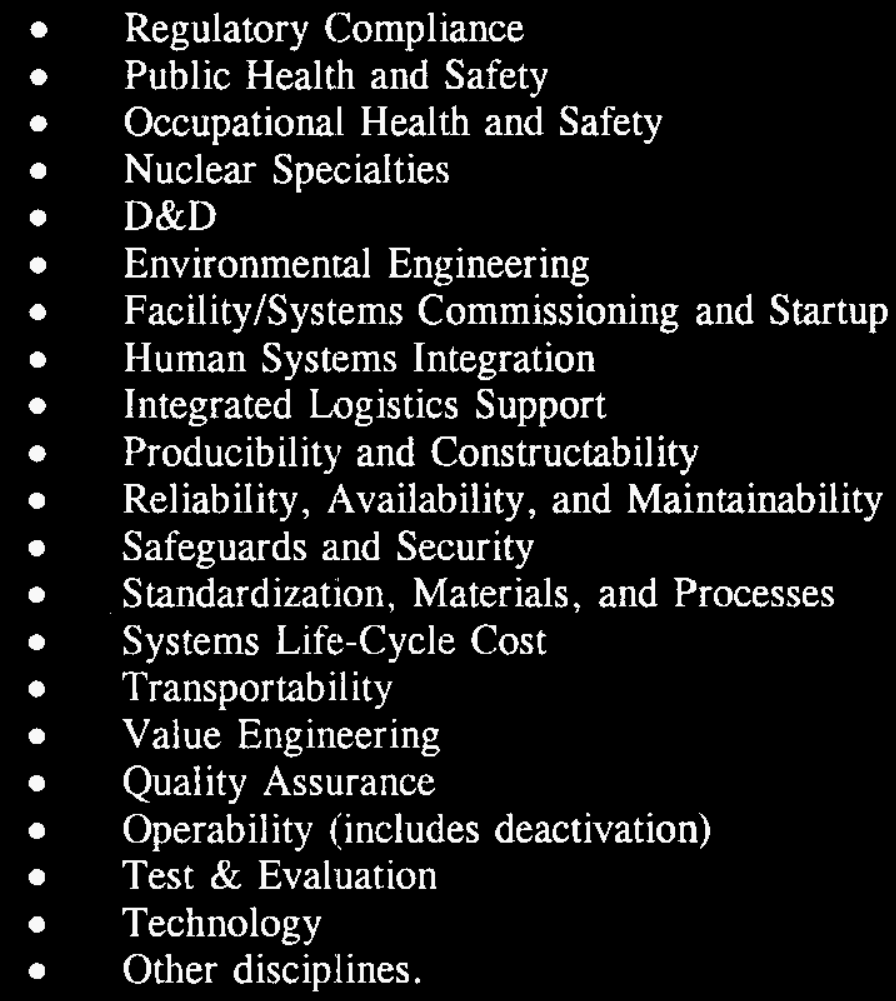

Appendix D includes descriptions of each of the disciplines. Personnel with specialty background or expertise should be identified by the Team Leader or other members for participation as required to ensure necessary requirements are established to impact the design process. 


\subsubsection{Systems Integration}

System integration fulfills two functions. It provides a vehicle to focus effort and resources where required by improving understanding of the Program path forward. Integration is also the assembly of the physical pieces of the system into a whole.

4.1.5.1 Management Systems Integration. Integration is the process of unifying all of the activities performed in developing a system to increase effectiveness and efficiency . It ensures that all entities involved in system development are interacting to successfully achieve the system purpose or satisfy the customer's need. Integration starts with the SEMP which integrates the customer's needs with the WHC and TWRS management system.

Successful integration requires communication, planning, scheduling, baseline management and interface management. Effective communication and the development of a Systems Integration Plan (SIP) are the keys to successful system integration. The effective communication is facilitated by the TWRS management structure and the use of concurrent engineering in the form of PDTs. An information system that provides consistent, accurate and timely data and direct face-to-face communication in the team interaction process are important aspects of effective communication. The SIP addresses the processes and procedures to be followed in integration of TWRS with other activities. The SIP will detail the formation and use of the PDTs. It will also specifically address the need for integration of private vendor facilities and project work with WHC and government-engineered efforts.

Integrated planning consists of consistent guidance, practical procedures, appropriate tools, adequate resources and integrated reporting. The three key taskings in integration are system definition, establishment of an architecture, and verification that the proposed architecture meets system objectives. The TWRS planning process ensures that no work is performed that does not contribute to satisfying the customer's need and results in the MYPP. The TWRS SE Program Summary Schedule, an event driven schedule which is coordinated to the TWRS WBS, identifies the key events and the accomplishments that must be achieved by those events.

Baseline management, or maintaining approved, defensible and integrated baselines, is covered by existing TWRS configuration management procedures. The TWRS Integrated Baseline, covered in Chapter 2.0, integrates the plans, schedules and technical baseline into a coherent management structure. Interface management, covered in Paragraph 4.2.3, prescribes the activities necessary to manage the inter-relationships of numerous sub-systems or components. The product of systems integration is integrated plans and schedules where key milestones for system definition, design, construction, test, deployment, operation and D\&D are assembled and conflicts resolved.

4.1.5.2 Physical System Integration. Physical System Integration is the process of creating an assembly from pieces of the system. It is used both top down and bottom up. TWRS will use system integration from the top down to analyze all parts of a complex system, and their interrelationships, to solve the problem and satisfy the customer's need with the best possible total solution. For TWRS this means that TWRS must be integrated with not only the site but must also be cognizant of interfaces and relationships with other DOE sites. The 
effects of TWRS on the interfacing components of other affected DOE sites, i.e., the repository, as well as the effects of the other sites on TWRS must be considered. The topdown integration continues with an in-depth evaluation, at each level of decomposition, of the integration of the components of TWRS to provide the best "integrated" solution. TWRS will use the FRAT process with emphasis on architecture definition and interface analysis to accomplish the complete integration activities.

Integration occurs from the bottom up when parts (components) are tested at the lowest level and the parts are then put together in a planned manner to verify the operation of the entire system. Some bottoms-up integration does not require actual testing, but may use analysis of the combinations of lower level results to verify the acceptance criteria has been satisfied. The TWRS Test and Evaluation Plan (TEP) will contain the details of this integration process.

\subsubsection{Training}

Training will be provided to TWRS staff so that they have the knowledge and skills necessary to understand and implement the SE Process as a way of doing business. This will include training for present and new employees. The TWRS Technical Integration group will have primary responsibility for developing the content and methods for training.

Training is a process that provides a managed training program, a training plan, training experience, and measures training effectiveness. The highest-level requirements for training and the type of training expected for management, project leaders and technical staff will be defined. A training plan will be prepared to detail specifically the content and methods of training. This will include an introduction to SE and the use of the specific SE procedures required for the conduct of TWRS work. The effectiveness of training will be measured by monitoring; 1) increase in employee skills for doing their job, and 2) the degree of improvement in the quality of the SE products.

\subsection{SYSTEMS CONTROLS}

The TWRS Program is implementing the systems controls described in this section, to develop the TWRS in a cost-effective manner. These methods provide the tools to effectively manage risks, configuration, interfaces, and decision making, to provide traceability of all requirements, and to manage $T \& E$ processes and technical performance measurement. Use of this structured approach provides management with cost-effective controls over the life of the project. 


\subsubsection{Risk Management}

The TWRS Program is establishing a systematic and integrated risk management program approach to support line management at program, project, and subproject levels with evaluations of programmatic cost, schedule, and technical performance risk. The approach uses a top-down, bottom-up flow of risk data and information (see Figure 4-2, Risk Management List Organizational Structure). The primary tool for managing risk is the risk management list (RML), which identifies risks, describes their likelihood and consequences, and identifies handling actions and responsibilities. The RML may be supplemented by a Critical Risk Management List (CRML) that includes only the highest risks. In some cases, the CRML may be the only risk list presented to management, but a RML still needs to be generated.

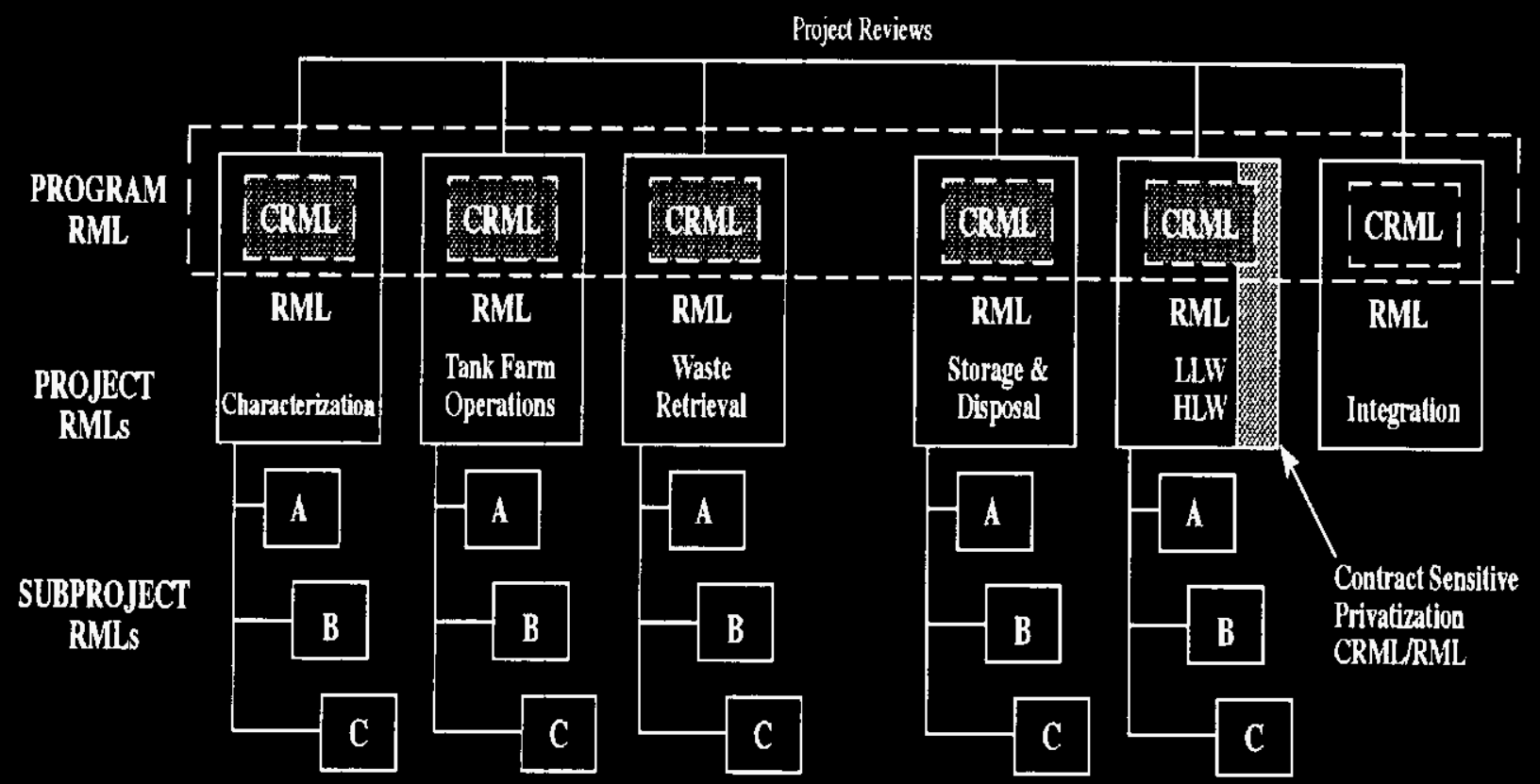

0146196 C960101.11a

Figure 4-2. Risk Management List Organizational Structure.

There will be an overall TWRS Program-level CRML and RML. Each project is to maintain its own CRML and RML and oversee the development of applicable subproject CRMLs and RMLs. Following are the key elements of TWRS risk management program. Additional details are contained in the TWRS Programmatic Risk Management Plan, WHC-SD-WM-PMP-018.

- $\quad$ Each TWRS project will develop an RML specific to its activities and consistent with the TWRS RML. 
- The TWRS Programmatic Risk Management Plan will be periodically updated to support fiscal year planning.

- An integrated risk database will be used by program, project, and subproject managers and technical staff to query, review, and distribute programmatic risk information.

- Continued improvements will be made in the process and tools for risk management including methods for identifying risks, selecting risk management actions, revision of procedures, training, and communicating lessons learned.

- Mentoring assistance will be provided to projects and subprojects to help them implement risk management.

- $\quad$ Projects will assign a point of contact for risk management integration.

- $\quad$ Programmatic risk will be used as evaluation criteria in trade-off studies.

The TWRS Risk Management Program will be managed and controlled through the performance of risk assessment (identification), risk analysis, and risk handling (see Figure 4-3, Risk Management Functions). Risk assessment involves the examination of all aspects of a project or subproject in order to identify potentially undesirable events that can detrimentally affect the program and make an initial assessment of the impact such an event could have if it occurred. Risk analysis involves the process of quantifying both the likelihood of an undesirable event and its impact should it happen. Risk handling involves the identification of handling actions, development of action plans, action implementation, and status tracking, including planning for follow-on actions in response to programmatic changes.

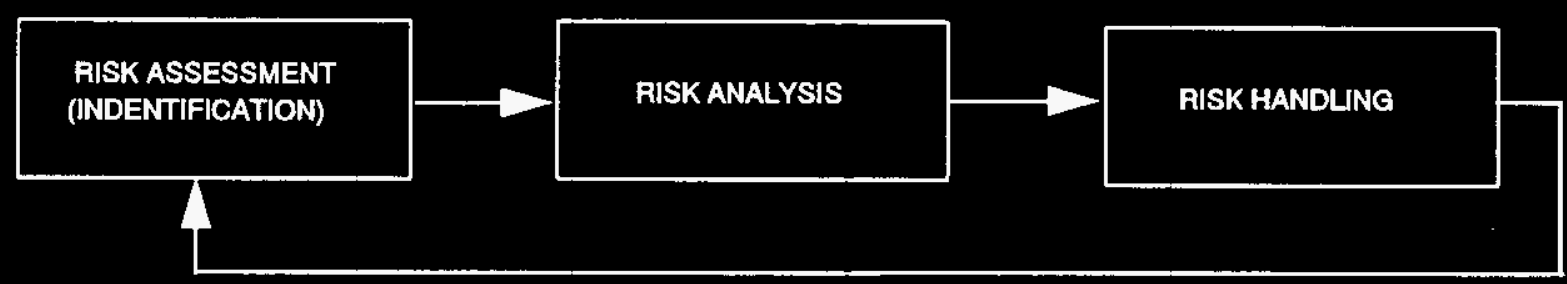

Figure 4-3. Risk Management Functions.

The TWRS Risk Management Program will be performed at all levels as functional process steps. The process steps should be iteratively performed and have feedback anywhere within the process. (See Figure 4-4, Risk Management Process.) 


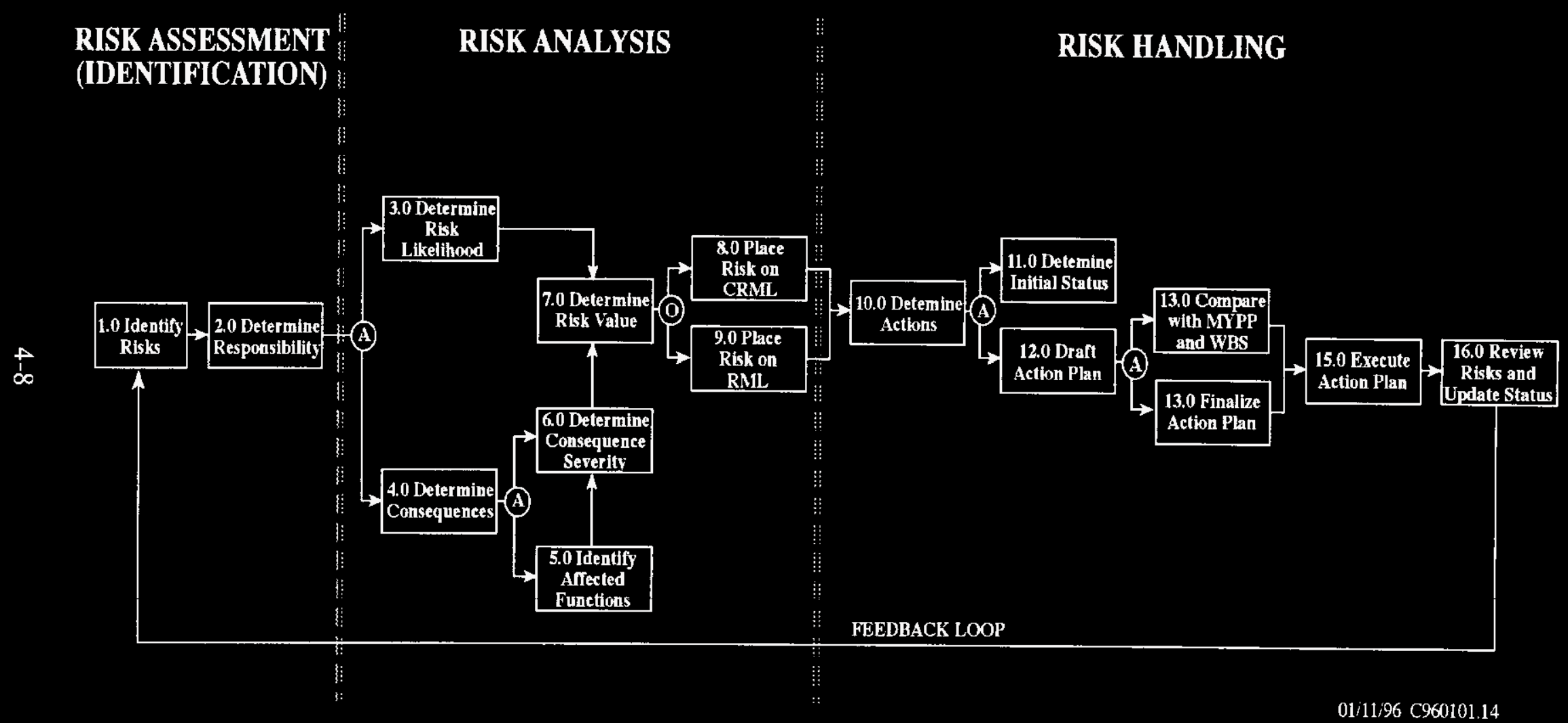


Detailed instructions for performing the TWRS Risk Management Program are contained in the TWRS Risk Management Procedures (Orsag et al. 1996).

\subsubsection{Configuration Management}

TWRS Configuration Management (CM) will be implemented in accordance with WHC-SD-WM-CMP-013, Tank Waste Remediation Systems Configuration Management Program Plan and WHC-SD-GN-CM-2001, Configuration Management Program Plan for Hanford Site Systems Engineering. The TWRS Configuration Management Program Plan (CMPP) describes the CM Program for TWRS and defines the requirements and responsibilities for execution of the TWRS Configuration Management Program. It provides the methodology to establish, upgrade, reconstitute, and maintain consistency among the requirements, product configuration, and product information. The technical consistency afforded by the TWRS CMPP provides for the safe, economic, and environmentally sound management of the TWRS products throughout their life cycles. This is necessary to achieve the mission objectives and support the DOE Integrated Site Baseline.

The TWRS CMPP complies with WHC CM requirements and aligns with the criteria established in the DOE Standard, DOE-STD-1073-93. The TWRS CM Program implements requirements of DOE/RL-93-0106, Tank Waste Remediation System, Program Management Policies, DOE/RL-95-58 (E), Hanford Site Systems Engineering Criteria Document (Draft), the Hanford Strategic Plan (October 1994); and RLPD 5000.1, Baseline Execution and Management Process, and complies with the requirements established in applicable DOE Orders and Directives.

\subsubsection{Interface Management}

The TWRS Program interface management process is comprised of identification and documentation of functional and physical interfaces, and establishing and maintaining control of interfaces. ICDs will be developed continuously throughout the TWRS Program life-cycle beginning with the early conceptual stage. ICDs are a component of the program Integrated Baseline and as such are required to be under configuration control. ICDs will be developed in accordance with the established TWRS Interface Control procedure (Orsag et al. 1996).

The TWRS Interface Control Working Group (ICWG) is tasked to manage alternative generation and architecture selection, evaluation and optimization, and verification activities between organizational elements. The ICWG is responsible for establishing and controlling TWRS interfaces. The ICWG has been set up within TWRS for the purpose of maintaining cognizance and control of TWRS functional and physical system interfaces in accordance with the TWRS ICWG Charter. 


\subsubsection{Requirements Traceability}

The TWRS Program will provide requirement traceability throughout the system life. TWRS will use an integrated database, the RMACS to store and manage the SE data. Changes to the database will be managed using CM processes (see Section 4.2.2). The RMACS engine is RDD-100*, a relational database.

Requirement management and CM processes will provide traceability for all of the SE data. Requirement traceablity includes managing the requirement source (e.g., constraining document, function decomposition, trade study), applicable requirements analysis to interpret the source, requirement allocations to architectures, test and evaluation method, and revision and approval records. These items plus all applicable issues, enabling assumptions, and decision management references will be recorded and managed to provide a defensible "pedigree" for TWRS requirements.

RMACS contains not only the single integrated database but also supporting information management tools to allow freer access to TWRS data for use by the engineering staffs and other personnel. The primary access for the engineering community is via the Browser, which is PC-based and readily available via the Hanford Local Area Network (HLAN). Figure 4-5 shows the information infrastructure.

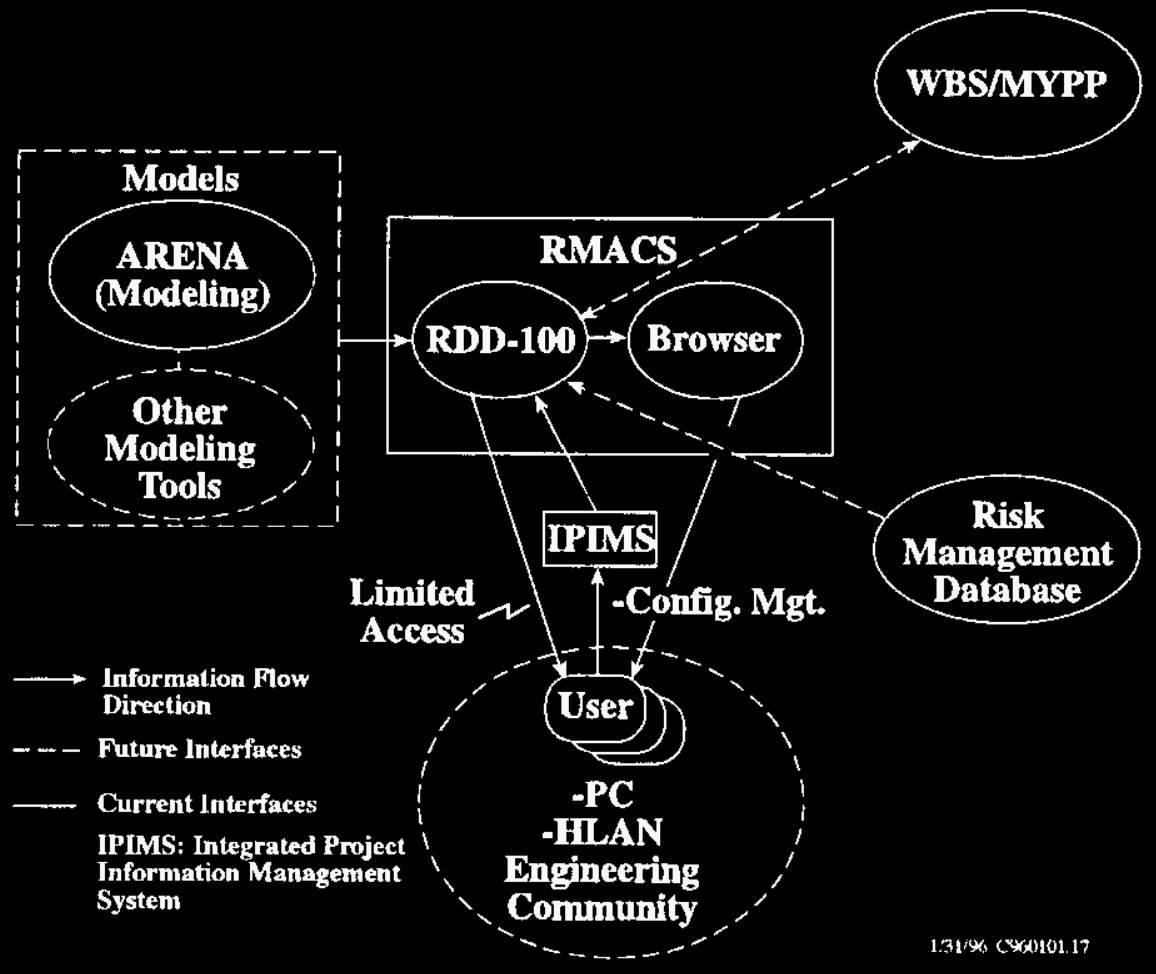

Figure 4-5. Information Infrastructure.

\footnotetext{
* RDD-100 is a trademark of Ascent Logic Corporation.
} 


\subsubsection{Decision Management}

The TWRS Program uses a Decision Coordinator to function as a central point of contact for maintaining awareness of TWRS decisions and thereby providing assurance that important decisions have been identified and considered in the decision prioritization process. The Decision Coordinator produces an Annual Decision Status Report that will identify, coordinate, and track the status of all TWRS decision-making efforts. The report contains summary descriptions of each decision, a prioritized list of decisions, indications of decision progress and status, and a compendium of decision documents from completed decision actions.

Decision management provides traceability for affected decisions through utilization of a rigorous and methodical decision-making process. Decision management encompasses a slightly broader perspective than decision making. This perspective acknowledges the interdependencies of decision making in complex environments and provides for the cataloguing and coordination of multiple decision-making activities. It is the responsibility of a decision coordinator to maintain this overview awareness and to schedule decision-making activities in a manner that promotes effective decision making. Once initiated, managing a particular decision involves three basic steps (bold boxes shown in Figure 4-6): (1) decision framing, (2) decision analysis, and (3) deciding.

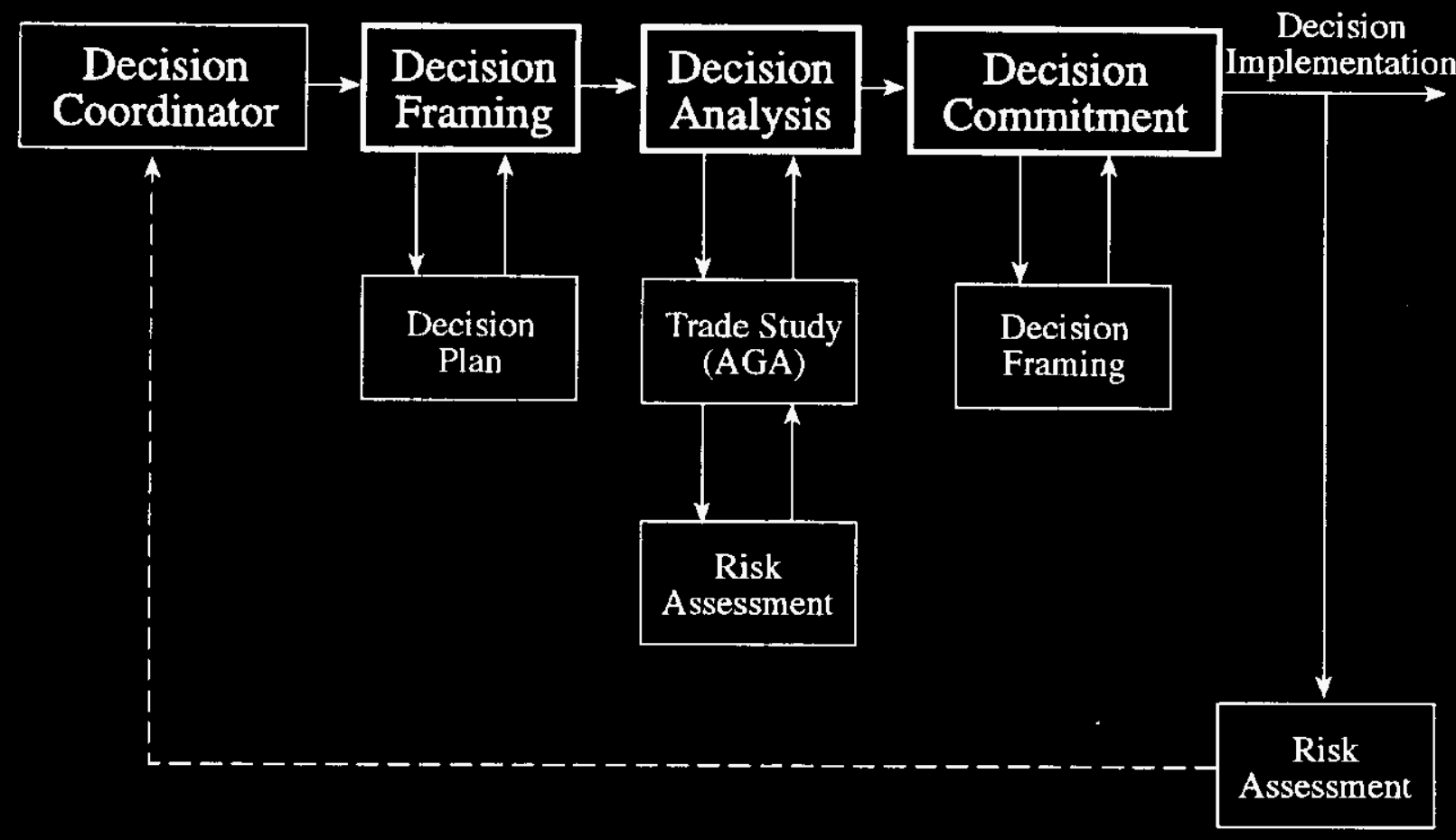

Figure 4-6. Decision Process. 
Decision Framing - Decision framing is the process of analyzing the problem and clearly identifying and formulating the decision to be made. Framing results in the identification of a specific statement of decision, identification of decision criteria, and the development of preliminary notions of acceptable decision alternatives. The development of a comprehensive set of alternatives falls under the responsibility of the Alternatives Generation and Analysis (Orsag et al. 1996) and is a fundamental part of the trade study analyses. However, the framing process develops essential insight into applicable constraints that will be applied to any proposed decision alternative. The responsibility for developing the decision frame is assigned to a decision action officer. Working with the decision maker, the action officer prepares a decision plan (described in Decision Management. (Orsag et al. 1996) which documents the results of the decision-framing effort. These plans form the basis of communication between the decision maker and those technical staff that will be responsible for developing needed information as part of the decision-analysis activities.

Decision Analysis - Decision analysis is the process of developing an understanding of the alternative outcomes to a decision. It is in the analysis process where all alternatives considered are measured against the relevant decision criteria. As the technical information is developed for these alternatives, insight may be gained that leads to the creation of additional alternatives that warrant consideration in the decision. Within the TWRS program, risk is a fundamental consideration in every decision. As a result, the identification and assessment of the risks of each alternative is part of each decision analysis. Results of a decision analysis are documented in two ways. First, the specific details of the analysis are captured in a detailed decision-analysis report (see the AGA procedure for guidance). Secondly, the results of that analysis are reduced to a summary of the information needed to make the selection of a preferred alternative. This summary information is prepared, as a decision summary report (see decision management procedure for guidance), by the action officer and presented to the decision maker to facilitate consideration of the analyses in the selection of the preferred alternative.

Deciding - The final outcome of the decision-management process is the selection of an alternative and the implementation of the decision. Each decision has an assigned decision maker. For many decisions two decision makers will be needed, one representing WHC and the other representing DOE/RL. The decision is signed by the decision maker(s). This selection is further publicized by informing the decision coordinator as part of the decision implementation activities. The decision coordinator maintains a record of the outcome of all scheduled decisions.

Interface with Risk Management - Any decision made retains an element of risk. Risk enters the decision-management process at two points (see Figure 4-6): 1) as an adjunct to the trade study efforts during decision analysis and 2) as an impact to the subsequently selected decision following the decision-commitment process. This risk results from assumptions and uncontrollable events that can not be resolved prior to making the decision. TWRS has established a risk-management procedure to address and manage the impact of these risks. The action officer is responsible for communicating risk related issues to those individuals responsible for risk management, as identified in the procedure for risk management (Risk Management, (Orsag et al. 1996). 


\section{WHC-SD-WM-SEMP-002 Rev. 0}

\subsubsection{Test and Evaluation}

The TWRS will use Test \& Evaluation (T\&E) to; (1) quantify technical and program risk; (2) verify design and product conformance with requirements and specifications; (3) support technology and design development; (4) provide continuing estimates of operational performance; and (5) ensure that program objectives are achieved. Verification evolves with program and project maturity and is accomplished through:

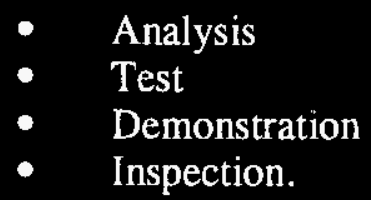

Model testing and simulation studies are conducted prior to the acquisition of prototype and operational assets. These tests and studies include subscale test models for verification of design and/or process solutions, full scale sub-systems to verify commercial product compatibility with system requirements and computerized simulations of subscale and full scale systems to assess system performance. They are conducted concurrently and sequentially with system designs and other T\&E methods to support the life-cycle management of the TWRS. Resource requirements (hardware, software, personnel, facilities) will be identified as well as conducting requirements and test planning analyses to assess cost and schedule impacts which will be integrated into the TWRS cost profile and master schedule.

The T\&E Program consists of both development test and evaluation (DT\&E) and operational test and evaluation (OT\&E). Although the primary goal for each is the same (i.e., verification of TWRS Program requirements), the specific approach and activities in each phase (development and operating) are different. DT\&E emphasizes technology development (research) and design development (prototype) testing. Program and projectlevel activities and involvement dominate this phase. The Technology Development Contractor or the vendor is also involved if there is emerging or innovative technologies being developed. DT\&E supports the following: (1) early technical baseline development, (2) requirements development and allocation, (3) technology verification, (4) prototype design performance, (5) risk mitigation, and (6) technical performance measurement. Initial DT\&E efforts will be supported by analytical techniques (mathematical models and simulations) and physical testing. Testing helps to define, develop, and select performance parameters and requirements as the design evolves. DT\&E culminates during the final design phase.

The intent of OT\&E is to ensure that the developing system is capable of meeting its objectives, within its intended operational environment. OT\&E is conducted on operational equipment and includes procurement acceptance, installation acceptance, pre-operational testing, and operational (turnover and startup) testing. In this phase, Project, Operations, Engineering, Architect/Engineer, and vendor activities predominate. OT\&E will be conducted to determine the performance and suitability of the integrated TWRS Program and its elements to meet the TWRS Program mission and TPMs. Performance assessment and 
technical performance measurement efforts continue during OT\&E to verify that test results meet specified requirements.

A WHC TWRS Test and Evaluation Plan (TEP) will be developed and implemented to guide and direct the management of TWRS T\&E activities. The TWRS TEP is the basis for other T\&E planning documents including TWRS Project T\&E plans.

The WHC TWRS Program TEP will be prepared and will:

- Summarize the objectives, responsibilities, logic, resources, and schedules for planned T\&E.

- Describe the system-level tests to be performed, test rationale, relationships to other tests in the integrated sequence, and the contribution each makes to verification of the system.

- Describe the evaluation process to be followed to ensure performance compliance and verification of the TWRS Program.

- Outline each participant's role in the T\&E effort.

T\&E documentation (Test Plans and Reports) will address the following information to support conformance verification; (1) test requirements, (2) acceptance criteria, (3) test scope, (4) test procedures, (5) test schedules, (6) estimated cost, (7) test data, and (8) test results. T\&E plans and reports must be developed, approved, controlled, and maintained according to applicable DOE orders and procedures.

\subsubsection{Technical Performance Measurement}

TWRS will use Technical Performance Measurement (TPM) to:

- Gain insight into the maturity of the engineering design

- Identify key parameters for the T\&E Program

- Provide inputs into overall program, decision, and risk management.

These parameters are compared to predicted values or are used on a relative basis for comparison of alternatives. TPMs are tracked as a function of time once the system architecture has been selected. From that point, deviations of the actual parameters from the estimated (or design "goal") values provide management with an estimated maturity of, and the associated risk in, the TWRS Program.

TPMs will be selected from requirements that are critical to accomplishing the mission objectives, protecting the environment, or ensuring public and worker safety. The parameters selected for tracking will be key indicators and forecasters of technical success. These parameters will be analyzed to help determine what should be verified along with 
when and how verification should be accomplished. (See Figure 4-7, TPM Relationships.) The Technical Performance Measurement Procedure (Orsag et al. 1996) contains additional information on TPMs and expands on Figure 4-7.

WHC TWRS Technical Integration will be responsible for updating, maintaining, and tracking the TPMs. Some parameters will be tracked throughout the program. Others will be tracked only during specific program phases or to identify and resolve specific risk issues. TPMs will be input to T\&E as test candidates for data collection. As the T\&E program progresses, test results will be reviewed, evaluated, and compared to the parameter limits. Trend analyses will be conducted to determine performance achievements (verification) and deviations (corrective action initiation). When performance exceeds specifications, opportunities for requirement or resources reallocation will be examined. 
WHC-SD-WM-SEMP-002 Rev. 0

Figure 4-7. Technical Performance Measurement Relationships.

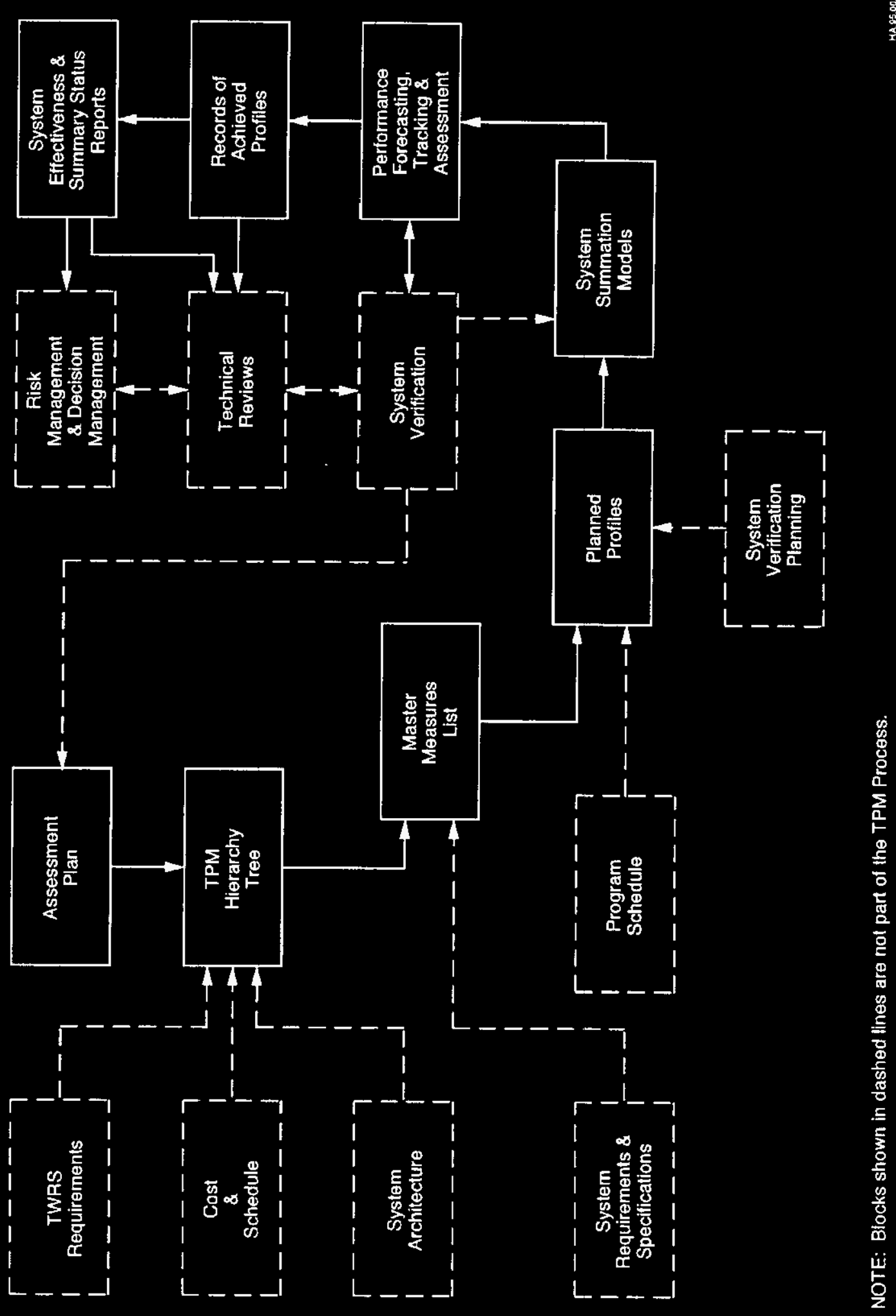


WHC-SD-WM-SEMP-002 Rev. 0

\subsection{ADDITIONAL SYSTEMS ENGNEERING RESPONSIBILITIES}

Includes other areas not specifically included in previous sections but that are essential for DOE understanding the performing contractor's proposed SE effort.

\subsection{STANDARDS AND PROCEDURES}

The documents shown in Section 5.1.1 are pertinent to the development, implementation, and application of SE principles and methodology to the TWRS Program and should be used in carrying out the detailed SE tasks and activities. The documents are shown in hierarchial form to represent precedence of one documents guidance over another. Other documents that provide additional guidance for performing the tasks are shown in Section 5.1.2. These documents are provided as guidance in understanding the intent and purpose of SE principles and activities.

\subsubsection{Applicable Documents}

DOE Order 4700.1 Project Management System

Tank Waste Remediation System Systems Engineering Management Policy, DOE/RL letter, 95-RTI-107, Oct. 31, 1995.

Tank Waste Remediation System Program Plan, DOE/RL-92-58 Draft, March 31, 1993.

Tank Waste Remediation System Program Management Plan, DOE/RL-92-59 Draft, March 31, 1993.

Tank Waste Remediation System Program Management Policies, DOE/RL-93-0106, Nov. 30, 1994, (Note: Not yet accepted by WHC).

Tank Waste Remediation System Multi-Year Program Plan, WHC-SP-1101, 1995.

Tank Waste Remediation System Configuration Management Program Plan, WHC-SD-WM-CM-013 Draft.

Tank Waste Remediation System Risk Management Plan, WHC-SD-WM-PMP-018.

Tank Waste Remediation System Decision Management Guide.

Westinghouse Hanford Company Tank Waste Remediation System Systems Engineering Manual, WHC-IP-1231, DRAFT. 


\subsubsection{Guidance Documents}

DOE/RL-95-12, Rev AE, Tank Waste Remediation System Systems Engineering Standard, DRAFT, April 3, 1995

DOE/RL-95-XX, Hanford Site Systems Engineering Criteria Document, Rev A, May 8, 1995

EIA/IS-632, EIA Interim Standard, Systems Engineering, December, 1994

DOE Order 430.1, Life-Cycle Asset Management and Supporting Guides, DRAFT.

IEEE P1220 Standards for Systems Engineering.

Defense Systems Management College Systems Engineering Guide, January 1990, Fort Belvoir, VA.

\subsection{OTHER PLANS AND CONTROLS}

- This section reserved.

\subsection{LONG-LEAD ITEMS}

This section reserved.

\subsection{DEVELOPING AND APPLYING CRITICAL TECHNOLOGIES}

The decision to proceed with the Privatization, the December 1995 TWRS Technology Needs review, and other actions have resulted in the obsolescence of the TWRS Integrated Technology Plan (ITP). The role of the ITP is being replaced by the Tank Focus Area efforts (see paragraph 1.4.4) and the efforts cited below. TWRS represents the TFA User's Steering Group for Hanford.

The development of critical technologies for TWRS will be handled primarily through the TFA. However, when the requirement exists for the development and application of critical technologies that are not addressed through the TFA the following process will be used:

The Hanford Site Technical Coordinating Group has applied the following needs prioritizing criteria to establish the immediate (FY77 \& FY98) technology needs: 
WHC-SD-WM-SEMP-002 Rev. 0

Technology Gaps - Does the technology need address a critical gap in the existing program baseline?

Urgency - Is the technology need extremely urgent for meeting cleanup schedules or reducing existing risk?

Cost Reduction - Does the technology need have the potential for significant cost savings over the current baseline technology?

Effectiveness Improvement - Does the technology need have the potential for significant increase in effectiveness over the current baseline technology?

Safety Improvement - Does the technology need have the potential for significant improvement in worker safety over the current baseline technology?

Schedule Improvement - Does the technology need have the potential for significant improvement in cleanup schedule over the current baseline technology?

Applying these as a screening or determining basis for critical technology needs will then result is a prioritized list to be used for establishing development projects. Each technology development project will be based on a Technology Development Plan (TDP) (format to be developed). Each TDP will be tailored to include those sections appropriate for the technology development effort at hand. The plan may include; a) an overall strategy, b) a path towards proof of concept, b) a plan for conversion from concept to application, d) scaleup and e) other sections as appropriate. Additionally the plan will describe the resource requirements and technical performance measurement parameters for tracking development. If appropriate, a more comprehensive process may be required, in which case the Systems Engineering grading procedure may be executed and a more comprehensive systems approach applied.

In all cases, technology development efforts will apply established engineering and systems engineering procedures as applicable. 
WHC-SD-WM-SEMP-002 Rev. 0

This page intentionally left blank. 


\subsection{GENERAL INFORMATION}

\subsection{NOTES}

This section reserved.

\subsection{GLOSSARY}

Alternative Solution. A candidate technical design strategy or approach that potentially satisfies the functions and requirements.

Analysis. A series of steps in assessing performance requirements or deficiencies.

Architecture. The selected design solution from the set of alternative solutions that best satisfies the requirements, and is used for more detailed design activities.

As-built. The end-item as actually produced (constructed, fabricated, etc.), which may differ from the item's design for construction. End-item design documentation should be changed, if differences occur, to reflect the "as-built" configuration.

As-Built Design. Constitutes the design of the as-built operational system. Confirmation of As-built condition ensures that the system is constructed according to the approved drawings and that the system performance, quality of materials and workmanship meets system requirements.

Assessment. An evaluation activity to determine whether results being obtained are accomplishing desired purposes; a determination of whether a job, task, operation or enditem satisfies all applicable requirements.

Baseline. A quantitative definition of cost, schedule, and technical performance, structured using a product based Work Breakdown Structure, that serves as a base or standard for measurement and control during the performance of an effort; the established plan against which the status of resources and the effort of the overall program, field programs, projects, tasks, or subtasks are measured, assessed, and controlled. Once established, baselines are subject to change control procedures.

Baseline Change Control Board. A formal body of representatives, designed and chartered by senior management, with responsibility for ensuring the proper definition, coordination, evaluation, and disposition of all proposed changes to program baselines within their jurisdiction, as defined in the TWRS Management Integrating Procedures or Change Control. 
Baseline, Cost. A budget that has been developed from the cost estimate made at approval of the technical baseline; the majority of the budget has been time phased in accordance with the schedule. The cost baseline is integrated with the technical and schedule baselines and is subject to formal change control. It normally contains direct and indirect budget; management reserve budget; undistributed budget and higher level budgets; contingency amount; and amount for fee, as appropriate.

Baseline, Integrated. A baseline composed of and integrating the program's technical, schedule, and cost baselines. This baseline is subject to formal change control. (See Baseline)

Baseline, Schedule. A time-phased, product based, life cycle plan with a logical sequence of interdependent activities, milestones, and events necessary to complete a TWRS project or program. This baseline incorporates the total technical scope of work and provides a basis for analyzing performance. The schedule baseline is integrated with the cost and technical baselines and is subject to formal change control.

Baseline System Description (BSD). Document that provides an overall description of the system, in an easily understood illustration and narrative format for visualizing architecture concepts. It is used by the participants working on the TWRS Program as a communication tool, and as a point of departure for briefings, studies, and cost estimates.

Baseline, Technical. The documented functions, requirements, and configuration from which the program will acquire an operational system. Describes all or part of an Activity's functional, performance, inter-operability, interface and verification requirements necessary to demonstrate the achievement of those specified requirements.

Change Control. A documented process applying technical and management review and approval of changes to technical, schedule, and cost baselines.

Characterization. Sampling and analysis activities designed to determine the condition and present status of tank material, and to better understand the impacts of past operations on the soil and groundwater.

Closure. (Hanford Site) The process by which a hazardous waste treatment, storage, or disposal facility, which has discontinued operation, is finally dispositioned in accordance with a Washington State-approved closure plan.

Configuration. (1.) Functional or physical characteristics of a set of controls, including hardware, firmware, software, and any other items as described in technical documentation and achieved in a product. (2.) Description of the current state of a system or system element, usually in quantitative terms. 
Configuration Management (CM). Part of an integrated management program that is used to control certain technical relationships among design requirements, technical documentation, and physical configurations within the TWRS Program.

Constraint. An externally imposed mandatory restriction, limitation or requirement, imposed by agencies and organizations, such as the U.S. Congress, U.S. Environmental Protection Agency, Washington State Department of Ecology, and other regulatory agencies, and DOE Orders, Secretarial Notices, and other regulatory documents. Where necessary, these constraints will be interpreted to derive performance requirements that are quantified and verifiable.

Construction. Any combination of engineering, procurement, erection, installation, assembly, or fabrication work involved in creating a new facility or altering, adding to, or rehabilitating an existing facility. It also includes the alteration and repair (including dredging, excavating and painting) of buildings, structures, or other real property.

Cost Estimate. A documented statement of costs estimated to be incurred to complete a project or activity.

CRWMS. DOE's Office of Civilian Radioactive Waste Management's system for acceptance, storage, disposal of spent nuclear fuel and high-level radioactive waste. The CRWMS does not include storage at the Hanford site.

Deactivation. The process of permanently ceasing active operation at a DOE facility in a planned and controlled manner. A deactivated facility has been adequately prepared to support ongoing surveillance and maintenance activities and subsequent decontamination activities.

Decision Criteria. A factor that is used to select a preferred alternative. A decision criterion may be quantitative or qualitative.

Decision Maker. An individual having the responsibility for making decisions.

Decomposition. The process of breaking down a whole into its parts. Functions, requirements, and systems each may be decomposed when proceeding from one level to a lower level.

Decontamination and Decommissioning (D\&D). As defined by DOE Order 5840.2 for the D\&D Program, decontamination is the removal of radioactive and hazardous contamination from facilities, equipment, or soils by washing, heating, chemical or electrochemical action, mechanical cleaning, or other techniques. Decommissioning is action taken to reduce the potential health and safety impacts of contaminated and non-contaminated facilities, including activities to stabilize, reduce, or remove radioactive and hazardous materials or to demolish the facilities. 
WHC-SD-WM-SEMP-002 Rev. 0

Design Requirements. The "build to," "code to," and "buy to" requirements for products and "how to execute" requirements for processes. Design requirements are developed through synthesis of detailed performance requirements, engineering standards and design concepts.

Design Requirements Documents (DRDs). Documents provided to projects from program elements, which define the project mission. DRDs establish the baseline which the program elements maintain.

Design Solution. Selected alternative approach or architecture that best satisfies the functions and requirements.

Development Test and Evaluation (DT\&E). A program consisting of technology and design testing, initiated to verify performance parameters of various system functions or elements, conducted during the development phase of a program or project.

Document Control. The act of ensuring that documents are reviewed for adequacy, approved for release by authorized personnel, and distributed to the appropriate people and groups.

End State. The desired condition at the completion of a program or project.

Evaluation. (1) A process to determine the significance or worth of a product, process, system, function, or result, or the impacts of proposed changes. The act of determining or verifying adequacy and effectiveness through audits, surveillance, reviews, self-assessments (including appraisals), or other means. (2) Establish fitness for continued use based on Federal and State regulatory requirements, U.S. Department of Energy (DOE) policy, Hanford Site needs, and WHC Environmental Division criteria.

Evaluation Criteria. Standards by which accomplishments of required technical and operational characteristics or resolution of operational issues may be assessed.

Function. A specific task, action, activity, or process that supports the achievement of an objective, e.g., an operation that a system must perform to accomplish its mission.

Functional Analysis. The first step of the functions requirements analysis at each level of the systems-engineering process. This step identifies what the system, or function is intended to accomplish.

Functions and Requirements Analysis. The determination of specific characteristics based on analyses of customer needs, requirements, and objectives; missions; projected environments for personnel, products, and processes; constraints; and measures of effectiveness. 
Functions and Requirements Document. A document containing the high level definition of functions, requirements and candidate architectural concepts that are in-line with the stated mission objectives and defined mission constraints.

Hierarchy. A structured tree arrangement used to describe relationships produced by and subordinate to other relationships for system descriptions such as functions or requirements.

Human System Integration. The process of integrating the full range of manpower, personnel, training, human factors engineering, system safety and health hazards, to improve total system performance throughout the life cycle of the product, system, etc.

Independent Review. A review conducted by individuals with no vested interest in the outcome of the review.

Independent Reviewer. Reviewers are not associated directly with the work under evaluation. May be part of the cognizant DOE organization overseeing the Activity in which the review is taking place.

Interface. A functional or physical system boundary between two or more sub-systems or end items, across which materials, data, or energy passes.

Interface Control Documents (ICDs). A document, representing a design agreement between interfacing hardware, or software systems, which fully defines the interface. An ICD is placed under Configuration Control and is considered part of the baseline.

Interface Requirement. A necessary function input that is defined at the system boundary across which material, data, or energy passes.

Life Cycle Cost. The sum total of direct, indirect, recurring, non-recurring, and other related costs incurred or estimated to be incurred in the acquisition, operation, decommissioning and disposal of a designated item.

Measure of Effectiveness. A set of attributes that define how the measure of success is satisfied. The measure of success is a general statement; the measure of effectiveness is more specific. Definition used by DOE managers to accept or reject deliverables.

Measure of Success. A set of attributes that, when compared to actual results, shows how well the mission was accomplished.

Memorandum of Agreement (MOA). Written agreement between organizations, agencies, etc., which formally describes and documents specific relationships between them.

Memorandum of Understanding (MOU). A written agreement between organizations, agencies, etc., broadly states and documents a basic understanding of tasks and describing a method for performing these tasks. 
Milestone. An important or critical event, with zero duration, that represents the achievement of a stated objective on a schedule. Each milestone will be specifically defined and uniquely identified, and will provide an objective statement of the criteria for its completion.

Mission Analysis Report. A high level evaluation of the mission statement, generated to provide sufficient information to allow the accomplishment of functional decomposition, the derivation of requirements, and the evaluation of architectures that will meet the mission objectives.

Mission Statement. A declaration (usually written) of what is to be accomplished.

Modification. Any work that involves a design configuration change to a facility, structure, system, subsystem, equipment, or component.

Multi-Year Program Plan (MYPP). Objectives, performance criteria, system (program) requirements, schedules, and high-level cost estimates for the foreseeable life of the program. The approved MYPP becomes the multi-year program baseline description document.

Need. A user related capability shortfall (such as those documented in a mission analysis or engineering change notice), or an opportunity to satisfy a capability requirement because of a new technology application or breakthrough, or to reduce costs.

Operational Effectiveness. The overall degree of mission accomplishment of a system when used in the environment planned or expected for operational employment of the system.

Operational Readiness Review (ORR). A review conducted by the responsible contractor for determining that an activity, project, process, or facility is ready to proceed to the next phase of operation (e.g., startup, restart, operation, or occupancy).

Operational Test and Evaluation (OT\&E). A program consisting of pre-operational and operational testing initiated to verify performance parameters of various system functions or elements.

Performance. A quantitative measure characterizing a physical or functional attribute relating to the execution of a mission of function. Performance attributes primarily include quantity (how many or how much), quality (how well), cost (how much), and timeliness (when and how responsive, how frequent) and may include coverage (how much area, how far), and readiness (availability, mean time between failure). Performance is an attribute for all system personnel, products and processes including those for development, production, verification, deployment, operations, support, training, and disposal. 
Performance Requirement. The extent to which a mission or function must be executed, generally measured in terms of quantity, quality, coverage, timeliness or readiness. Performance requirements are initially defined through requirements analyses and trade studies using mission need, objective, and/or requirement statements. Performance requirements are assigned to lower level system functions through top-down allocation, and are assigned to programs, program elements and projects through synthesis.

Physical System. Facilities, systems, equipment, materials, information, activities, and the personnel required to perform those activities necessary to manage waste remediation.

Program. An organized set of activities directed toward a common purpose or goal undertaken or proposed in support of an assigned mission area. A program may include one or more major system acquisitions or major projects, other projects, operations, or some combination thereof.

Project. Unique discrete work within the TWRS Program or program element that has firmly established objectives (deliverables), budget (cost) and scheduled beginning, intermediate, and ending date milestones. These discrete elements of work have unique constraints due to capital funding requirements and reporting to Congress. (These are some times called a program element.)

Public. Any person, organization, company, or foreign country having interest in information concerning site activities, but not having a specific contract or agreement obligating it to protect the information.

Public Involvement. Process by which the views of all parties interested in Hanford decisions (interested and affected individuals, organizations, customers, State and local governments, and other federal agencies) are integrated into Hanford's decision-making process. The public involvement process provides a means by which public concerns, needs, and values are identified prior to decisions, so that decisions reflect the views of the public, to the extent possible given environmental, financial, legal, and technical constraints.

Quality Assurance. All planned and systematic actions necessary to provide adequate confidence that a facility, structure, system or component will perform satisfactorily in service. Quality assurance includes quality control, which comprises all those actions necessary to control and verify the features and characteristics of a material, process, product, or service to specified requirements.

Remediation. Action taken to safely store, maintain, treat, and dispose of tank waste, the main focus of the TWRS Program mission. 
Requirement. (1) Characteristics that identify the accomplishment levels needed to achieve specific objectives for a given set of conditions. (2) How well the system needs to perform a function. The extent to which a function must be executed, generally measured in terms of quantity, quality, coverage, timeliness, or safety. Requirements include constraints, performance requirements and interface requirements.

Requirements Analysis. The determination of system specific characteristics based on analyses of customer needs, requirements, and objectives; missions; projected utilization environments for people, products, and processes; constraints; and measures of effectiveness.

Restoration. Return of a system to the operating condition for which it was originally designed, or the return of an environment to its natural state.

Risk. A measure of the uncertainty of attaining a goal, objective, or requirement pertaining to technical performance, cost, and schedule. Risk level is categorized by the probability of occurrence and the consequences of occurrence. It is assessed for program, product, and process aspects of the system, and includes the adverse consequences of process variability. The sources of risk include technical (e.g., feasibility, operability, producibility, testability, and systems effectiveness); cost (e.g., estimates, goals); schedule (e.g., technology/material availability, technical achievements, milestones); and programmatic (e.g., resources, contractual) uncertainty.

Risk Analysis. Process to determine the probability of events occurring and the consequences the potential events would have on the program, should they occur. The purpose of risk analysis is to discover the causes, effects, and the magnitude of perceived risks.

Risk Assessment. The process of reviewing, examining and judging whether potential risks are acceptable.

Risk Handling. The development and the implementation of techniques and methods to reduce or control the risk.

Risk Management. An organized, analytic process to identify what can go wrong, to quantify and assess associated risks, and to implement/control the appropriate approach for preventing or handling each risk identified.

Risk Planning. The process of organizing an approach to identifying, quantifying, determining impact, and then eliminating, minimizing, or containing the effects of undesirable occurrences and minimizing the probability of those occurrences. 
Specification. (1) A document prepared to support acquisition and life cycle management that clearly and accurately describes essential technical requirements and verification procedures for items, materials and services. (2) A statement of a set of requirements to be satisfied by a product, material, or process indicating, whenever appropriate, the procedure by which it may be determined whether the requirements given are satisfied.

Specification Tree. The hierarchical depiction of all the specifications needed to control the development, manufacture, and integration of items in the transition from customer needs to the complete set of system solutions that satisfy those needs.

Stakeholder. An individual or group who is likely to be affected by, or who perceives itself to be affected by, and has an interest in a DOE policy, program, or project.

Stakeholder Values. Principles and standards held by stakeholders, which are used in the decision making process for a DOE Activity.

System. A combination of related functions or equipment integrated into a single activity.

Synthesis. The translation of functions and requirements into possible integrated solutions (resources and techniques) satisfying basic input requirements. System element alternatives that satisfy allocated performance requirements are generated; preferred system element solutions that satisfy internal and external physical interfaces are selected, system concepts, preliminary designs and detailed designs are completed as a function of the development phase; and system elements are integrated into a physical architecture.

System. (1) An integrated compilation of people products and processes that provides a capability to satisfy a stated need or objective. (2) A combination of related functions or equipment integrated into a single activity.

System Life Cycle. The period extending from inception of development activities, based on an identified need or objective, through decommissioning and disposal of the system.

Systems Engineering. A comprehensive, iterative problem-solving process that is used to: (a) transform validated DOE needs and requirements into a life cycle balanced solution set of system product and process designs, (b) generate information for decision makers, (c) integrate to optimize and (d) provide information for the next program phase. The problem-solving process and success criteria are defined through requirements analysis, functional analysis, and systems analysis and control. Alternative solutions, evaluation of those alternatives, selection of the best life cycle balanced solution, and the description of the solution through the design package are accomplished through transitioning from a functional concept to a physical concept using systems analysis and modeling techniques. 
Systems Engineering Management. Organizing and directing tasks, activities, and performances related to the technical baseline work, defining the Systems Engineering process, ensuring that the process is followed, reviewing technical results, and making strategic technical decisions based on those results for the system under development.

Systems Engineering Management Plan (SEMP). The document that defines the policies and guidance for the application of systems engineering.

Tank Waste Remediation System (TWRS). An integrated solution for carrying out the specific functions associated with remediating tank waste. The TWRS encompasses: existing facilities; waste storage tanks (including the tank waste); evaporators; pipelines; supporting facilities that comprise the total TWRS infrastructure, including upgrades to existing facilities/equipment; and new facilities.

Technical Performance Measurement. An evaluation, preferably quantitative, that predicts the future performance of a physical system, subsystem, or component, and compares that prediction to performance requirements.

Technical Reviews. A series of systems engineering evaluations by which the progress of a program is assessed relative to its technical or contractual requirements. These are conducted at logical transition points in the development effort to reduce risk by identifying and correcting problems/issues resulting from work completed before the program can be disrupted or delayed. Technical Reviews provide a method for the performing contractor and the DOE to determine that the development of a project and its documentation have met its requirements.

Technical Requirements Specifications (TRS). Documents containing the results of functional decomposition, requirements analysis, architecture selection and test methodology development that defines the performance characteristics of a system necessary for the system to achieve its objectives. The document is approved during the Technical Requirements Review.

Test and Evaluation. The complete set of activities that verify that End Products meet customer requirements. T\&E includes (1) reviews and analysis performed during the design process, (2) inspection activities during manufacturing and construction, and (3) testing performed during design, manufacturing, construction and turnover activities.

Trade Study. (1.) A process of comparing or trading the strengths and weaknesses of alternative approaches or attributes; (2.) A feedback process for resolving inconsistencies between the levels of an activity; (3.) the analysis of the ability of a design solution to meet its stated objectives.

Uncertainty. Lack of technical, schedule, cost, or institutional information that could adversely impact the outcome or ability of a program to accomplish the mission. 
Validation. (1) An assessment to verify system requirements will satisfy mission objectives. (2) A demonstration that a predictive model and its mathematical expression adequately reflect reality. Validation usually consists of comparing the results of the applied mathematical expression to measured results from the system being modeled (or from similar or identical systems), and showing that any differences were expected and/or within acceptable error.

Value System. The identification and definition of public and stakeholder values -- their measures of success, effectiveness, and performance. These values include constraints and criteria.

Verification. The act of determining and documenting whether items, activities, processes, services, or documents conform to specified constraints, requirements or commitments. This process is performed at each level of system architecture development (i.e., from hardware item components through the system level). The method used to show compliance (test, inspection, demonstration, or analysis) is dependent on architecture complexity, engineering test data availability, and validated analytical methods availability or existence.

Work Breakdown Structure (WBS). A product-oriented family tree composed of hardware, software, services, data, and facilities which result from systems engineering efforts during development and construction, completely defining the program or projects. Provides framework for work planning, scheduling, budgeting, cost accumulation and reporting of performance during the life of program or project.

\subsection{REFERENCES}

Kinzer, J., 1995, Tank Waste Remediation System (TWRS) Systems Engineering Management Policy, (Letter \#95-RTI-107 to President, Westinghouse Hanford Company, Richland, Washington, October 31, 1995) U.S. Department of Energy, Richland Operations Office, Richland, Washington.

WHC, 1995a, Tank Waste Remediation System Fiscal Year 1996 Multi-Year Program Plan, WHC-SP-1101, Rev. 1, Westinghouse Hanford Company, Richland, Washington.

WHC, 1995b, Standard Engineering Practices, WHC-CM-6-1, Westinghouse Hanford Company, Richland, Washington.

Carpenter, 1996, Tank Waste Remediation System Functions and Requirements Document, WHC-SD-WM-FRD-020, Rev. 0, Westinghouse Hanford Company, Richland, Washington.

DOE, 1992, Project Management System, DOE Order 4700.1, U.S. Department of Energy, Washington, D.C. 
Knutson, 1995, Tank Waste Remediation System Mission Analysis, WHC-SD-WM-MAR-008, Rev. 0, Westinghouse Hanford Company, Richland, Washington.

Blanchard, B. S., and Fabrycky, W. J., 1981, Systems Engineering and Analysis, PrenticeHall, Inc., Publishers, Englewood Cliffs, New Jersey.

Waite, J. L., 1993, Tank Waste Remediation System Program Management Plan, DOE/RL-92-59, Draft, Westinghouse Hanford Company, Richland, Washington.

Seaver, D. A., 1995, Tank Waste Remediation System Programmatic Risk Management Plan, WHC-SD-WM-PMP-018, Rev. 0, Westinghouse Hanford Company, Richland, Washington.

DOE/RL, 1994, Baseline Execution and Management Process, RLID 5000.1, U.S. Department of Energy, Richland Operations Office, Richland, Washington.

Orsag et al., 1996, Westinghouse Hanford Company, Tank Waste Remediation System Systems Engineering Manual, WHC-IP-1231. 
WHC-SD-WM-SEMP-002 Rev. 0

APPENDIX A

SYSTEMS ENGINEERING GRADING GUIDELINES

A-1 
WHC-SD-WM-SEMP-002 Rev. 0

This page intentionally left blank. 


\section{A.1 INTRODUCTION}

Because activities within TWRS differ greatly in type, cost, scope, and complexity, it is appropriate that the level of detail related to SE be tailored to the particular effort. This "graded approach" will allow for a screening of the proposed activity by program/project personnel and, based on consideration of key elements and present state of the activity, establish the appropriate level of SE and documentation to be generated. Agreement on the chosen SE approach must then take place between project management and the DOE customer. The graded approach will be applied to ensure that:

- The appropriate level of planning is performed,

- Necessary and sufficient documentation is created,

- Needed levels of reviews are conducted, and

- The project is integrated with the overall program.

A screening process is used to determine the level of implementation of systems engineering to a project. The steps to be followed are:

1. Determine the project risk/complexity factors (high/moderate/low) using Table A.1.

2. Assign an SE level;

- SE-1: Rigorous application of SE (high risk/complexity)

- SE-2: Full set of SE, but tailored to project (moderate risk/complexity)

- SE-3: Selective application of SE (low risk/complexity)

- SE-4: Does not require SE products (management decision, virtually no risk)

3. Select project SE requirements using guidance from Table A.2.

Application of the first step is described in Section A.2.

The assignment of SE level to the project is discussed in Section A.3.

Section A.4 gives guidance on selection of required project SE activities and documents, based on the results of the previous steps. Examples are included that show how the results might be applied to generic projects.

Section A.5 describes how present stage of the project influences the application of systems engineering. This recognizes the fact that within TWRS some projects have already begun. 


\section{A.2 DETERMINING THE PROJECT RISK/COMPLEXITY FACTORS}

The initial task for application of a graded approach to systems engineering is to determine the possible impacts to safety, environmental compliance, safeguards and security, programmatic importance, magnitude of the hazard, and financial impacts, system capability from the project-specific requirements. A screening of the project with respect to these elements is the first step in determining the level of systems engineering required for the project. This is accomplished through use of Table A.1, "Graded Project Risk Areas/Complexity Factors." This table is taken from a draft of PMG-10, the "Project Execution and Engineering Management Planning Guide," $(9 / 15 / 95)$, one of the guides that will be used in application of DOE-430.1. The elements of this table should be used by the project manager and the DOE counterpart to identify and determine the risk and complexity factors of the project. The table is qualitative in that it involves an assignment of "low," "medium," or "high" to each element of the table.

\section{A.3 ASSIGNING SE LEVEL TO THE PROJECT}

Once the elements of the table have been assigned a value, it is up to the project management and their DOE-RL customer to agree on an overall screening level; high, medium, or low. This is a subjective process, and should be guided by an objective appraisal of the results of the application of Table A.1 to the project.

An overall project risk/complexity value of high will result in the project being assigned a systems engineering level of SE-1. At this level the full suite of systems engineering activities and products must be accomplished.

An overall project risk/complexity value of moderate will result in the project being assigned a systems engineering level of SE-2. Assignment at this level will also result in a full suite of systems engineering activities and products, however they will be tailored to be commensurate with the project risk/complexity. This means, for example, that even though this level project must develop a design requirements document (DRD), the document may be less comprehensive and the level and extent of review may be less than that required for an SE-1 project.

A overall project risk/complexity value of low will result in the project being assigned a systems engineering level of SE-3. SE-3 level projects require selective application of systems engineering. In many cases this means that a specific SE activity may be performed informally, and documentation is not necessarily required.

The project is assigned a systems engineering level of SE-4 if it is decided that the risk/complexity of the project is low enough that no systems engineering is required. 
Table A.1 Graded Project Risk Areas/Complexity Factors

\begin{tabular}{|c|c|c|c|}
\hline $\begin{array}{l}\text { RISK/COMPLEXITY } \\
\text { FACTOR } \\
\end{array}$ & LOW RISK & MODERATE RISK & HIGH RISK \\
\hline TECHNOLOGY & $\begin{array}{l}\text { Common/off-the-shelf technology } \\
\text { Civil/conventional construction }\end{array}$ & $\begin{array}{l}\text { Proven/state-of-the-art technology } \\
\text { Engineered equipment } \\
\text { Testing }\end{array}$ & $\begin{array}{l}\text { Unproven technology } \\
\text { New system } \\
\text { Highly engineered equipment } \\
\text { R\&D or investigative requirements } \\
\text { Extensive testing } \\
\text { Nuclear facility }\end{array}$ \\
\hline TIME & Ample time to perform work & $\begin{array}{l}\text { Reasonable time to perform work (tight } \\
\text { but possible) }\end{array}$ & $\begin{array}{l}\text { Compressed time frame to perform work } \\
\text { DOE commitments with other agencies } \\
\text { (e.g., DoD, NASA, EPA, NRC), states, } \\
\text { etc. }\end{array}$ \\
\hline INTERFACES & $\begin{array}{l}\text { No major impact on site } \\
\text { operations, other contractors, } \\
\text { projects, programs etc. }\end{array}$ & $\begin{array}{l}\text { Potential impact on site operations, other } \\
\text { contractors, projects, programs, etc. }\end{array}$ & $\begin{array}{l}\text { Potential major impact on site operations, } \\
\text { other contractors, projects, programs, etc. }\end{array}$ \\
\hline $\begin{array}{l}\text { NUMBER OF KEY } \\
\text { PARTICIPANTS } \\
\end{array}$ & 1 & $2-3$ & 3 or more \\
\hline $\begin{array}{l}\text { CONTRACTOR } \\
\text { CAPABILITIES } \\
\end{array}$ & Proven track record & Limited experience & Newly acquired capabilities \\
\hline $\begin{array}{l}\text { MAGNITUDE AND TYPE } \\
\text { OF ENVIRONMENTAL } \\
\text { CONTAMINATION } \\
\end{array}$ & $\begin{array}{l}\text { Hazardous or low-level waste, fully } \\
\text { characterized }\end{array}$ & $\begin{array}{l}\text { Hazardous or low-level waste, } \\
\text { moderately characterized }\end{array}$ & $\begin{array}{l}\text { High-level or mixed waste, regardless of } \\
\text { characterization }\end{array}$ \\
\hline $\begin{array}{l}\text { REGULATORY } \\
\text { INVOLVEMENT }\end{array}$ & None & EPA, NRC, or states & EPA, NRC, or states \\
\hline $\begin{array}{l}\text { NEPA } \\
\text { ENVIRONMENTAL } \\
\text { PERMITS (RCRA, CWA, } \\
\text { CAA, etc.) or LICENSING }\end{array}$ & $\begin{array}{l}\text { Categorical Exclusion } \\
\text { and } \\
\text { No permitting }\end{array}$ & $\begin{array}{l}\text { Environmental Assessment } \\
\text { and } \\
\text { Ordinary permitting required }\end{array}$ & $\begin{array}{l}\text { Environmental Assessment or } \\
\text { Environmental Impact Statement or } \\
\text { Unique permitting required }\end{array}$ \\
\hline
\end{tabular}


Table A.1 Graded Project Risk Areas/Complexity Factors

\begin{tabular}{|c|c|c|c|}
\hline $\begin{array}{l}\text { RISK/COMPLEXITY } \\
\text { FACTOR }\end{array}$ & LOW RISK & MODERATE RISK & HIGH RISK \\
\hline $\begin{array}{l}\text { NUMBER OF } \\
\text { LOCATIONS }\end{array}$ & 1 & $2-3$ & 4 or more \\
\hline SITE OWNERSHIP & DOE property & $\begin{array}{l}\text { Government, state, or participant } \\
\text { property }\end{array}$ & Private property \\
\hline $\begin{array}{l}\text { SITE } \\
\text { IMPROVEMENTS/ACCE } \\
\text { SS }\end{array}$ & $\begin{array}{l}\text { No infrastructure/improvements } \\
\text { required and accessibie }\end{array}$ & $\begin{array}{l}\text { Minor infrastructure/improvements } \\
\text { required and accessible }\end{array}$ & $\begin{array}{l}\text { Major infrastructure/improvements } \\
\text { required or difficult access }\end{array}$ \\
\hline LABOR SKILLS & Low or moderate skill labor & Moderate or highly skilled labor & Moderate or highly skilled labor \\
\hline AVAILABILITY & Readily available & Availability restricted & Availability severely restricted \\
\hline STAFF BUILD-UP & Gradual & Measured or phased & Rapid \\
\hline PRODUCTIVITY & $\begin{array}{l}\text { Low or average productivity } \\
\text { assumed and low schedule risk }\end{array}$ & $\begin{array}{l}\text { Low or average productivity assumed } \\
\text { and moderate schedule risk }\end{array}$ & $\begin{array}{l}\text { Average or high productivity assumed } \\
\text { and moderate or high schedule risk }\end{array}$ \\
\hline $\begin{array}{l}\text { QUALITY } \\
\text { REQUREMENTS }\end{array}$ & $\begin{array}{l}\text { Large quality tolerances and low } \\
\text { productivity risk }\end{array}$ & $\begin{array}{l}\text { Moderate quality tolerances (re-work } \\
\text { likely) and moderate productivity risk }\end{array}$ & $\begin{array}{l}\text { Precision work (re-work expected) and } \\
\text { moderate or high productivity risk NQA } 1\end{array}$ \\
\hline FUNDING & $\begin{array}{l}\text { Less than one-year duration } \\
\text { Small project (e.g., GPP size) }\end{array}$ & $\begin{array}{l}\text { 2-3-year duration } \\
\text { Other Line Item Project size }\end{array}$ & $\begin{array}{l}2 \text { or more year duration } \\
\text { Other Line Item, MP, MSA size }\end{array}$ \\
\hline POLITICAL VISIBILITY & None & Minor & Major \\
\hline COST SHARING & None & 1 & 2 or more \\
\hline
\end{tabular}


WHC-SD-WM-SEMP-002 Rev. 0

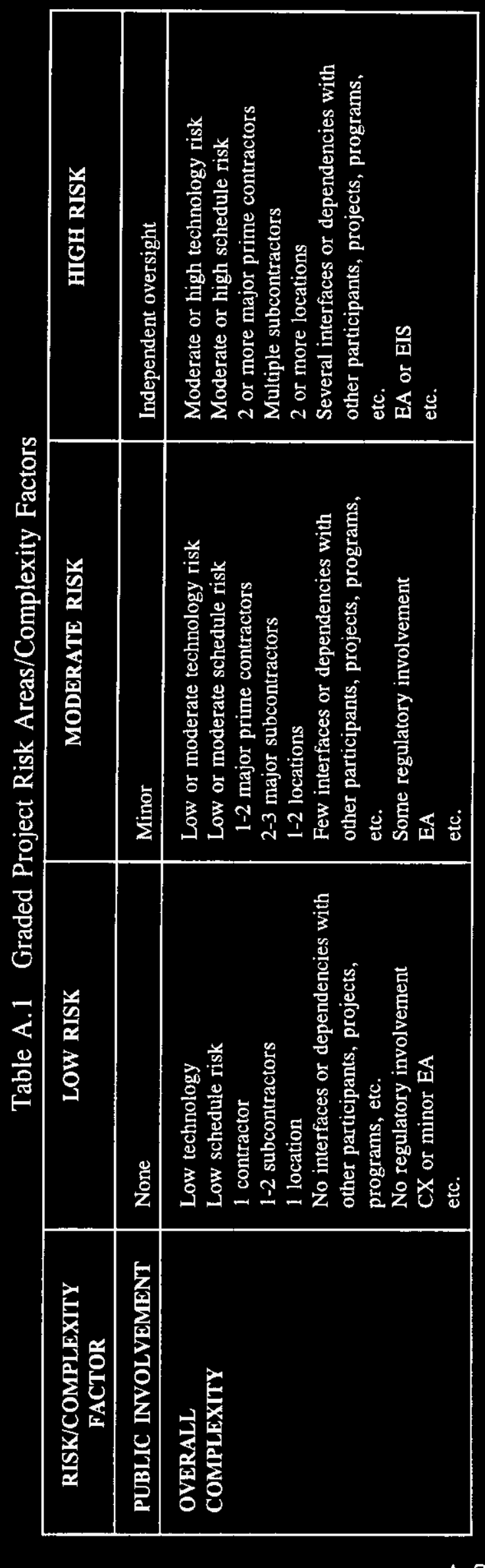




\section{A.4 PROJECT SE REQUTREMENTS}

The following sections describe the different levels of projects, resulting in a graded application of systems engineering. Specific criteria are given, along with examples of types of projects that fit those criteria. Given a project, the level of systems engineering to be applied will depend on the highest category (SE-1 being the highest) in which the criteria fit the project. Table A.2 gives a summary of requirements for SE activities and documents based on the assigned SE level.

Because most of the projects described involve systems, structures, and/or components, additional sections describing analysis and software projects are included.

\section{A.4.1 SE-1 Projects}

The SE-1 level projects are those which are rated as a high risk/complexity as described in Section A.2. These are usually major projects of significant importance to the Hanford Mission, involving systems, structures, and/or components (SSCs) where project failure would result in significant delay to the TWRS mission, and could prevent accomplishment of the TWRS mission.

Projects within this category generally include, Major System Acquisitions and Major Projects. For example, under this definition a project to develop a TWRS waste retrieval system or major storage system would be determined to be at the SE-1 level.

The SE-1 level projects require rigorous application of SE as defined in this SEMP and shown in the diagonal diagram of Figure 2-2. SE-1 level project SE requirements are also shown for comparison to the other SE level projects in Table A.2.

\section{A.4.2 SE-2 Projects}

The SE-2 level projects are those which are rated as a moderate risk/complexity as described in section A.2 and A.3. These are usually major projects of significant importance to the Hanford Mission, involving systems, structures, and/or components (SSCs) where project failure would result in significant delay to the TWRS mission.

Projects within this category generally include, (a) an existing systems modification with significant complexity and other factors as described in Table A.1, and (b) modification to facilities or systems undergoing a change in status if they have been in one condition or had one purpose or function for an extended period of time (months), and a substantial change in condition or purpose is planned (includes facilities that have been in stand-down or shutdown for several months, and are being returned to service). 
The SE-2 level projects require full application of SE as defined in this SEMP and shown in the diagonal diagram of Figure 2-2. However, the documentation and level of review for SE-2 projects may be less than SE-1. SE-2 level project SE requirements are also shown for comparison to the other SE level projects in Table A.2.

\section{A.4.3 SE-3 Projects}

The SE-3 level indicates a project that scored a low on the screening process in Section A.2. This type of project is typically one that is only moderately complex, and for which failure of the SSCs would cause or allow only minimal off-site impact and minor cost and schedule impacts.

Projects within this category may include, an equipment/system changeouts not-in-kind, and other projects that are relatively uncomplicated. In addition, many analysis and software projects may fall into this category, even though they do not involve SSCs.

The SE-3 level projects require selective application of systems engineering as shown in Table A.2.

\section{A.4.4 SE-4 Projects}

The SE-4 level indicates a project that consistently scored a value of low during the screening process and, in the opinion of the project manager and DOE counterpart, does not require systems engineering. Projects within this category include, "changeout-in-kind, "where the change is a form, fit and/or function replacement of essentially identical specification to the replaced part.

The SE-4 level projects do not require systems engineering, however some documentation as shown in Table A.2 is required to document changes to the system from the work done.

\section{A.4.5 Analysis Projects}

Analysis projects do not produce SSCs. They are typically set up with very specific goals, with the product being documents or management systems. This type of project is typically graded as an SE-3 project, requiring selective SE documentation.

An example is a project to develop a safety document such as a Safety Analysis Report. This is an analysis that is well defined by regulations. It does not satisfy an "architecture" in the systems engineering sense, the project is carried out to define requirements for the the safety envelope in which future SSCs must operate. The project mission must be clearly defined and requirements specified, and kept distinct from other ancillary projects. As such, a Mission Analysis must be performed and documented. This Mission Analysis should clearly tie the 
project back to other program or project functions \& requirements. Additional SE products, such as functions \& requirements analyses, trade studies, and various system specifications are not applicable to this type of work.

Another example is a project to resolve a specific program or project issue. For example, do organic materials in the TWRS waste tanks pose a safety problem. In this case a project is set up to initially analyze by various means to see if there is indeed a problem. This analysis project must perform a mission analysis to develop agreed-upon requirements to be met and a clear mission. If, as a result of the analysis, it is determined that there is a safety problem, and the decision is to develop a mitigation system to resolve the problem, the project must be re-evaluated according to the criteria in Sections A-2.1 through A-2.4 as it now includes developing SSC. Because the original issue was one of safety, this probably will elevate the SE level requirements.

If it is clear from the start that there is a safety problem, and a SSC project is developed to solve this problem, then the screening method shown in Table 2-1 should be used to evaluate the SE level of the project. In this case it is no longer an "analysis" project.

\section{A.4.6 Software Projects}

Software projects are a special case of project. Requirements and procedures for development of software are well defined at Hanford and must be followed (See WHC-CM-3-10, "Software Practices"). In this sense it has its own well-defined version of systems engineering. However, when the software is integral to an SSC project it must be driven by the functions and requirements analysis performed by the project. Once it is thus defined the software development will again follow the normal software development path. 
Table A.2 Required SE Activities and Products for Given SE Level Project.

\begin{tabular}{|c|c|c|c|c|c|}
\hline & SE ACTIVITY & $\begin{array}{c}\text { SE } \\
\text { LEVEL } 1 \\
(\text { SE-1) }\end{array}$ & $\begin{array}{c}\text { SE } \\
\text { LEVEL } 2 \\
\text { (SE-2) }\end{array}$ & $\begin{array}{c}\text { SE } \\
\text { LEVEL } 3 \\
\text { (SE-3) }\end{array}$ & $\begin{array}{c}\text { SE LEVEL } \\
4(\mathrm{SE}-4)\end{array}$ \\
\hline 0 & Mission Analysis & Yes & $\operatorname{Yes}(1)$ & Yes(1) & Yes* \\
\hline 0 & $\begin{array}{l}\text { Functions \& } \\
\text { Requirements Analysis } \\
\text { \& Allocation }\end{array}$ & Yes & Yes(1) & Yes & Yes* \\
\hline $\mathbf{o}$ & $\begin{array}{l}\text { Alternative Generation } \\
\text { and Analysis }\end{array}$ & Yes & $\operatorname{Yes}(1)$ & $\operatorname{Yes}(1)$ & No \\
\hline 0 & Trade Studies & Yes & $\mathrm{Yes}(1)$ & I & No \\
\hline $\mathbf{o}$ & System Effectiveness & Yes & Yes (1) & I & No \\
\hline 0 & Life-Cycle Cost & Yes & $\operatorname{Yes}(1)$ & I & No \\
\hline $\mathbf{0}$ & Test and Evaluation & Yes & Yes(1) & Yes $(1)$ & Yes** \\
\hline 0 & Risk Management & Yes & $\operatorname{Yes}(1)$ & I & No \\
\hline 0 & $\begin{array}{l}\text { Configuration } \\
\text { Management }\end{array}$ & Yes & $\operatorname{Yes}(1)$ & Yes(1) & No \\
\hline $\mathbf{o}$ & Interface Management & Yes & $\operatorname{Yes}(1)$ & Yes $(1)$ & No \\
\hline $\mathbf{o}$ & $\begin{array}{l}\text { Requirements } \\
\text { Traceability }\end{array}$ & Yes & Yes(1) & Yes(1) & No \\
\hline $\mathbf{0}$ & Decision Management & Yes & Yes(1) & I & No \\
\hline \multicolumn{6}{|c|}{ PROJECT PRODUCTS } \\
\hline 0 & SEMP & Yes & Yes $(1)$ & Yes(1) & No \\
\hline 0 & $\begin{array}{l}\text { Project Mission } \\
\text { Analysis Report }\end{array}$ & Yes & Yes(1) & Yes(1) & $\mathbf{M}$ \\
\hline o & $\begin{array}{l}\text { Trade Study } \\
\text { Documents }\end{array}$ & Yes & Yes(1) & $\mathbf{M}$ & No \\
\hline 0 & $\begin{array}{l}\text { Risk Management Plan } \\
\& \text { List }\end{array}$ & Yes & Yes(1) & I & No \\
\hline 0 & $\begin{array}{l}\text { Project Interface } \\
\text { Control Documents }\end{array}$ & Yes & Yes(1) & Yes(1) & $\mathbf{M}$ \\
\hline 0 & $\begin{array}{l}\text { Project Design } \\
\text { Concept }\end{array}$ & Yes & Yes(1) & I & No \\
\hline o & $\begin{array}{l}\text { Project Design } \\
\text { Specification }\end{array}$ & Yes & Yes(1) & I & No \\
\hline 0 & $\begin{array}{l}\text { Mass/Energy Flow } \\
\text { Sheets }\end{array}$ & Yes & Yes(1) & No & No \\
\hline
\end{tabular}


WHC-SD-WM-SEMP-002 Rev. 0

Table A.2 Required SE Activities and Products for Given SE Level Project.

\begin{tabular}{|ll|c|c|c|c|}
\hline & $\begin{array}{c}\text { SE } \\
\text { LEVEL 1 } \\
\text { (SE-1) }\end{array}$ & $\begin{array}{c}\text { SE } \\
\text { LEVEL 2 } \\
\text { (SE-2) }\end{array}$ & $\begin{array}{c}\text { SE } \\
\text { LEVEL 3 } \\
\text { (SE-3) }\end{array}$ & $\begin{array}{c}\text { SE LEVEL } \\
\text { 4 (SE-4) }\end{array}$ \\
\hline 0 & $\begin{array}{l}\text { Piping \& Instrument } \\
\text { Diagrams }\end{array}$ & Yes & Yes(1) & Yes(1) & No \\
\hline 0 & $\begin{array}{l}\text { Technology } \\
\text { Development Reports }\end{array}$ & $M$ & $M$ & No & No \\
\hline 0 & Project Logistics Plan & Yes & Yes(1) & I & No \\
\hline 0 & Project Reports & Yes & Yes(1) & M & M \\
\hline
\end{tabular}

\section{Table Notes:}

(1) Activity. or product is tailored in size and complexity to the project size/complexity

I "Informal;" No documentation required, but process should be used.

M Management direction/decision required.

* The decision to accomplish the activity must be documented.

** Some level of testing is always required, even if only to make certain the replacement functions as previously.

\section{A.5 PRESENT STAGE OF PROJECT}

The diagonal diagram shown in Figure 2-2 indicates that the normal start of a project involving SSCs is determined by a specification, called a Design Requirements Document (DRD), generated by the program. This is the "birthright" of the project. However, some TWRS projects were started prior to program generation of a DRD. In these cases, where it has been decided to continue the project, a modification to the normal SE process must be carried out. In most cases this involves project generation of an "equivalent" DRD, along with an up-front determination of the program risks assumed by this process. Once the project DRD has been generated, and the review completed, the project can continue until complete traceability to program requirements is established. Reassessment of project activities will be necessary to assure linkage to program-level requirements.

Analysis and Software projects are treated as described in Sections A.4.5 and A.4.6, respectively. In cases where such projects have been underway without meeting the minimum SE requirements of this SEMP, the projects must develop the necessary SE products to support project continuation. 
WHC-SD-WM-SEMP-002 Rev. 0

\section{APPENDIX B}

\section{TECHNICAL REVIEWS}

B-1 
WHC-SD-WM-SEMP-002 Rev. 0

This page intentionally left blank.

B-2 


\section{B-1 Introduction}

Independent technical reviews are performed to provide management and the customer an opportunity to assess progress, evaluate program risk, and refocus program activities. Organizers and participants of technical baseline reviews will vary from review to review. For example, an Technical Requirements Review will be organized by the Program while a Preliminary Design Review will be organized by the project. The reviewing authority will transfer from DOE for Program level reviews to the M\&O for Project level reviews. Stakeholders will participate in reviews, as required, to ensure the consistency and technical adequacy of the evolving TWRS Technical Baseline.

\section{B-2 Technical Review Descriptions.}

The following paragraphs describe the purpose, scope, organizer, and reviewing authority for each review.

B-2.1 System Requirements Review (SRR) The SRR is a program level review, conducted to evaluate progress in defining Program F\&R, the architectural concept to satisfy mission needs and to approve the Functional Requirements Baseline. The WHC TWRS Technical Integration organization will organize the review with RL TWRS Office participation. DOE is the reviewing authority.

B-2.2 Technical Requirements Review (TRR). The TRR is a program level review of system requirements. It is conducted to; (1) evaluate the system requirements for adequacy and risk; (2) ensure a mutual understanding among TWRS Program and Project participants of TWRS Program system requirements, the corresponding system architecture (design concepts), and test strategies, (3) assess the SE process that produced the system requirements, and (4) approve the Technical Requirements Baseline.

The WHC TWRS Technical Integration will organize and conduct the TRR, with DOE/RL participation. DOE is the reviewing authority. The TRRs will be phased, reviewing the portion of the baseline applicable to specific architecture elements with sufficient commonality to combine into one review.

B-2.3 Design Requirements Review (DRR). A DRR is held for each project to demonstrate readiness for proceeding to design development. DRRs are conducted to; (1) verify project requirements conform with system requirements; (2) identify requirements to be refined by the project; (3) approve the project DRD, project architecture, and the Design Requirements Baseline.

For each project, the responsible WHC Project organization organizes and conducts the DRR. The RL TWRS Program Office will participate in selected reviews, and the M\&O is the reviewing authority. The products presented at DRR form the foundation for the Key Decision 0 review.

B-2.4 System Design Review (SDR). The SDR is conducted to evaluate the optimization, traceability, correlation, completeness, and risk of the allocated requirements, including the corresponding test requirements to fulfill the project technical requirements. This review encompasses the total system requirements and includes a summary review of the System Engineering management work (e.g., integrated test planning, specialty discipline studies, and Configuration Management) that produced the system definition products. Successful completion of the SDR results in the approval of the Design Configuration Baseline Phase 1. The project 
is responsible to identify all required participants. DOE/RL will participate in selected reviews, and the $\mathrm{M} \& \mathrm{O}$ is the reviewing authority. For additional information on the scope of the review including a listing of products required for a technically complex project, see $D O E / R L-95-12$ TWRS Systems Engineering Standard, Rev AE (Draft). The products presented at the SDR form the foundation for the Key Decision \#1 review.

B-2.5 Preliminary Design Review (PDR). The purpose of a PDR is to review each project's basic design approach, the associated risks and to approve the Design Configuration Baseline Phase 2. The review is organized by the project and includes review of: requirements development, design activities, trade studies, risk analysis, specialty engineering, test planning and conduct, interface management, risk analysis and configuration management. The project is responsible for identifying required participants. DOE/RL will participate in selected reviews. The $\mathrm{M} \& \mathrm{O}$ is the reviewing authority. For additional information on the scope of the review including a listing of products required for a technically complex project, see $D O E / R L-95-12$ TWRS Systems Engineering Standard, Rev AE (Draft).The products presented at the PDR form the foundation for the Key Decision \#2 review.

B-2.6 Definitive Design Review (DDR). A DDR is held for each project to demonstrate readiness to start procurement, construction, manufacturing, and coding of projects for verification. DDR is conducted to; (1) verify design conformance with the design requirements; (2) approve the design specifications updates; (3) evaluate the adequacy of the detailed design; (4) assess design producibility, constructability, testability, inspectability, and risk areas; (5) assess design readiness to proceed with procurement and construction; and (6) to approve Design Configuration Baseline Phase 3.

The project will organize and conduct the DDR ensuring the participation of the appropriate WHC organizations. RL TWRS Program Office will participate in selected reviews, and the $\mathrm{M} \& \mathrm{O}$ is the reviewing authority. The DDR can be used for design verification purposes if it meets requirements of applicable quality assurance procedures. For additional information on the scope of the review including a listing of products required for a technically complex project, see DOE/RL-95-12 TWRS Systems Engineering Standard, Rev AE (Draft). The products presented at the DDR form the foundation for the Key Decision \#3 review.

B-2.7 Operational Readiness Review (ORR). ORRs are held following completion of facility construction. This review is conducted to; (1) compare the as-built configuration with the design configuration; (2) assess start up; (3) allow for the orderly pre-operational testing and turnover of the facility to the WHC facility operations; and (4) to approve the As-Built Baseline.

The ORR is conducted and organized by the project and the A/E. The organizers will ensure participation by the WHC Program Office and RL TWRS Program Office. The Construction, Test, and Turnover Packages and the Operations and Maintenance Packages are presented at the ORR. The as-built system will be reviewed against the technical baseline to support the DOE review milestones and to permit facility operation approval. The M\&O is the reviewing authority. 
WHC-SD-WM-SEMP-002 Rev. 0

B-2.8 Decontamination and Decommissioning Review (D\&DR). A D\&DR is held to ensure that D\&D activities can be performed safely and to ensure that all necessary permits properly reflect the baseline.

The responsible $M \& O$ organization will organize and conduct the D\&DR and will ensure the participation of all responsible parties including the D\&D organization. D\&D baseline documentation and the updated operational baseline configuration are presented at the D\&DR.

After successful completion of the D\&DR, the D\&D baseline configuration will be submitted for approval and configuration control. Approval will authorize proceeding with the D\&D.

The boundary between D\&D and the ERC has not been defined. After it is defined, this section will be modified to describe the review to proceed with the ERC work.

\section{B-3. Technical Review Entry and Exit Criteria}

The following is a sample set of entry and exit criteria set developed for the Program level TRR, provided as an example. In conjunction with their DOE/RL monitor, each project will develop its own project review criteria. Each project will have entry and exit criteria signed by the review authority prior to initiating the review. 


\section{TECHNICAL REQUIREMENTS BASELINE CRITERIA}

\begin{tabular}{|c|c|}
\hline $\begin{array}{c}\text { CRITERIA } \\
\text { (and points of contact) }\end{array}$ & $\begin{array}{l}\text { DESCRIPTION } \\
\text { (proposed standards for the TRR) }\end{array}$ \\
\hline Functional Analysis & $\begin{array}{l}\text { * Show that a complete set of functions which satisfy the mission have been developed. } \\
\text { - includes showing that the SRR has been completed, and updating the functional analysis as } \\
\text { needed to reflect any modifications or interpretations of the mission since the SRR. } \\
\text { - "complete set of functions" is defined as all items needed to specify the content and } \\
\text { boundaries of the functions that include the necessary and sufficient solutions to the problem. } \\
\text { - each function should be traceable to the TWRS and Site mission needs. } \\
\text { - the set of functions should satisfy the mission goals and objectives as defined by the } \\
\text { TWRS Strategic Plan and the Hanford Mission Plan. } \\
\text { * Show that functional interfaces are defined. } \\
\text { - interface definitions should be of sufficient detail to identify organizational interactions that } \\
\text { will be needed in interface control working groups. }\end{array}$ \\
\hline
\end{tabular}


WHC-SD-WM-SEMP-002 Rev. 0

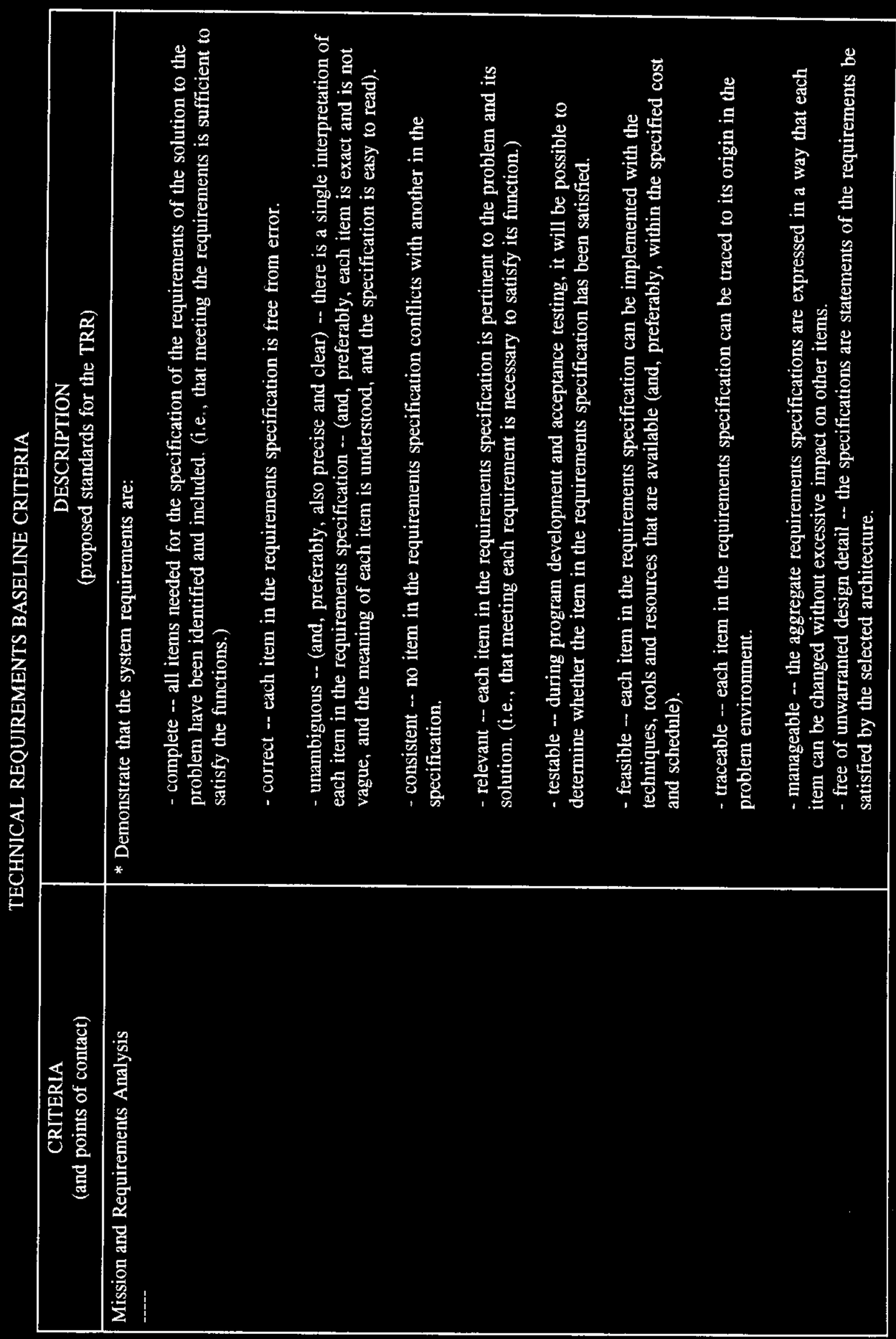


TECHNICAL REQUIREMENTS BASELINE CRITERIA

\begin{tabular}{|l|l|}
\hline \multicolumn{1}{|c|}{$\begin{array}{c}\text { CRITERIA } \\
\text { (and points of contact) }\end{array}$} & $\begin{array}{c}\text { DESCRIPTION } \\
\text { (proposed standards for the TRR) }\end{array}$ \\
\hline \begin{tabular}{l} 
System/Cost Effectiveness Analysis \\
\hdashline-
\end{tabular} & $\begin{array}{l}\text { * Provide evidence that life cycle cost and risk management are considered in all decisions regarding } \\
\text { selection of alternatives. } \\
\text { - Measures of success are defined. } \\
\text { - Life Cycle Cost Analysis has been performed and documented. } \\
\text { - analyses should include the } \\
\text { - expected range of potential values for performance (technical processes and ES\&H), } \\
\text { - expected range on potential values for schedule, and } \\
\text { - sensitivity of performance parameters to cost. }\end{array}$ \\
\hline
\end{tabular}




\section{TECHNICAL REQUIREMENTS BASELINE CRITERIA}

\begin{tabular}{|c|c|}
\hline $\begin{array}{c}\text { CRITERIA } \\
\text { (and points of contact) }\end{array}$ & $\begin{array}{c}\text { DESCRIPTION } \\
\text { (proposed standards for the TRR) }\end{array}$ \\
\hline $\begin{array}{l}\text { Trade Studies } \\
\text {--- }\end{array}$ & $\begin{array}{l}\text { * Trade-offs among operational needs, stakeholder values, program schedule and budget, and life } \\
\text { cycle costs, are identified (and preferably assessed). } \\
\text { * Trade-off studies have been scheduled or accomplished to support the decision needs of the system } \\
\text { engineering process. -- Results of the studies will include supporting rationale and impact on the } \\
\text { TWRS program. } \\
\text { * Trade studies / decision analyses have been completed or are planned to provide a basis for TRS } \\
\text { decisions necessary to establish the technical baseline architecture. These studies/analyses: } \\
\text { are explicitly tied to decisions/issues identified through the system engineering functional and } \\
\text { requirements analysis process; } \\
\text { resolve (or provide a clear approach to resolve) all open decisions/issues; } \\
\text { have explicitly identified decision makers who are the consumers of the study/analysis results } \\
\text { and will make the decision; and have explicitly identified organizational responsibilities for } \\
\text { resulting actions; } \\
\text { are completed or are scheduled for completion to meet program requirements derived from } \\
\text { system engineering; } \\
\text { have well-defined, explicit, and documented scope; } \\
\text { use a consistent approach to establishing values and decision criteria to be applied; } \\
\text { use values/decision criteria that are explicitly linked to an established basis, i.e., system } \\
\text { constraints, requirements, stakeholder values, etc.; } \\
\text { document (or reference) the values/decision criteria used, their basis, and how they were } \\
\text { identified; }\end{array}$ \\
\hline
\end{tabular}


WHC-SD-WM-SEMP-002 Rev. 0

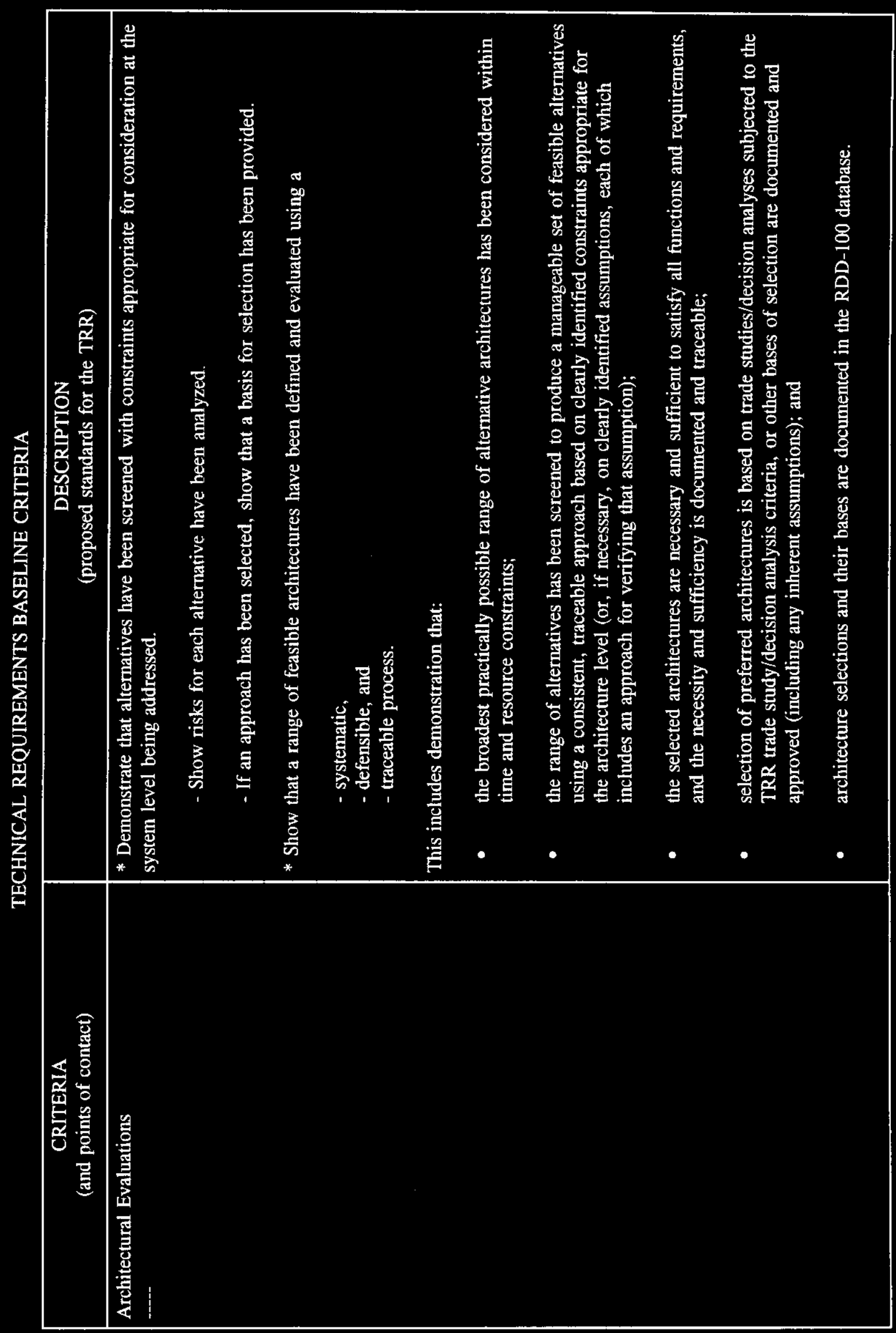

B-10 
TECHNICAL REQUIREMENTS BASELINE CRITERIA

\begin{tabular}{|c|c|}
\hline $\begin{array}{c}\text { CRITERIA } \\
\text { (and points of contact) }\end{array}$ & $\begin{array}{c}\text { DESCRIPTION } \\
\text { (proposed standards for the TRR) }\end{array}$ \\
\hline $\begin{array}{l}\text { Standards to be imposed on Projects } \\
\text {---- }\end{array}$ & $\begin{array}{l}\text { * Nationally recognized codes and standards imposed on projects are identified in DOE Order } \\
\text { 6430.1A, "General Design Criteria". } \\
\text { DOE Order 6430.1A } \\
\text { The following requirement (constraint) will reside in the TWRS requirements } \\
\text { database at the TRR milestone: } \\
\text { The general design criteria provided by DOE Order } 6430.1 A \text { shall be applied to all } \\
\text { facilities which shall be reported on in the Department's Real Property Inventory } \\
\text { System (RPIS), or which shall be reported on in the General Services Administration's } \\
\text { annual "Summary Report of Real Property Owned by the United States Throughout } \\
\text { the World". } \\
\text { [DOE Order } 6430.1 A, 4 . a . J \\
\text { The above requirement levies the applicable design standards and guides to be } \\
\text { implemented on the design of facilities to be reported on the Department's RPIS. } \\
\text { Division 1, Section 0109 gives a listing of all the standards and guides called-out in } \\
\text { 6430.1A. It also encompasses the requirement called-out in DOE Order } 5820.2 A \text {, } \\
\text { Chapter I, 3.a.(1)(b), "Designs for new storage and treatment facilities shall meet the } \\
\text { requirements of DOE } 6430.1 \text {, applicable EM Orders and } 40 \text { CFR } 264 \text { ", since the } \\
\text { applicable sections of } 40 \text { CFR } 264 \text { are in the TWRS requirements database. } \\
\text { Note: Other general requirements from 6430.1A will also be present and allocated to } \\
\text { functions and architectures in the TWRS requirements database (e.g., flexibility) as } \\
\text { they apply to the technical requirements baseline. } \\
\text { * Hanford Plant standards will be imposed where national standards are insufficient or not developed } \\
\text { as required by RL directive, RL } 6430.1 \mathrm{C} \text {, "Hanford Plant Standards (HPS) Program." } \\
\text { Hanford Plant Standards. }\end{array}$ \\
\hline
\end{tabular}


TECHNICAL REQUIREMENTS BASELINE CRITERIA

\begin{tabular}{|c|c|}
\hline $\begin{array}{c}\text { CRITERIA } \\
\text { (and points of contact) }\end{array}$ & $\begin{array}{c}\text { DESCRIPTION } \\
\text { (proposed standards for the TRR) }\end{array}$ \\
\hline Standards to be imposed on projects, continued. & 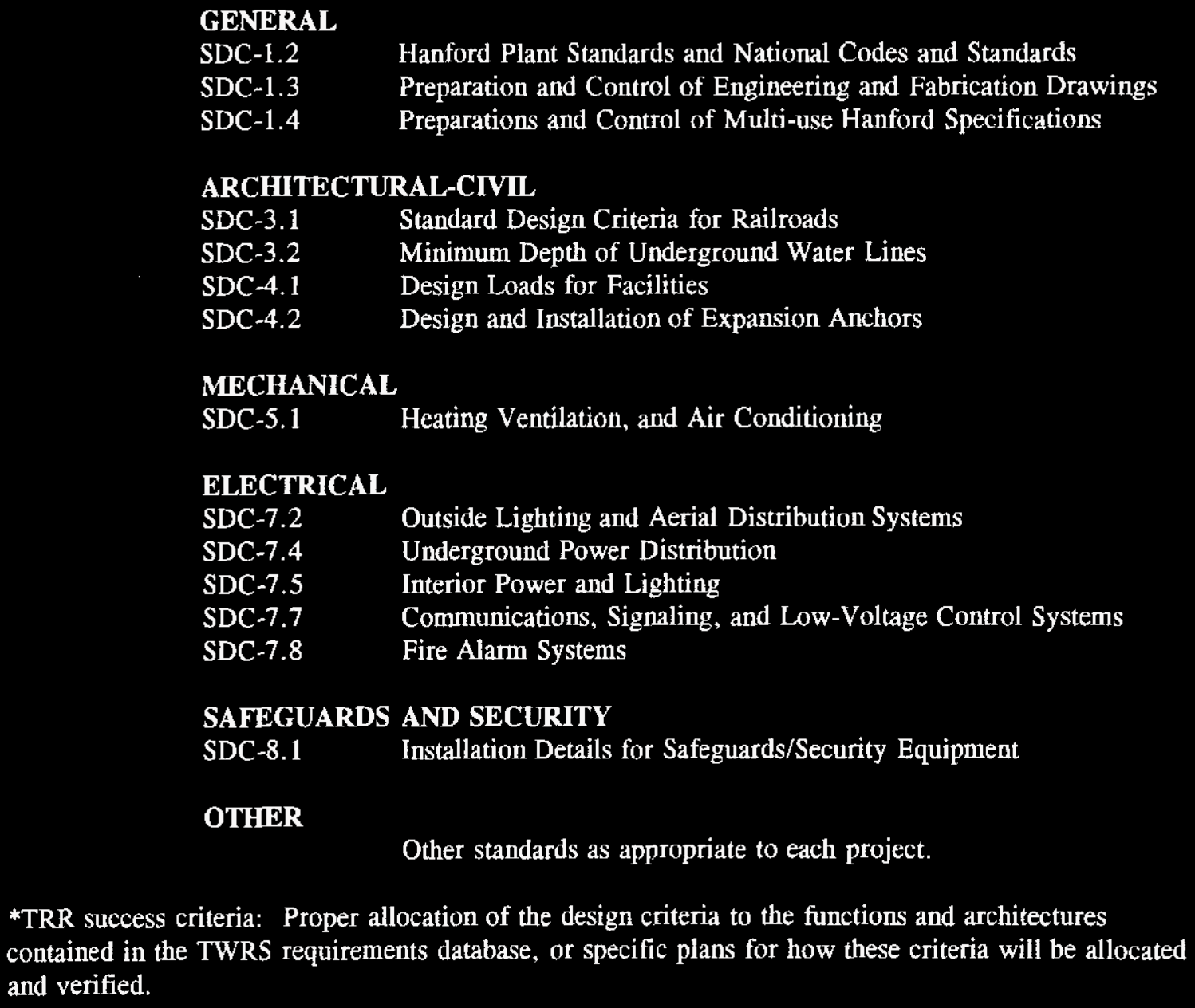 \\
\hline
\end{tabular}


TECHNICAL REQUIREMENTS BASELINE CRITERIA

\begin{tabular}{|c|c|}
\hline $\begin{array}{l}\text { CRITERIA } \\
\text { (and points of contact) }\end{array}$ & $\begin{array}{l}\text { DESCRIPTION } \\
\text { (proposed standards for the TRR) }\end{array}$ \\
\hline $\begin{array}{l}\text { Identification of projects supported, and } \\
\text { Review of plans to plans to proceed into the next } \\
\text { phase. }\end{array}$ & $\begin{array}{l}\text { * The TWRS TRR Planning chart should be updated, reflecting latest plans for DRD scheduling based } \\
\text { on TRR results. } \\
\text { - Planning schedules are available at the time of the TRR depicting the timing of availability } \\
\text { of necessary and sufficient systems engineering documentation to permit necessary TWRS } \\
\text { projects to proceed to the DRD phase. } \\
\text { - Processes are identified for tailoring systems engineering documentation for work activities } \\
\text { not requiring complete systems engineering application. } \\
\text { * Identify project(s) encompassed by the functionality. } \\
\text { - Functions in the TRS are analyzed and associated with existing and proposed TWRS work } \\
\text { activities (e.g. projects). } \\
\text { - Every function is traceable to (allocated to) specific work activities. } \\
\text { - Functions not directly allocable to existing projects are highlighted so that appropriate work } \\
\text { activities can be proposed. } \\
\text { * Demonstrate evidence of initial planning and scheduling for } \\
\text { - completion of Technical Baseline, based upon functional baseline, to include technical } \\
\text { requirements specification (requirements allocated to functions and physical interfaces between } \\
\text { programs), and associated ICD's (interface control documents) and supporting documentation. } \\
\text { - approach for transition to Design Requirements Baseline, based upon technical baseline, } \\
\text { which would include DRD, associated ICD's, and supporting documentation. } \\
\text { - approach for development of Design Configuration Baseline, based upon design requirements } \\
\text { baseline, which would include specifications, drawings, operating and maintenance manuals, } \\
\text { and associated ICD's and supporting documentation. }\end{array}$ \\
\hline
\end{tabular}




\section{TECHNICAL REQUIREMENTS BASELINE CRITERIA}

\begin{tabular}{|c|c|}
\hline $\begin{array}{l}\text { CRITERIA } \\
\text { (and points of contact) }\end{array}$ & $\begin{array}{l}\text { DESCRIPTION } \\
\text { (proposed standards for the TRR) }\end{array}$ \\
\hline $\begin{array}{l}\text { Risk Analysis and Decision Management } \\
----\end{array}$ & $\begin{array}{l}\text { * Program definition includes risk management, risk analysis and appropriate mitigation of the risks } \\
\text { associated with the related cost, schedule, and technical parameters. } \\
\text { * Program definition also identifies critical areas. } \\
\text { * Risk management is integrated into the decision process. } \\
\text { - A procedure is defined and implemented that incorporates operational requirements, life cycle cos } \\
\text { and risk information, stakeholder values, and program schedule and budget into a structured, well- } \\
\text { documented decision process that articulates the trade-offs among these attributes. } \\
\text { - The initial risk assessment screening process is used to provide risk information to the TRS } \\
\text { development. }\end{array}$ \\
\hline
\end{tabular}


WHC-SD-WM-SEMP-002 Rev. 0

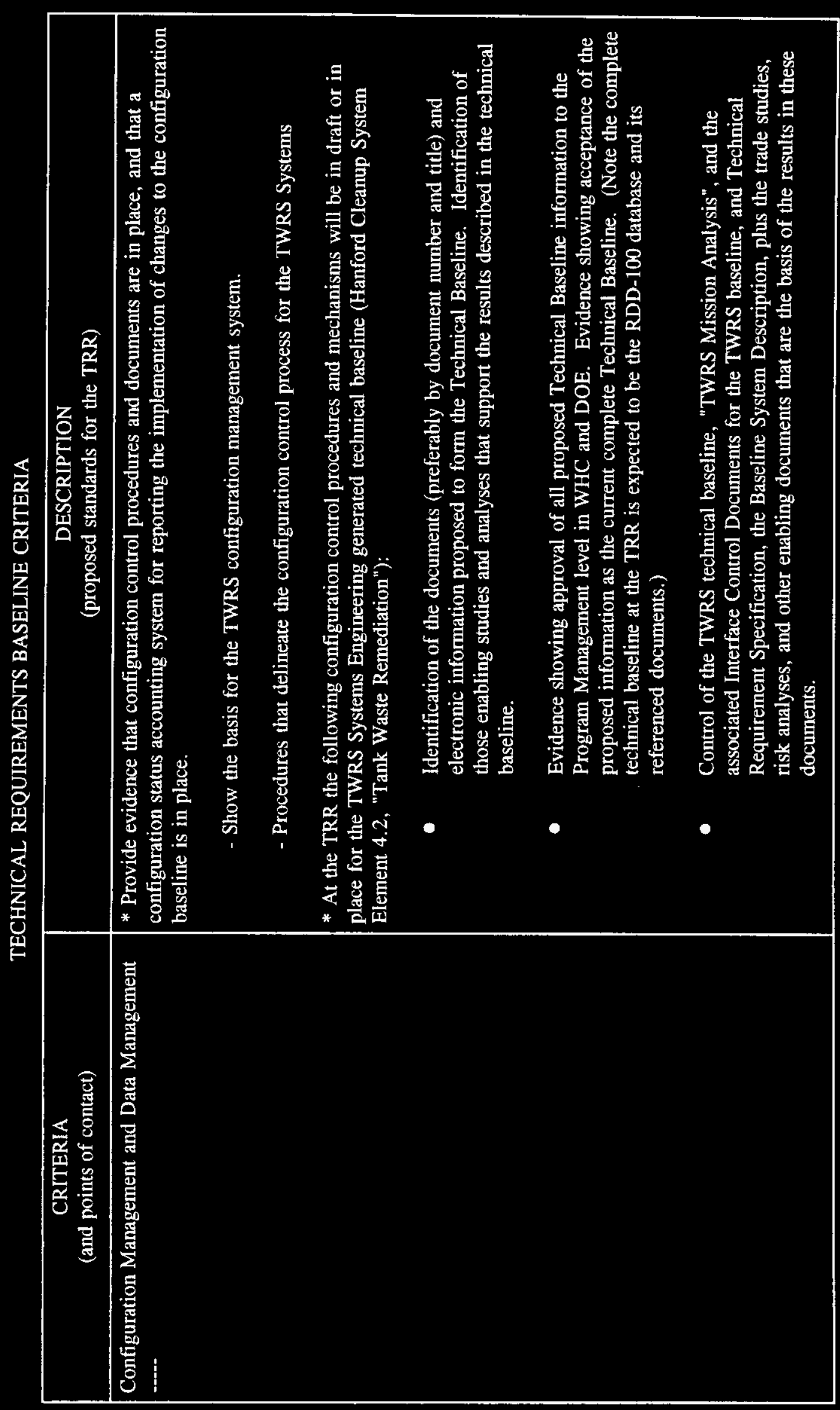

B-15 
WHC-SD-WM-SEMP-002 Rev. 0

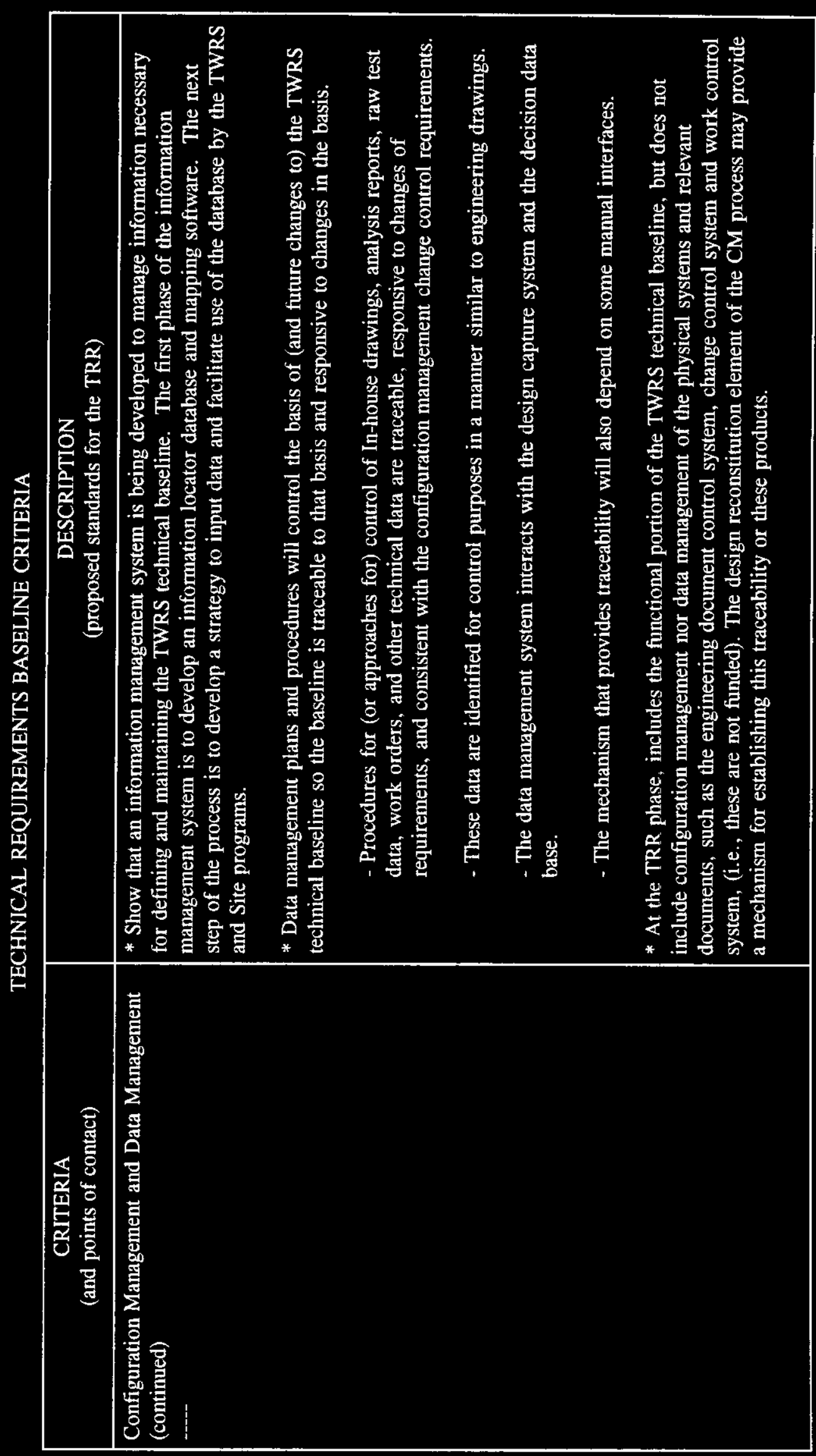

B-16 


\section{TECHNICAL REQUIREMENTS BASELINE CRITERIA}

\begin{tabular}{|c|c|}
\hline $\begin{array}{l}\text { CRITERIA } \\
\text { (and points of contact) }\end{array}$ & $\begin{array}{l}\text { DESCRIPTION } \\
\text { (proposed standards for the TRR) }\end{array}$ \\
\hline $\begin{array}{l}\text { Milestone schedules } \\
-\ldots-\end{array}$ & $\begin{array}{l}\text { * Show that an integrated program schedule } \\
\text { - has been developed, } \\
\text { - considered alternatives within the constraints imposed by the TPA, DOE objectives, and } \\
\text { other requirements, } \\
\text { - is consistent with, and a driver of the Program Multi-Year Program Plan (MYPP). } \\
\text { * The schedule must identify critical tasks and milestones, including system engineering milestones. }\end{array}$ \\
\hline $\begin{array}{l}\text { Preliminary test planning } \\
---\end{array}$ & $\begin{array}{l}\text { * Show that a preliminary test plan is being developed that includes } \\
\text { - the total system scope and objectives (i.e., that details an approach to verifying the } \\
\text { subsystem architectures satisfy the functions and requirements allocated to them, and to } \\
\text { integrated verification of total system performance), } \\
\text { - subsystem scopes for characterization, laboratory and bench-scale testing, and pilot } \\
\text { demonstrations necessary to define the subsystems and reduce the system risk. } \\
\text { * The objectives, scope, and type of system testing will be products of the engineering effort. }\end{array}$ \\
\hline
\end{tabular}


TECHNICAL REQUIREMENTS BASELINE CRITERIA

\begin{tabular}{|c|c|}
\hline $\begin{array}{l}\text { CRITERIA } \\
\text { (and points of contact) }\end{array}$ & $\begin{array}{c}\text { DESCRIPTION } \\
\text { (proposed standards for the TRR) }\end{array}$ \\
\hline Technical performance measurement planning & $\begin{array}{l}\text { * Show that a TPM plan is being developed to include cost, schedule, and technical performance } \\
\text { measurements coincident with the Program Work Breakdown Structure. TPM parameters selected for } \\
\text { tracking will be key indicators of program success. } \\
\text { * Technical performance measurement is explicitly defined to confirm progress and identify } \\
\text { deficiencies that may jeopardize meeting a critical system requirement. This will include } \\
\text { demonstration that: } \\
\text { organizational responsibility for selecting, profiling, and evaluating technical performance } \\
\text { measures (TPM's) is assigned; } \\
\text { the TPM's selected for tracking are appropriate, i.e., critical to mission success, uncertain, } \\
\text { and quantifiable; } \\
\text { the number of TPM's is relative small; } \\
\text { the basis for the TPM's is clearly established and linked to requirements; } \\
\text { the specific TPM's are linked to specific functions and WBS elements; } \\
\text { the methods for evaluating each TPM are defined (using models/analysis and/or test data); } \\
\text { a schedule for performing the evaluations is defined; and } \\
\text { a profile for each TPM has been prepared that includes achievement-to-date, the current } \\
\text { estimate of the TPM at tracking completion, and the profile in between. }\end{array}$ \\
\hline
\end{tabular}


TECHNICAL REQUIREMENTS BASELINE CRITERIA

\begin{tabular}{|c|c|}
\hline $\begin{array}{l}\text { CRITERIA } \\
\text { (and points of contact) }\end{array}$ & $\begin{array}{c}\text { DESCRIPTION } \\
\text { (proposed standards for the TRR) }\end{array}$ \\
\hline $\begin{array}{l}\text { Specialty Discipline Studies; includes: } \\
\text {-reliability analysis, } \\
\text {-maintainability analysis, } \\
\text {-logistics support, } \\
\text {-system safety, } \\
\text {-human factors, } \\
\text {-manpower requirements personnel analysis, } \\
\text {-value engineering studies, } \\
\text {-environmental considerations. } \\
\text {----- }\end{array}$ & $\begin{array}{l}\text { * Demonstrate that the integration and coordination of the program efforts for the engineering specialty } \\
\text { areas, to achieve a best mix of the technical/performance values, is described in the SEMP. } \\
\text { - The SEMP depicts the integration of the specialty efforts and parameters into the system } \\
\text { engineering process and shows their consideration during each iteration of the process. } \\
\text { - Show that engineering analysis incorporates specialty discipline considerations as } \\
\text { appropriate. }\end{array}$ \\
\hline $\begin{array}{l}\text { Systems Engineering Management Plans } \\
---\end{array}$ & $\begin{array}{l}\text { * Demonstrate that a comprehensive SEMP has been produced which describes an integrated } \\
\text { engineering effort. The SEMP should identify: } \\
\text { - organizational responsibilities and authority for system engineering management, } \\
\text { - levels of control established for performance and design requirements and the control method } \\
\text { used, } \\
\text { - technical program assurance methods, } \\
\text { - plans and schedules for design and technical program reviews, and } \\
\text { - control of documentation. } \\
\text { * The plan will contain a } \\
\text { - detailed description of the process to be used, including the specific tailoring of the process } \\
\text { to the requirement of the system and program, } \\
\text { - procedures to be used in implementing the process, } \\
\text { - in-house documentation, } \\
\text { - trade study methodology, and } \\
\text { - models to be used for system and cost effectiveness evaluations. }\end{array}$ \\
\hline
\end{tabular}


WHC-SD-WM-SEMP-002 Rev. 0

This page intentionally left blank. 
WHC-SD-WM-SEMP-002 Rev. 0

APPENDIX C

ROLES AND RESPONSIBILITIES MATRIX

C-1 
WHC-SD-WM-SEMP-002 Rev. 0

This page intentionally left blank.

C-2 


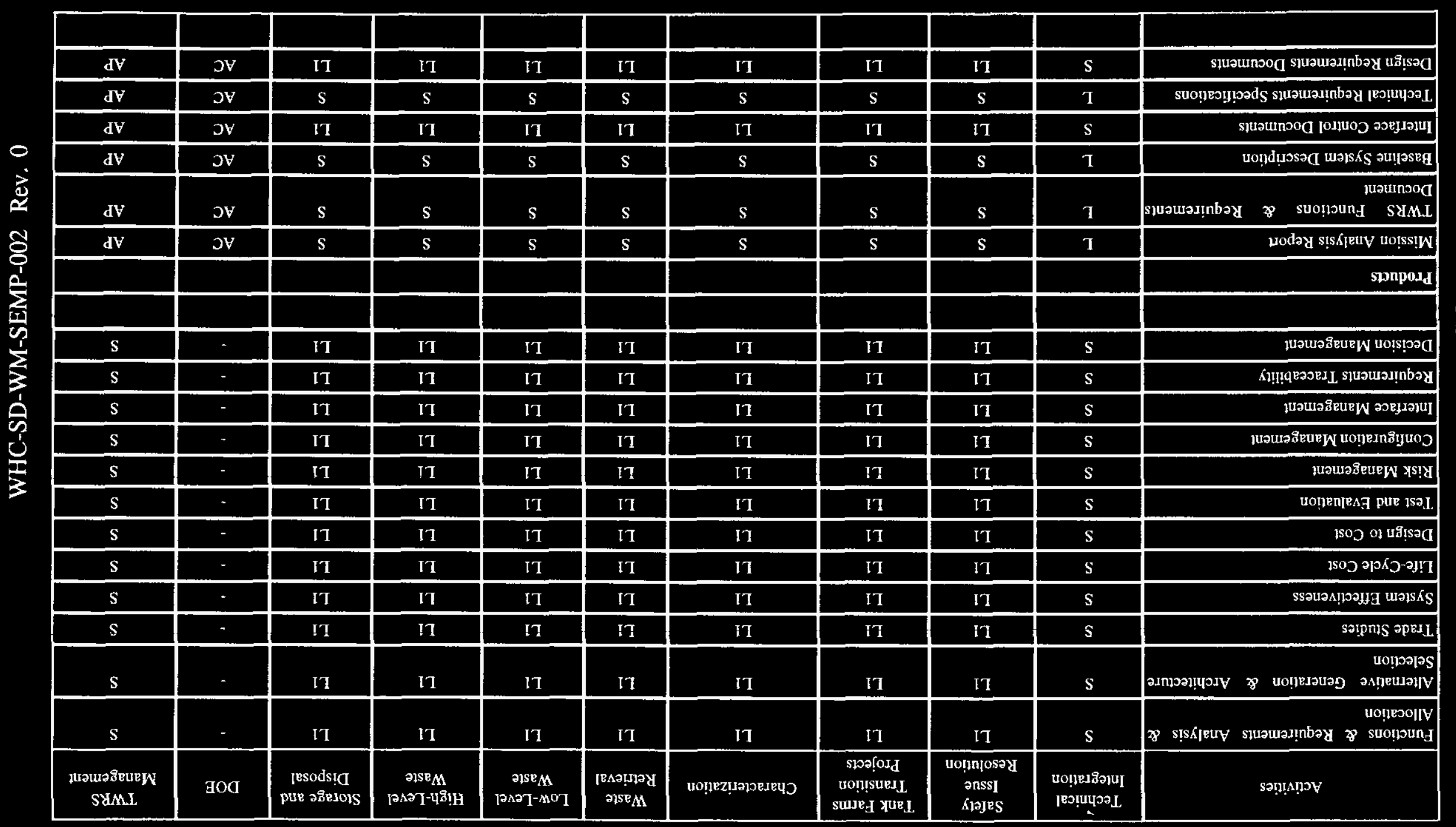


WHC-SD-WM-SEMP-002 Rev. 0

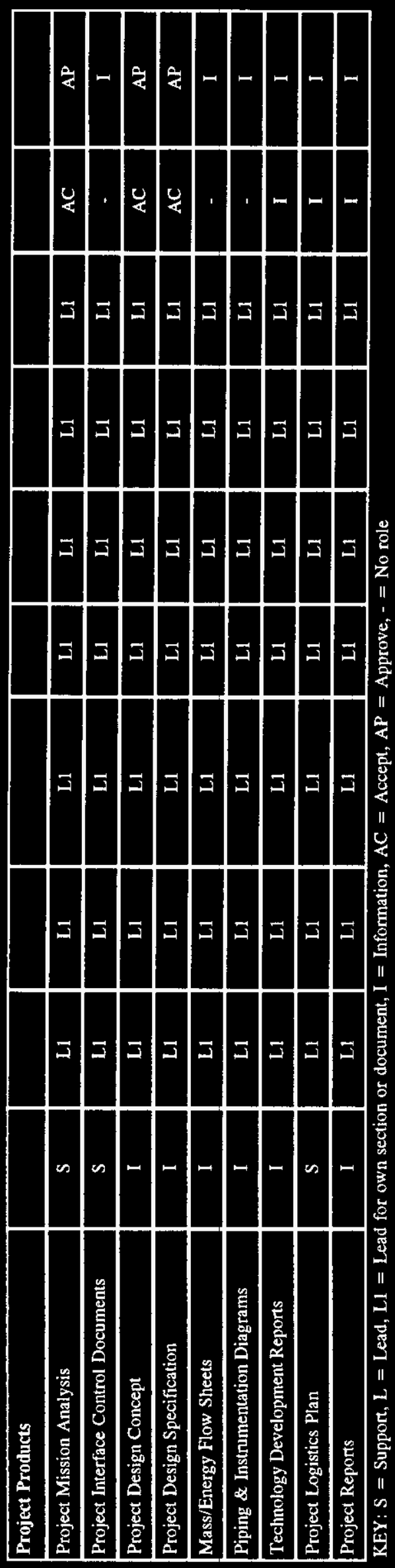


WHC-SD-WM-SEMP-002 Rev. 0

APPENDIX D

SPECIALTY ENGINEERING DESCRIPTIONS

D-1 
WHC-SD-WM-SEMP-002 Rev. 0

This page intentionally left blank.

D-2 


\section{WHC-SD-WM-SEMP-002 Rev. 0}

\section{D1.0 INTRODUCTION}

The following descriptions describe each of the specialty engineering areas and their role in system development.

\section{D1.1 REGULATORY COMPLIANCE INTEGRATION}

Regulatory support personnel will begin their involvement with the technical baseline requirements definition and alternatives development. This early integration into the SE process provides an evolutionary development of inputs and outputs based on compliance criteria. Regulatory support and TWRS personnel must continuously interface during the entire acquisition process for successful implementation of the TWRS Program.

In general, the role of regulatory compliance will continue over the life of the TWRS Program. It will start on receipt of program strategy from which the bounds of applicable regulatory requirements can be established. A complete set of compliance constraints and the associated compliance approach will be produced for integration into the program. Later efforts will concentrate on obtaining the necessary regulatory approvals for operating the TWRS, maintaining those approvals, and confirming the compliance status of the TWRS Program. Regulatory integration will continue throughout the TWRS life-cycle.

To ensure that the TWRS Program and technical baseline meets regulatory requirements, the following activities will be implemented.

- Identify regulations applicable to the TWRS Program and its technical baseline

- Develop criteria and strategies along with associated technical requirements for regulatory compliance

- Integrate permits, approvals, and other prerequisites with the SE process for construction, operation, and deactivation of the TWRS Program

- Determine the acceptability of technical regulatory compliance activities and SE verification process against applicable regulations

- Prepare regulatory documents supported by the SE and technical baseline processes

\section{D1.2 HEALTH AND SAFETY}

Health and safety personnel will participate with TWRS personnel throughout the lifecycle of the system. Health and safety will be integrated with the systems engineering process. These specialists can identify health and safety requirements, identify health and 
safety issues related to architectures, and aid in health and safety risk assessment and mitigation. The TWRS Program will address public health and safety and occupational health and safety.

\section{D1.2.1 Public Health and Safety}

Public health and safety requirements will be included as an integral part of the TWRS Program technical baseline. These requirements may be public values or from Environmental Protection Agency guidelines or other public health and safety regulations. Proposed architectures will be evaluated for public health and safety hazards and exposure scenarios during operation and after D\&D when the area may be given to the public.

\section{D1.2.2 Occupational Health and Safety}

Occupational health and safety requirements will be included as an integral part of the TWRS Program technical baseline. These requirements may be employee values or concerns or from occupational health and safety regulations such as Occupational Safety and Health Administration. Propose architectures will be evaluated for occupational health and safety hazards and exposure scenarios throughout the systems life cycle.

The TWRS Program safety program will ensure that system safety is integrated into all phases of the SE process. Figure 4-1 shows how safety integrates with the technical baseline. The $\mathrm{M} \& \mathrm{O}$ contractor establishes and manages the safety program. The safety program will interface with the regulatory compliance program which addresses compliance with environmental, nuclear, safety, and health regulations. This interface will ensure that safety aspects are addressed, particularly the provision for engineering support for the preparation of safety documentation such as the Safety Analysis Report (SAR). Industrial and radiation safety requirements and standards will often require special interpretation and guidance by the Safety discipline. These standards will be identified, analyzed, and allocated during the F\&R process.

The TWRS safety program will include the Hazard and Operability (HAZOP) process to identify potential hazards and provide operability requirements that will be incorporated into the SE process. Potential hazards will be systematically identified, potential consequences analyzed, and reasonable efforts taken to ensure that the hazards are eliminated, controlled, or mitigated. Identification of hazards related to these requirements will be documented for design verification and safety reporting.

Minimizing exposure to hazardous, toxic, and radioactive materials will be a primary goal of the TWRS safety program. This will be achieved using the As Low As Reasonably Achievable (ALARA) program. The ALARA program will establish requirements and evaluate designs to ensure that exposure to hazardous, toxic, and radioactive materials is minimized throughout the TWRS Program. ALARA requirements will be established during 
WHC-SD-WM-SEMP-002 Rev. 0

Figure D-1. Safety and Design Engineering Interface.

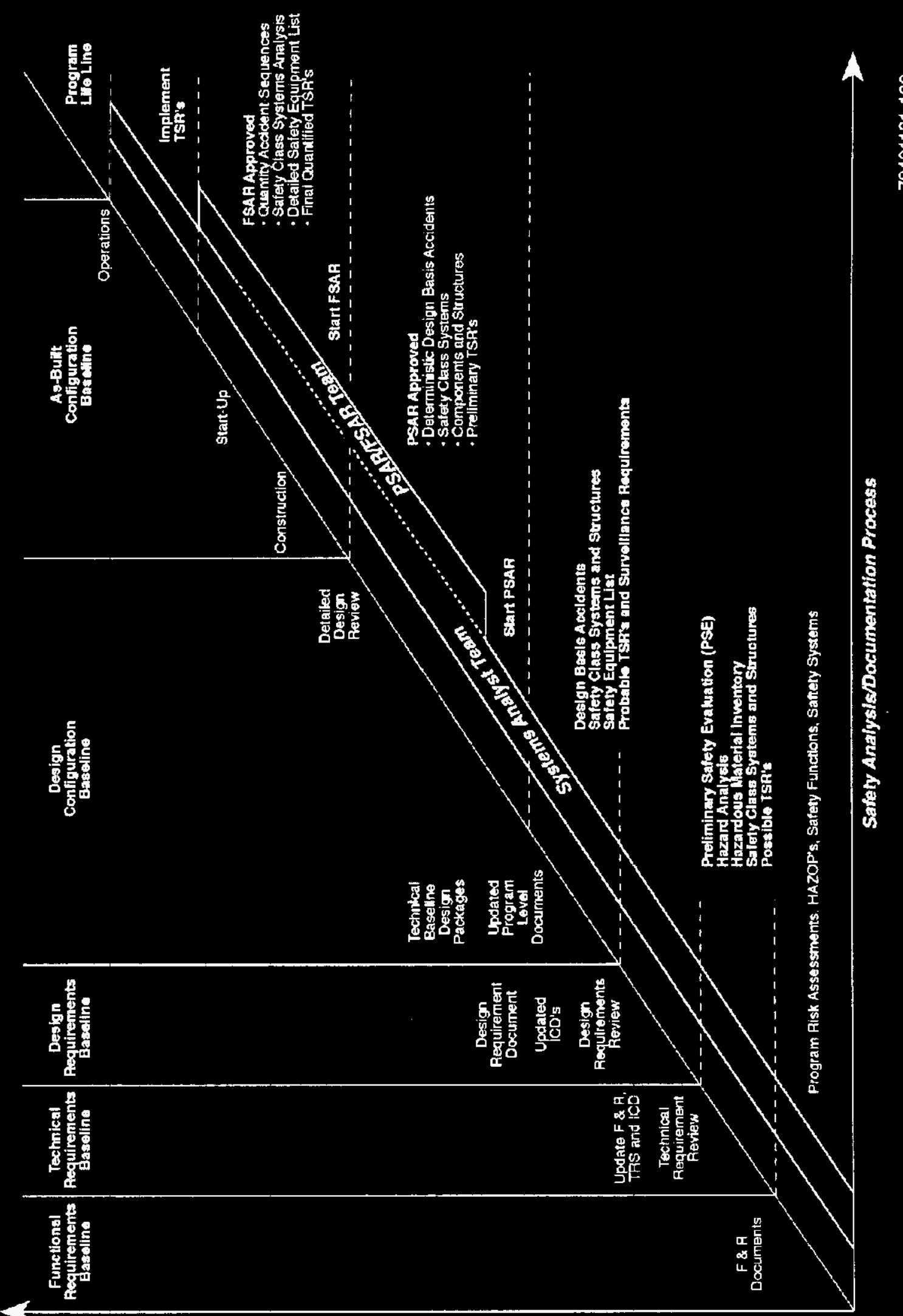

옹

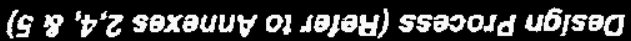

D-5 
the F\&R analysis and allocation process. Designs will be evaluated against these requirements during alternative generation and architecture development. Because TWRS Program will process mixed waste that contains toxic chemicals, safety requirements will be developed and designs evaluated for safe operation.

\section{D1.2.3 Nuclear Specialties}

These are specialties directly related to the fact that the TWRS program deals with radioactive materials. Specialties include nuclear criticality, radiation shielding, nuclear ALARA, and general nuclear safety.

\section{D1.3 DECONTAMINATION AND DECOMMISSIONING}

The D\&D specialists ensure that shutdown and D\&D requirements for TWRS Program facilities are identified and addressed during the SE process. D\&D requirements will be developed throughout the evolution of the technical baseline and embedded in the baseline. D\&D requirements will be developed, deactivation guidelines will be written, and advice on D\&D requirements implementation will be given to the TWRS designers.

\section{D1.4 ENVIRONMENTAL ENGINEERING}

Environmental engineers ensure that the system is designed to meet environmental constraints and verify that environmental monitoring systems are properly designed, installed, and operated during the life-cycle. Environmental requirements will be identified and allocated to the program elements/projects during all phases of the SE process. These requirements are based on applicable Federal and state regulations, standards, and Statutes, along with DOE directives and environmental compliance documentation. Environmental engineers will verify that environmental requirements are properly interpreted and embedded in the technical baseline.

\section{D1.5 FACILITY STARTUP}

Facility Startup specialists identify early in the design process design requirements that enable facility commissioning and startup to be efficiently accomplished. These specialists will be included in the SE process throughout the development of the technical baseline. The goal is to incorporate design features that could reduce the cost and schedule of the commissioning phase of a facility. 


\section{D1.6 HUMAN SYSTEMS INTEGRATION}

Human systems integration engineers ensure that designs are compatible with the capabilities and limitations of the personnel who will operate, maintain, transport, supply, control, and dispose of the system. Human system performance requirements address all relevant information in the following domains: 1) Human factors engineering, 2) Manpower, and 3) Personnel. Human factors engineering will be applied during development and design of the TWRS Program and its projects. Where human interfaces occur within the physical system, the interfaces will be appropriately engineered. Special attention will be given to those requirements and design attributes affecting the safety of personnel who operate and maintain the system. Additionally, special attention will be given to the potential for the system to release radioactive or toxic materials to the environment through human error or through a poorly designed human-equipment interface.

\section{D1.7 INTEGRATED LOGISTICS SUPPORT}

Operational servicing personnel will provide the logistics support for the system. They will review the evolving design for logistics requirements and will address logistics support issues. The logistics support personnel will participate in the system development by developing the logistics program for the architecture. The program will address availability of the system, maintenance planning, facilities needed, supply support, support equipment, technical data requirements, computer resources support, manpower, training support requirements, and packaging, handling, storage, and transportation requirements. The Operational Servicing model will be used to support the logistics planning. The logistics program is documented in the Project Logistics plan.

\section{D1.8 PRODUCIBILITY AND CONSTRUCTABILITY}

The Producibility and Constructability specialists consider equipment production, fabrication, facility construction, facility startup testing, and operational requirements. The technical baseline will be reviewed for compliance to these requirements on an ongoing basis. Cost trade studies will be performed where other design requirements conflict with producibility and constructability requirements. Fabrication and construction disciplines will use the technical baseline as the basis for planning efforts. The design approach can significantly impact the ability to construct, test, and operate equipment or facilities. Therefore, producibility and constructability requirements will be established, along with design guidelines, at the start of the SE process. These requirements will be given consideration throughout the technical baseline development and SE process. 
WHC-SD-WM-SEMP-002 Rev. 0

\section{D1.9 RELIABLITY, AVAILABILITY, AND MAINTAINABILITY}

The reliability, availability, and maintainability (RAM) specialists provide RAM inputs into development of the technical baseline. As part of the requirements development and design process, RAM requirements are developed and assigned to the designs. Examples of RAM requirements are; (1) mean time between failures, (2) mean time to replace, (3) availability, (4) corrective maintenance times, and (5) preventive maintenance. The RAM data will be collected from appropriate sources to monitor the status of the system. When RAM system requirements are not met, these specialist will recommend corrective action. RAM requirements are developed and designs are evaluated against these requirements throughout the SE process.

\section{D1.10 SAFEGUARDS AND SECURITY}

Safeguards and Security personnel identify safeguard and security issues and develop safeguards and security plans throughout the TWRS program. Safeguard and security issues will be identified and defined during the programmatic F\&R analysis and allocation stage. These issues affecting the development of the technical baseline will become requirements. In addition to identifying requirements, safeguards and security personnel will provide inputs regarding methods for verifying design conformance.

Safeguards and security planning will be incorporated into all phases of the systems engineering process. The planning will be developed to establish and maintain adequate safeguard requirements, including physical security, to protect nuclear materials and program facilities. The TWRS Program safeguards and security planning will describe the safeguards and security programs that need to be defined, documented, and implemented.

\section{D1.11 STANDARDIZATION MATERIALS AND PROCESSES}

The Standardization, Materials, and Processes specialists emphasize reducing the variety of parts, variability in processes, and associated documents used with items. This discipline ensures that Hanford Site design standards are used to the greatest extent possible in the design of all elements of the TWRS Program. Hanford Site design standards will be used in the TWRS Program design as appropriate. Standard equipment, materials, and processes will be incorporated into the design where these standards exist and can be used. This discipline will be incorporated into all phases of the SE process.

\section{D1.12 SYSTEM LIFE-CYCLE COST}

System Life-Cycle Cost (LCC) analyses develop the requisite cost information to support decisions on alternatives, personnel, product, process solutions, and risk assessments. LCC is the total of the direct, indirect, recurring, nonrecurring, and related costs incurred or 
estimated to be incurred during the anticipated life span of the system. The life span consists of design development, production, construction, operation, maintenance, support, and final disposition. System LCC analyses will be performed and maintained by the M\&O contractor according to applicable DOE directives. Early design evaluations will include system trade studies that establish a desirable balance among performance, risk, supportability, schedule, cost, and other significant attributes while complying with safety, regulatory, and permitting requirements. The TWRS Program LCC analysis will be performed on a continuing basis as the program evolves and will be established specifically at each technical baseline review.

\section{D1.13 TRANING}

The training discipline provides requirements into the SE process by performing a training analysis. This analysis determines the number of personnel and skills required to operate and maintain the facilities and equipment in the TWRS Program. The analysis also identifies the training and training equipment required to support the program. Training tasks are identified through analysis of the personnel tasks, which are derived during the F\&R analysis and allocation step of the SE process. After training tasks have been identified, further analysis determines student task requirements, instructor requirements, and trainer requirements. Instructor requirements are further analyzed to determine the instructor training requirements for the program. After all requirements have been determined, they are compared with current training resources to determine additional resources that may be needed to train personnel. Training analysis is conducted during F\&R analysis and allocation and training requirements are given consideration throughout the development of the technical baseline.

\section{D1.14 TRANSPORTABLITY}

Identifies the local, state, and federal requirements constraining movement of system elements on public transportation routes and physical limitations of system elements due to existing interferences or capacities.

\section{D1.15 VALUE ENGINEERING}

System Value Engineering (VE) studies will assist in development of design configurations or alternative designs to achieve the optimum design configuration and value based on LCC (Section 1.3.11) and other value criteria. VE study results must be consistent with satisfying constraints and requirements for the following; (1) constructability, (2) quality of performance, (3) reliability, (4) availability, (5) productivity operability, and (6) safety. VE studies will be incorporated into all phases of the SE process.

\section{D1.16 QUALITY ASSURANCE}


Quality Assurance includes all those planned and systematic actions necessary to provide adequate confidence that a structure, system, or component will perform satisfactorily in service [ASME NQA-1, 1994]

\section{D1.17 OPERABILITY (INCLUDES DEACTIVATION)}

Operability deals with the ease of operation, the ability of the system to be operated by individuals with basic skills and a minimum of special training, and whether the system operation can be accomplished with a minimum of error. It also includes shutdown of the plant by the operating staff for turnover to the D\&D contractor. Operability has to be considered throughout the engineering process and lifetime of the system.

\section{D1.18 TEST AND EVALUATION}

This refers to the examination and judgement of a system (or an element of a system) in terms of worth, quality of performance, degree of effectiveness, condition and the like. Evaluation is an ongoing iterative process which begins during the conceptual phase and extends through the product use and logistic support phase until the system is retired. The purpose is to determine the true characteristics of the system and to ensure that is successfully fulfills its intended mission [Blanchard \& Fabrycky, 1981]

\section{D1.19 TECHNOLOGY}

To achieve an efficient, effective product, it is essential to ensure that new technologies are identified, evaluated, selected, and incorporated into an organization's activities and processes. To do this, individuals knowledgeable about new, innovative technologies applicable to the system being designed must be a part of the engineering process. This is especially important during the formulation and evaluation of alternatives for performing system functions. 


\section{DISTRIBUTION SHEET}

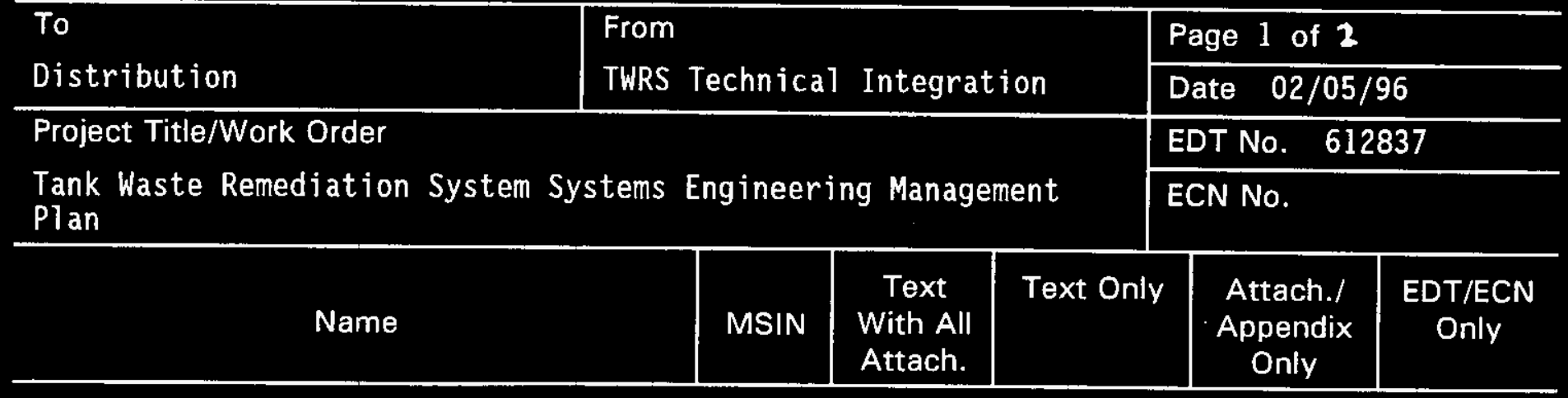

\begin{tabular}{|c|c|}
\hline $\begin{array}{l}\text { N. G. Awadalla } \\
\text { D. G. Baide } \\
\text { P. A. Baynes } \\
\text { R. A. Bilskis } \\
\text { K. D. Boomer } \\
\text { R. K. Brown } \\
\text { J. G. Burton } \\
\text { K. E. Carpenter } \\
\text { R. D. Claghorn } \\
\text { J. C. Danley } \\
\text { C. W. Dunbar } \\
\text { G. L. Dunford } \\
\text { L. F. Ermold } \\
\text { H. P. Fox } \\
\text { G. R. Franz } \\
\text { J. S. Garfield } \\
\text { K. A. Gasper } \\
\text { J. E. Geary } \\
\text { C. J. Geier } \\
\text { B. C. Gneiting } \\
\text { M. L. Grygiel } \\
\text { J. W. Hagan } \\
\text { W. A. Hesser } \\
\text { J. L. Homan } \\
\text { J. O. Honeyman } \\
\text { M. E. Johnson } \\
\text { T. J. Kelley } \\
\text { A. G. King } \\
\text { E. J. Kosiancic } \\
\text { B. J. Knutson } \\
\text { C. N. Krohn } \\
\text { A. Lee } \\
\text { L. S. Legowick } \\
\text { R. E. Lerch } \\
\text { E. J. Lipke } \\
\text { G. A. Meyer } \\
\text { W. C. Miller } \\
\text { T. L. Moore } \\
\text { T. Morton } \\
\text { R. J. Murkowski } \\
\text { R. L. Nelson } \\
\text { E. G. Norman } \\
\text { F. J. Orsag } \\
\text { S. P. Otte }\end{array}$ & 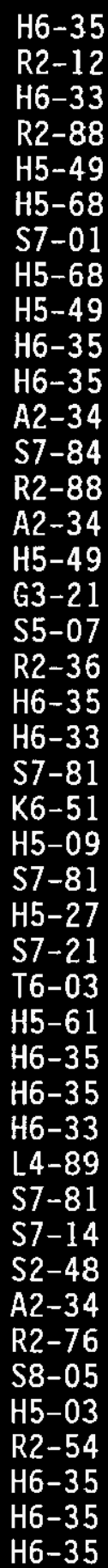 \\
\hline
\end{tabular}




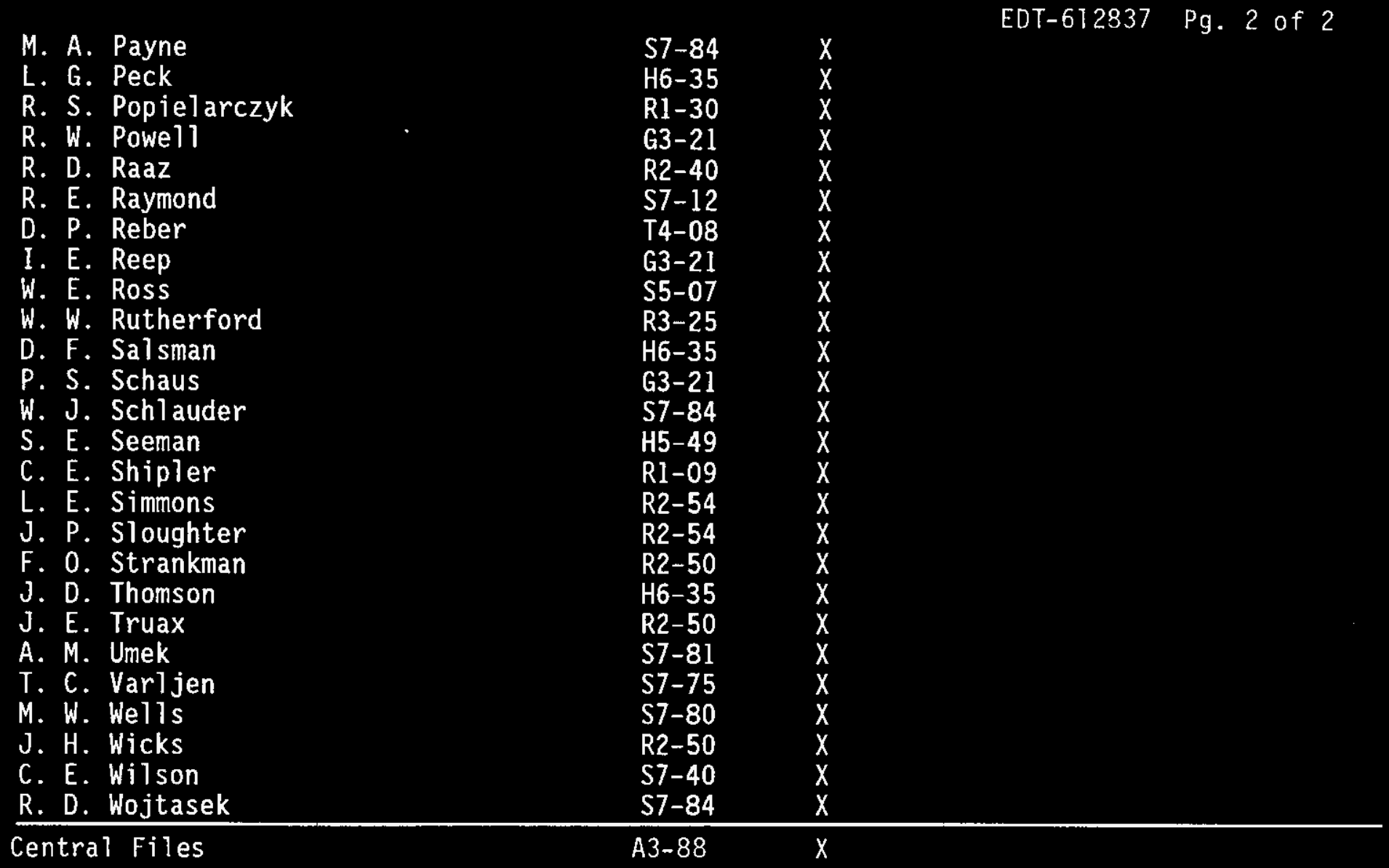

